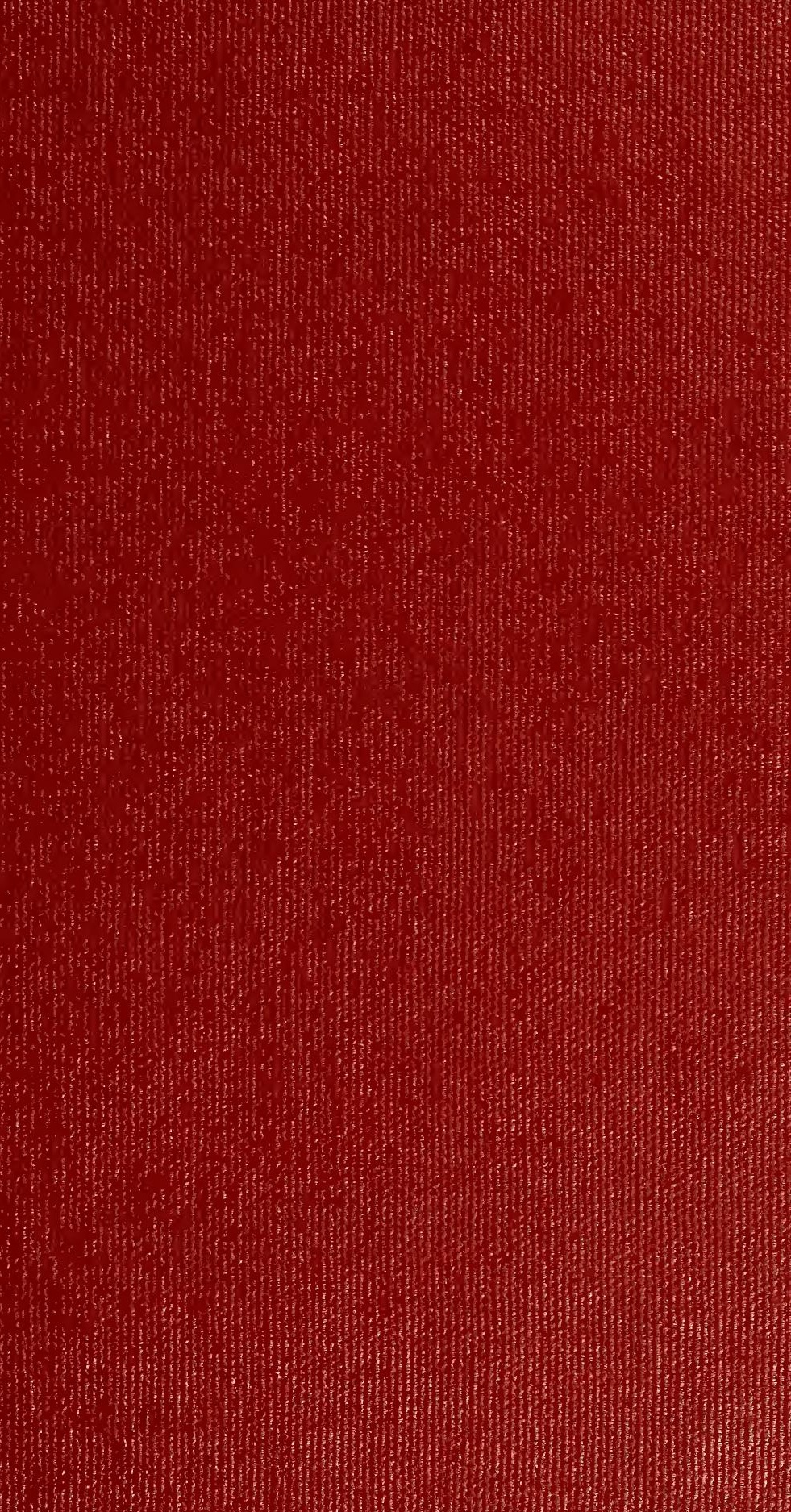




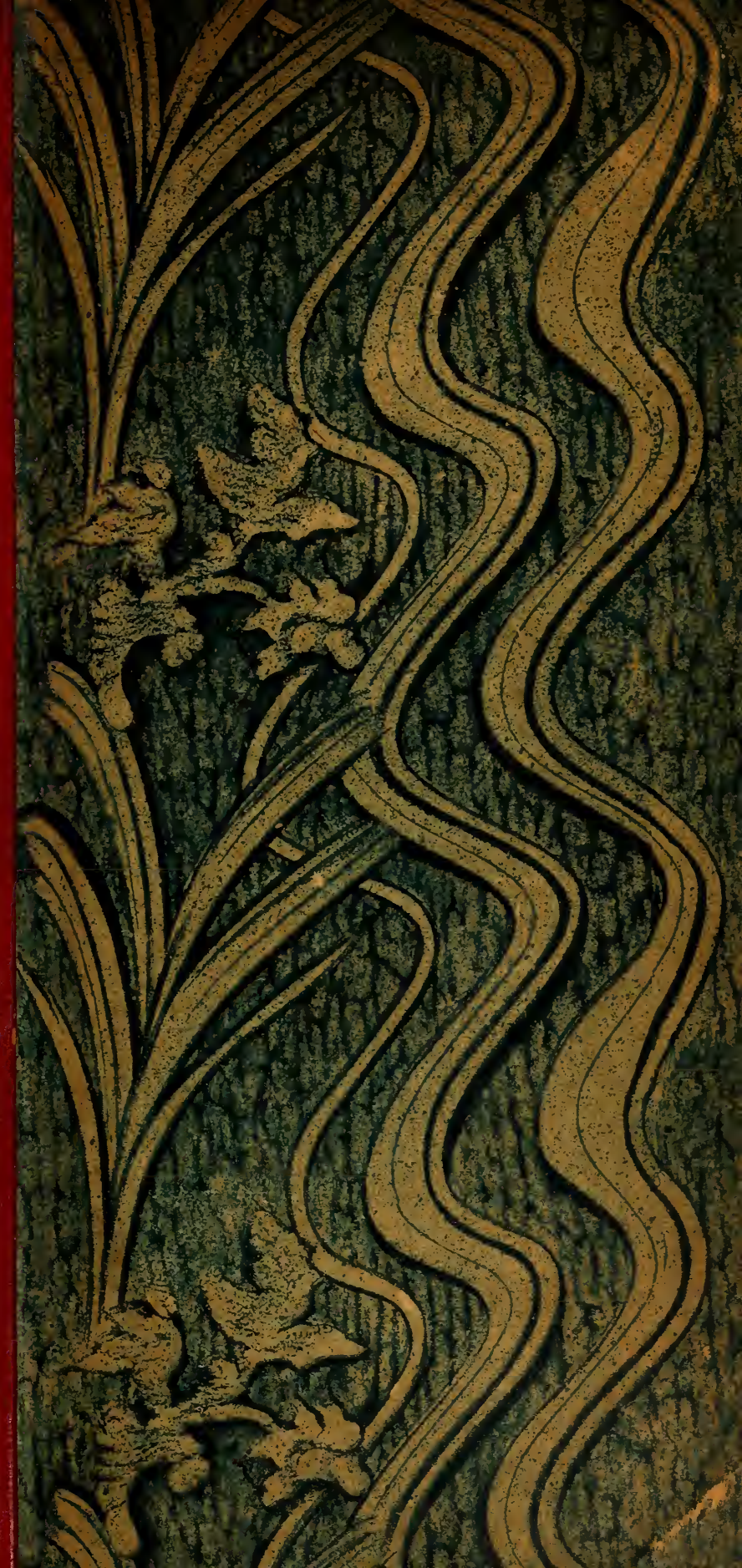




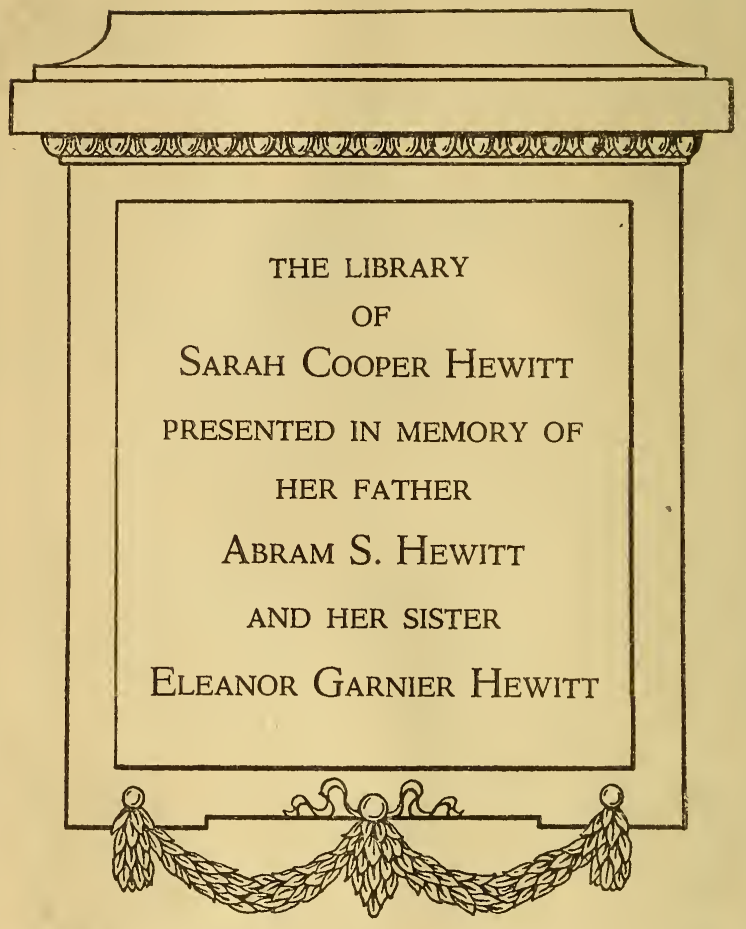






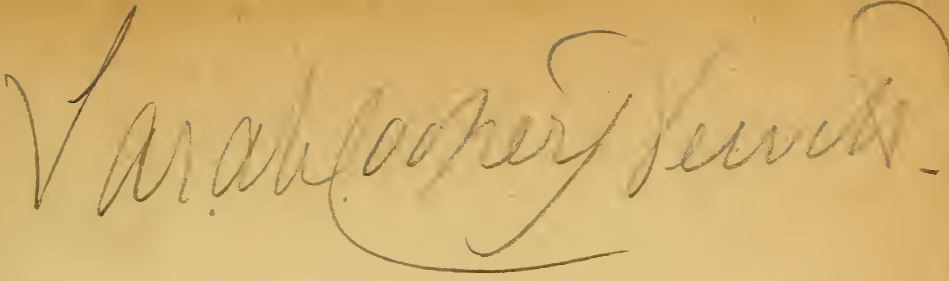

IES ÉCOLES PROFESSIONXELILE

FI

LES ÉCOLES D'ART INDUSTRIEL

EN ALLEMAGNE ET EN AUTRICHE 
Imprimerie L. Braeckmans, à Brecht. (Anvers) 



\title{
LES
}

\section{ÉCOLES PROFESSIONNELLES}

ET LES

\author{
ÉCOLES D'ART INDUSTRIEL
}

\section{EN ALLEMAGNE ET EN AUTRICHE}

LE DESSIN DANS LES ÉCOLES PRIMAIRES ET MOYENNES

Missions et études à Hambourg, Hannovre,

Iserlohn, Remscheid (Westphalie), Vienne, Dresde, Munich, Dusseldorf, Berlin, Leipsig

PAR

\section{OMER BUYSE}

Professeur à l'École de dessin et d'industrie Régent à l'École moyenne de Schaerbeek.

UNE PLANCHE ET 36 CROQUIS DANS LE TEXTE

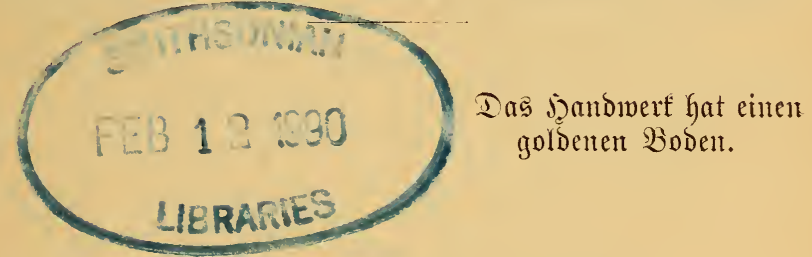

SCHAERBEEK-BRUXELLES

En vente chez l'auteur, rue de Robiano, 86 



\section{TABLE DES MATIERES.}

PAGES

Les Écoles professionnelles et industrielles primaires. Les Écoles professionnelles du métal d'Iserlohn et de Remscheid. Les Écoles d'art industriel de Hannovre et de Hambourg.

I. - Préface. . . . . . . . . . I

II. - Situation de l'apprentissage. . . 6

III. - Le Dessin dans les écoles moyennes. L'École moyenne d'Iserlohn ?Westphalie!. 13

IV. - Le Dessin dans les Écoles primaires allemandes. . . . . . . . . 34

I. - Les Écoles professionnelles et industrielles obligatoires. (rontbildutugidulcur).

VI. - Les Écoles secondaires d'art industriel avec ateliers. Les Écoles d'apprentissage pour l'industrie du métal d'Iserlohn et de Remscheid. (Fachid)ulen). . . . 65

VII.- Les Écoles d'art industriel de Hannovre et de Hambourg. ( Rumitgewerbejd)ulcu).

VIII, - Conclusion. 
L'École supérieure d'art industriel de Vienne. Les Écoles de métiers de Dresde et de Munich.

IX. - Avant-propos. Situation de notre industrie artistique. . . . . . . . $\mathrm{I}_{4} 3$

X. - Les Écoles de Dresde et de Munich. $\quad$ I57

XI. - L'École supérieure des arts industriels et décoratifs de Vienne. . . . . 173

XII. - Conclusion. . . . . . . . 227

L'École de métiers artistiques de Dusseldorf.

XIII. - Dusseldorf. La ville. L’École. . . $\quad 237$

XIV. - Conclusion. . . . . . . . 255

L'École de métiers de Berlin. (igandwerferidgule).

XV. - Considérations générales. . . . 263

XVI. - Berlin. La ville. L’École de métiers. $\quad 270$

XVII. - Conclusion. . . . . . . . 3 I 2 


\section{ERRATA.}

Page is', 6e ligne; lisez debarrassé au lieu de debarassé

Page 54. 8e ligne; " professionnelles " professionelles

Page 57, I $2^{\mathrm{e}}$ ligne; " réunis "réunies

Page 8o, 23e ligne; " composée "composé

Page 85, 8e ligne; " les formes "des formes

Page 97, Ire ligne; "VII \# VIII

Page 98, I9e ligne: " un luxe "une luxe

Page IIO, 24 ligne; " les cours "le cours

Page II2, $4^{\mathrm{e}}$ ligne; " ils composent "ill composent

Page I 5, 25e ligne; " menace "ménace

Page i94, I7 ligne; " lesquels "lesquelles 



\section{I. - PRÉFACE}

Un des indices les plus frappants $\mathrm{du}$ progrès des idées à notre époque, c'est l'aspiration impérieuse de la population ouvrière à un plus grand bien-être, à une dignité et à une indépendance plus complètes.

Aussi, jamais le peuple n'a été l'objet de tant de sollicitude : l'initiative des ouvriers, l'action plus puissante des patrons et des pouvoirs publics, les efforts de tous sont, dans un élan de générosité et de solidarité dirigés vers l'amélioration de la condition des travailleurs; la Bienfaisance, la Mutualité, les Coopératives, les Caisse de retraites, les Institutions patronales, toutes les forces sociales, en un mot, s'appliquent à soulager la souffrance, à redresser les abus, à augmenter le bien-être.

L'amélioration provoquée par toutes ces œuvres philanthropiques est certes considérable, mais elle ne saurait être durable si l'on 
ne développe pas chez l'artisan la force individuelle, l'initiative personnelle; sous ce rapport l'enseignement généralisé des industries et des métiers constitue un remède préventif aux misères sociales : il fait fructifier les efforts collectifs de l'association et fait naître des aptitudes, qui donnent au monde travailleur son maximum d'énergie et de productivité.

C'est dans l'éducation professionnelle des artisans et des ouvriers, que l'industrie doit puiser la puissance nécessaire pour vaincre les difficultés, nées de la concurrence étrangère; dans l'augmentation de la valeur du travail, la production doit trouver une compensation aux dépenses imposées par l'accroissement constant des salaires, des frais d'exploitation et des charges résultant des législations douanières.

Pour faire prospérer l'industrie et surtout l'industrie artistique, il ne suffit plus de former des ingénieurs, des constructeurs et des artistes qui s'occupent par coquetterie des arts industriels; il importe de cultiver les aptitudes techniques et le goût artistique de tous les travailleurs manuels. L'industrie d'art pourra prendre un essor nouveau, lorsque les artisans posséderont les éléments des 
sciences et de l'art, qui constituent avec les progrès actuels les éléments fondamentaux des industries et des métiers.

Rien n'est plus intéressant que de voir à l'œuvre tous ces gens de métier obcurs exploitant leur petit capital, leur métier rudimentaire. Ils ont assis sur la routine les conditions de leur existence. Quelle puissance latente récèle ce monde! Un rien d'art, un peu de dessin, une lueur de sciences élargiraient l'horizon si borné, permettraient de donner plus de forme à la fabrication, plus de logique au travail. Par l'apprentissage industriel et professionnel les travailleurs de la petite industrie, artisans, fabricants d'objets de consommation courante; pourraient augmenter la valeur de leur travail, améliorer les conditions matérielles et intellectuelles de leur existence et collaborer plus largement au développement de la richesse publique.

L'enseignement du travail artistique est appelé à rendre à l'art ses droits sur toutes choses, à lui marquer sa place partout, il donnera aux objets même usuels un cachet propre, une forme caractéristique. La jouissance artistique ne peut rester l'apanage de quelques privilégiés; il faut que la fabrication à bon marché répande le beau sous toutes ses 
formes et concoure à l'éducation esthétique du public.

Nos écoles purement industrielles sont admirablement organisées; elles peuvent se glorifier d'avoir collaboré dans une large mesure à l'extension de la grande industrie, qui occupe une place si brillante dans la production universelle.

De grandes lacunes existent dans notre industrie artistique. Les écoles de dessin et d'industrie s'occupent trop exclusivement de l'éducation esthétique pour exercer une influence salutaire sur l'éducation professionnelle des artisans; elles devraient s'inspirer davantage des besoins des industries et suppléer réellement à l'insuffisance de l'apprentissage à l'atelier.

Un enseignement du dessin et du modelage avec branches théoriques, pendant les soirées d'hiver, pourrait, à la rigueur, suffire aux ouvriers, qui désirent rester tels; mais pour imprimer au travail artistique une vigueur nouvelle, la création d'écoles sécondaires d'art industriel, avec ateliers s'impose dans les centres assez importants.

Les professions manuelles doivent devenir une carrière aussi recherchée, que les emplois intellectuels. L'industrie artistique a grand 
intérêt de s'assurer le concours des éléments les plus actifs et les plus instruits; comme la grande industrie, elle se transforme, s'affine et devient plus scientifique. Grâce à la diffusion de l'enseignement professionnel et au progrès dans l'outillage, les conditions de fabrication seront bientòt les mèmes partout; il arrivera un moment où l'on n'aura plus qu'une seule supériorité à opposer au rival : la supériorité artistique et technique des produits. Cette éventualité même n'a rien d'effrayant pour nous Belges, qui possédons un fond artistique et une habileté natives remarquables : l'école professionnelle avec ateliers, doit poursuivre le développement simultané des aptitudes techniques et du goût esthétique; alors elle contribuera à améliorer la main d'œuvre et l'aspect des produits et nous fera reprendre le rang honorable que notre pays a longtemps occupé sur le marché artistique. 


\section{II. - SITUATION DE L'APPRENTISSAGE}

Le développement croissant du machinisme entraînant avec lui la division extrême du travail détruit de plus en plus les conditions de l'apprentissage dans toute une catégorie d'industries. La science s'est substituée à la tradition; la chimie et la physique transforment continuellement les procédés de fabrication et révolutionnent les anciennes méthodes de travail. Dans cette marche vers le progrès économique, l'apprentissage traditionnel tend à disparaître; la plupart des petites industries et des métiers, qui enseignaient d'une façon si charmante les professions manuelles, sont mises en déroute.

Le serrurier, par exemple, était autrefois un artisan complet; il confectionnait de ses mains les objets usuels en métal, les serrures et accessoires d'une ingéniosité et d'une perfection admirables. 
La serrurerie comptait une série complète de manipulations bien appropriées à l'apprentissage : le forage, la forge, le travail à la lime, au tour, la soudure, le polissage etc. etc. Toutes ces opérations se présentaient journellement dans un ordre varié. Le chef-d'œuvre, qui devait couronner les études, était une serrure artistique pour meuble, ou tout autre objet artistique en métal. Cette œuvre finale se composait de parties bien ajustées, bien. achevées et l'apprenti, qui parvenait à la confectionner, possédait les aptitudes multiples et variées d'un ouvrier parfait. A présent, les grandes serrureries n'offrent plus de traces de cet apprentissage paternel.

Une série de jeunes apprentis sont occupés, chacun à une spécialité; l'un tourne pendant des journées entières, l'autre lime, un troizième fore etc. et toutes les pièces affluent vers le monteur, qui les ajuste.

Quantité de serrures sortent journellement de la fabrique et pas un artisan n'est capable d'en confectionner une de ses mains.

Le patron permettrait même à un apprenti de passer par toutes ces spécialités, celui-ci ne saurait pas encore apprendre le métier. Il produit, il est vrai, immédiatement un travail utile ; mais restreint à cette occupation 
étroite, l'esprit et le corps déformés par le travail déprimant pour lequel l'habitude physique remplace le raisonnement, il est à tout jamais condamné à la médiocrité ; il restera un simple manœuvre, un journalier dressé à telle besogne spéciale. On est stupéfait de la dextérité merveilleuse de ces ouvriers, mais rien n'est plus triste que de voir l'esprit et le talent naissants s'atrophier dans un travail aussi exempt d'effort intellectuel.

Dès qu'il est au courant d'une spécialité, l'apprenti passe chez un autre patron où une seconde spécialité l'attend : ainsi, d'atelier en atelier, d'échelon en échelon, le jeune homme acquiert des aptitudes manuelles éparses, et, arrivé à l'âge adulte, il ne connaît du métier, que ce que les autres ouvriers ont pu lui apprendre. Son gagne-pain sera toujours précaire, la moindre convulsion dans la fabrication le jettera sur le pavé. Tôt ou tard il sera dans le cas de cet ouvrier cordonnier, qui, réduit à la mendicité donnait cette réponse lamentable à ceux qui l'interrogeaient sur son métier : " Je suis cordonnier, monsieur, mais à la fabrique de chaussures je n'ai fait que clouer des talons »!

Il n'est pas possible aux parents, soucieux 
de l'avenir de leurs enfants, de les engager dans un tel apprentissage.

Si dans tous les ateliers la situation n'est pas aussi difficile, il n'en est pas moins vrai que le travail manuel est très menacé; les parties régulières, qui entrent dans la fabrication des objets, sont fournies par les machines et la machine-outil mécanise de plus en plus le travail de l'homme.

Le perfectionnement des procédés mécaniques est un progrès immense que l'on ne peut et que l'on ne pourra jamais arrêter. Les artisans, qui possèdent toutes les ressources de leur métier, affirmeront toujours l'existence de la petite industrie vis à vis de la grande; jamais la machine ne saura remplacer l'homme que dans son travail mécanique. La faiblesse de l'aptitude professionnelle est une des causes du développement de plus en plus envahissant du machinisme. L'école, en substituant à la routine inintelligente de l'atelier un apprentissage rationnel, peut seule circonscrire le champ d'action de la grande industrie.

\section{Les Patrons, les Ouvriers.}

Les expositions rétrospectives du travail artistique nous ramènent encore de temps à 
autre vers les époques patriarcales, où le patron dirigeait dans son atelier l'éducation professionnelle de ses futurs ouvriers. Si humble que fût l'objet par sa destination, l'élève apprenait à déposer dans le travail de ses mains un peu de son invention, de sa vie, de son cœur; il y acquérait la science et l'art nécessaires à l'expression originale de ses sentiments personnels. Guidés par leurs patrons, ces modestes artisans poussaient leur métier jusqu'au grand art et produisaient des œuvres au sujet desquelles nous inventons des esthétiques compliqueés, mais que nous aurions peine à imiter en notre siècle de progrès industriel.

De nos jours, le patron travaille rarement lui-même, il gère trop son industrie, comme une affaire financière; comme, en général, il ne possède pas suffisamment le métier, l'apprentissage des jeunes gens est abandonné aux ouvriers. Comment ceux-ci pourraient-ils se prêter de bonne grâce à ce rôle? Ils contestent évidemment la pénurie d'ouvriers; leur intérêt consiste à élever à còté d'eux le moins de concurrents possible, à ne pas leur donner des aptitudes, qui pourraient occasionner une concurrence sérieuse aux anciens.

N'a-t-on pas vu dans une récente grève des 
métallurgistes à Gand, les ouvriers mécaniciens se plaindre, de ce que les élèves de l'Ecole d'apprentissage pour le bois et le fer envahissaient de plus en plus les ateliers et y faisaient, grâce à leur habileté et leur science supérieures, une rude concurrence aux autres travailleurs?

Ils sont allés jusqu'à demander à leur syndicat aide et protection... pour leur ignorance.

Comment les ouvriers, intéressés à conserver le statu quo et animés d'un tel esprit, sauraient-ils consciencieusement veiller à l'apprentissage dès jeunes gens, qui leur sont confiés?

\section{LA QUALITÉ DU TRAVAIL.}

Dans les industries et métiers, même restés plus ou moins à l'abri du machinisme, un autre élément encore vient abaisser le niveau de l'apprentissage : c'est le travail rapide et à bon compte, qui est imposé par une concurrence effrénée, par l'altération du goût et l'amour du clinquant.

Produire beaucoup et à bas prix : telle est la loi de l'industrie actuelle. Il devient totalement impossible aux patrons de donner d'une manière continue du beau travail à leurs ouvriers. L'aptitude indispensable au travail 
soigné, la science et le goût nécessaires pour en apprécier la beauté et la valeur, se perdent insensiblement chez les artisans, parce que ce n'est qu'exceptionnellement et à des intervalles de plus en plus espacés, qu'ils peuvent exercer leur savoir professionnel, appliquer leur goût à la confection de travaux de luxe.

Si les institutions et les œuvres tendant à la vulgarisation de l'art et à la culture du sens esthétique parvenaient à provoquer une réaction contre la fabrication commune, on trouverait difficilement les artisans habiles capables de satisfaire au besoin nouveau. Ils deviendront de plus en plus rares à mesure que la tradition et le souvenir du travail soigné et réellement artistique se perdront dans la production vulgaire et dans la mécanisation du travail.

On sent instinctivement, qu'il est temps de réagir avec vigueur contre l'abaissement du niveau professionnel des travailleurs manuels. L'enseignement primaire et moyen, les écoles de dessin et d'apprentissage doivent être pénétrées d'un esprit nouveau; elles doivent contribuer avec unité à raviver le culte du travail dans toutes ses formes, mais surtout dans ses applications artistiques. 


\section{III. - LE DESSIN DANS LES ÉCOLES MOYENNES}

Dans tous les pays il y a une tendance à rendre l'enseignement primaire et moyen plus pratique, à réduire l'importance de la théorie, à supprimer dans l'étude des langues et du calcul les parties abstraites, qui, sans profit pour l'intelligence, nécessitent des efforts considérables.

La loi de I884, qui laisse à la commune la faculté de renforcer certaines branches d'un intérêt local, permet d'imprégner l'enseignement primaire d'un esprit positif, de le compléter par des branches propres à développer l'intelligence des enfants en vue des besoins réels des futurs ouvriers.

Dans notre étude sur les Ecoles de Leipzig qui suit nous avons signalé la place importante que le commerce, l'industrie et le métier manuel occupent à l'école primaire et l'effet 
salutaire que ces études exercent sur les idées des enfants.

Si l'école primaire s'est sensiblement transformée avec les conditions sociales, l'école moyenne est restée immuable et constitue un véritable anachronisme au milieu des exigences de la vie moderne. Son enseignement a une tendance exclusivement abstraite. Les concours généraux viennent périodiquement vivifier cet esprit théorique et entraîner l'école moyenne dans le sillage des athénées.

Les cours d'humanités des athénées et des collèges préparent les jeunes gens aux études du droit, de la philosophie, de la médecine; sur les cours professionnels moyens viennent se greffer les études d'ingénieur, de docteur en sciences physiques et mathématiques etc. Quel est le but des écoles moyennes? Où versent-elles tous ces jeunes gens qu'elles laissent dans l'ignorance absolue des métiers et des industries?

L'interprétation la plus large du programme ne permet pas d'initier les élèves, fils d'artisans, aux éléments du travail manuel qui donne l'existence à leurs parents!

Ayons le courage de l'avouer : nous en sommes réduits à déclasser sciemment les jeunes gens! 
L'élève qui finit ses études à l'Ecole moyenne, est à tout jamais perdu pour les industries et pour les métiers. Il est le produit typique de ce fameux enseignement " intégral » qui prétend que le seul moyen d'augmenter la capacité intellectuelle de l'enfant est de lui donner une bribe de toutes les sciences. Les réalités, telles que la vie industrielle, professionnelle et commerciale, doivent rester étrangères à l'éducation, parce qu'elles manquent de valeur éducative.

Pareil enseignement est franchement hostile au travail manuel.

L'Ecole moyenne a toujours été la pépinière des employés. Ce rôle était utile autrefois, mais actuellement les universités et les écoles moyennes supérieures fournissent un nombre tellement considérable de travailleurs intellectuels, que ni les administrations, ni les industries, ni le commerce, ni les arts libéraux ne sauraient les absorber. (I)

(I) Statistique très incomplète pour 1894 :

Pour roo emplois de Commis du chemin de fer : I 400 candidats; Pour 200 factcurs de poste : Pour Igo gardes-convoi : 2400 candidats; 2600 candidats;

Pour un certain nombre d'agents de police à Bruxelles, 200 inscrits, dont plusieurs sont porteurs de diplômes de pharmacien, de docteur en droit, de candidat-notaire.

Pour 90 emplois de commis au chemin de fer, 800 postulants, etc. I 896

3000 postulants pour 200 emplois de garde-convoi. 
Pendant que, avec une sereine persévérance, nos écoles moyennes contribuent dans une large mesure à grossir le nombre de sanstravail intellectuels et de déclassés, les petites industries et les métiers, privés de tous ces éléments intelligents, pataugent dans la routine et sont incapables d'une sérieuse expansion; l'étranger supplée amplement à notre insuffisance en nous envoyant ses produits et ses ouvriers même, qui viennent se créer de superbes positions chez nous (I).

Une réforme s'impose.

L'école moyenne doit répondre aux besoins actuels, et se borner à inculquer aux futurs

(I) Tableau statistique du mouvement commercial avec l'Allemagne et la France. I894.

\begin{tabular}{|c|c|c|c|c|}
\hline ОвJет & Pays & IMPORTATION & ExPORTATION & $\left\{\begin{array}{c}\text { L'importation } \\
\text { dépasse } \\
\text { l'exportation de }\end{array}\right.$ \\
\hline Quincaillerie & $\begin{array}{l}\text { (Allemagne } \\
\text { (France }\end{array}$ & $\begin{array}{l}24.165 .000 \\
19.430 .000\end{array}$ & $\begin{array}{l}8.298 .000 \\
8.656 .000\end{array}$ & $\begin{array}{l}\text { I } 5.867 .000 \\
\text { I0. } 774.000\end{array}$ \\
\hline $\begin{array}{l}\text { Bijouterie, or- } \\
\text { fèvrerie (or, ar- } \\
\text { gent, nickel etc.) }\end{array}$ & $\begin{array}{l}\text { (Allemagne } \\
\text { (France }\end{array}$ & $\begin{array}{l}7.151 .000 \\
3.427 .000\end{array}$ & $\begin{array}{l}2.56 \% .000 \\
1.455 .000\end{array}$ & $\begin{array}{l}4.584 .000 \\
1.972 .000\end{array}$ \\
\hline Meubles & $\begin{array}{l}\text { (Allemagne } \\
\text { (France }\end{array}$ & $\begin{array}{l}4.448 .000 \\
3.927 .000\end{array}$ & $\begin{array}{r}988.000 \\
\text { I.704.000 }\end{array}$ & $\begin{array}{l}3.460 .000 \\
2.223 .000\end{array}$ \\
\hline & Totaux & 62.548 .000 & 23.668 .000 & 38.880 .000 \\
\hline
\end{tabular}

L'importation dépasse l'exportation de près de 39 millions de francs par an pour ces seules branches du travail! 
travailleurs industriels et commerçants, les fondements des sciences nécessaires à l'exercice intelligent de leur profession. Sans cesser d'ètre une école de culture générale, elle peut, par l'esprit utilitaire de son programme, par le développement du cours de dessin et des travaux manuels, orienter les idées des élèves vers les industries et les métiers, s'identifier avec les besoins de la région qu'elle dessert et contribuer au relèvement du travail. Le Gouvernement a consacré le principe en instituant des cours facultatifs d'agronomie dans les régions rurales, de technologie maritime dans les villes de la côte. Un programme spécial, adapté aux besoins des régions industrielles laisserait à l'école moyenne une individualité propre et lui donnerait, dans ces localités, un caractère d'utilité pratique, qu'elle ne saurait avoir actuellement avec son programme théorique et uniforme pour tout le pays.

\section{L'ECOLE MOYENNE DES RÉGIONS}

INDUSTRIELLES.

L'enseignement moyen inférieur des régions industrielles devrait constituer l'enseignement supérieur du monde des ouvriers et des artisans, et jeter les bases des études des futurs 
commerçants. Comme tel, il devrait développer les jeunes gens dans l'esprit du travail, chercher ses moyens de culture, ses exemples, ses matériaux dans cette vivifiante étude du commerce, des industries et des métiers.

L'étude de la langue débarassée de toutes les subtilités grammaticales et littéraires, pourrait fournir des notions utiles au plus haut degré; les excursions périodiques dans les ateliers, sur les chantiers, dans les manufactures et usines, offriraient ample matière à des descriptions de procédés de fabrication, de faits commerciaux; des sujets traitant du beau idéal cultiveraient le sens moral et esthétique de l'élève.

L'histoire n'est étudiée que dans les faits politiques, ayant eu une influence sur la marche des idées; l'histoire du travail, qui, aux différentes époques, porte l'empreinte caractéristique des mœurs, du sentiment, des besoins du peuple, compléterait avantageusement l'histoire politique; elle frapperait vivement l'esprit des enfants, parce qu'elle s'appuie sur des documents précis : les monuments des grandes époques et les objets, qui sont enfouis dans nos musées archéologiques. Elle évoquerait la vie populaire sous son aspect le plus intéressant, les périodes de 
splendeur de l'Antiquité égyptienne, grecque et romaine, les Corporations du moyen-âge, le relèvement du travail sous l'impulsion des souverains aux XVIe , XVII e et XVIII ${ }^{\mathrm{e}}$ siècles, le travail moderne et son expansion par suite de l'invention et des progrès prodigieux de la machine à vapeur. Cette étude, condensée en quelques planches, renforcée par des visites aux musées, montrerait le peuple au travail au lieu de le représenter sans cesse au combat.

La géographie étudierait plus à fond, à côté des divisions politiques et physiques générales, les régions de l'industrie, de la production minière et de la culture de plantes industrielles, les voies de communication, l'exportation, l'importation, les pays d'émigration.

Parmi les branches les plus propres à développer le sens positif de l'enfant figurent les mathématiques. L'enseignement actuel est exclusivement théorique à l'école moyenne et constitue une véritable torture pour l'esprit, sans autre utilité qu'une faible importance éducative.

Les propriétés des figures géométriques, les règles fondamentales de l'algèbre et de l'arithmétique auraient certainement le même pouvoir éducatif et une utilité considérable, 
si elles étaient appliquées aux figures et solides géométriques et par extension aux métrés et aux données industrielles et commerciales.

La représentation par les projections de ces formes géométriques et objets réguliers serait un complément heureux aux mathématiques. Plus que la théorie, elle ferait connaitre les propriétés des figures et solides et permettrait en outre, d'appliquer les notions de mathématiques au dessin, avec une tendance professionnelle.

Pour coordonner toutes ces branches dans un sens utilitaire, des entretiens très simples au sujet de l'économie politique et industrielle devraient donner aux élèves de la classe supérieure une idée du travail, des salaires, des grèves, des intérêts communs du capital et du travail, de l'échange - protection et libre échange - , de la monnaie, des institutions de crédit et de prévoyance : de la caisse d'épargne et de retraite, des sociétés de secours mutuels, etc.

Bref, toutes les branches d'enseignement, les exercices de conversation, d'élocution, de déclamation, devraient inspirer aux élèves le respect et l'amour du travail manuel et cultiver dans leur esprit un idéal utilitaire. 
Le dessin, plus développé dans un sens pratique et professionnel, couronnerait l'enseignement des écoles moyennes industrielles; il ramenerait les jeunes gens les plus intelligents dans les écoles industrielles et professionnelles et éveillerait leur vocation pour les professions manuelles.

\section{L'Ecole MOyenNe D'ISERLohn}

(WESTPHALIE)

Les idées développées dans le chapitre précédent ne sont ni audacieuses ni utopiques. En ce qui concerne le dessin, la géographie, les mathématiques, elles sont réalisées dans la plupart des écoles moyennes des régions industrielles de Saxe, de Westphalie, de Hesse, de Bohème.

$\mathrm{Au}$ sein des Conseils communaux, des Conseils provinciaux, des hommes clairvoyants élèvent périodiquement la voix contre l'ancienne pédagogie, qui a surchargé le programme des écoles primaires et moyennes de branches récitatives exclusivement destinées à développer la mémoire de l'enfant. Les sommités du monde de l'enseignement demandent de remettre en honneur les exercices, qui cultivent le sens pratique et l'esprit d'observation. 
Nous exprimons notre vive reconnaissance à Monsieur Breithof, Professeur à l'Université de Louvain, Inspecteur du dessin dans les établissements d'enseignement moyen, qui a bien voulu approuver nos idées, et nous donner ainsi le plus précieux encouragement.

La comparaison du cours de dessin dans nos écoles moyennes et de celui d'Iserlohn, montrera comment l'Allemagne adapte son enseignement moyen inférieur aux besoins de la région où il est établi.

\section{L'ENSEIGNEMENT DU DESSIN DANS NOS} ÉCOLES MOYENNES.

Le programme porte : le dessin géométrique, les principes des projections, la perspective et le tracé des ombres, le dessin d'après des modèles en relief, tels que formes géométriques, fragments d'architecture, pour aboutir au dessin de masques.

Il ressort de l'énumération de ces branches, que le but du programme est d'exercer les élèves à la copie d'un modèle sans se soucier de l'application utile.

Il serait nécessaire de donner une base plus exacte et une tendance plus utilitaire à ce cours, sans négliger son influence esthétique. 
La perspective centrale dont on enseigne le tracé, est du domaine exclusif de l'artiste et ne trouve aucune application dans la pratique des industries, le programme devrait lui donner le caractère expérimental qu'il a dans les écoles primaires (programme de I8g3) : l'éducation de l'œil par l'observation constante des effets perspectifs suffit pour guider l'élève dans le dessin à main levée.

La perspective centrale pourrait être avantageusement remplacée par la perspective cavalière, qui constitue la véritable perspective de l'artisan. Elle est d'un usage courant à l'atelier, parce qu'à l'aide d'une simple construction géométrique elle donne une idée suffisante des mesures et de l'aspect pittoresque des objets de dimensions restreintes. La perspective cavalière est d'ailleurs le complément nécessaire des projections.

Le dessin par les projections, déjà étudié au point de vue mathématique, serait condensé en une série graduée de modèles simples empruntés à la maçonnerie, à la charpente, à la taille des pierres, à la construction de machines etc.; il habituerait l'élève à l'analyse de la structure intime des objets, et l'initierait à la lecture et à la confection de plans et de dessins industriels. 
Le dessin ornemental d'après nature, d'après des objets usuels, des fragments d'architecture conduirait à la composition de simples sujets décoratifs.

Toutes les branches du dessin ainsi conçues et enseignées jetteraient les bases du dessin industriel et décoratif sans perdre leur caractère éducatif général.

LE DESSin A L'ECOLE MOYEnNe D'ISERLOHN.

Le programme assigne une importance dominante au cours de dessin.

Nombre d'heures par semaine :

En $I^{\mathrm{e}}$ année d'études : $4 \mathrm{~h}^{\mathrm{s}}$ de dessin à main libre;

En $2^{\mathrm{e}}$ année d'études : $4 \mathrm{~h}^{\mathrm{s}}$ de dessin à main libre et 2 heures de dessin à l'aide d'instruments; total : 6 heures; En 3e année d'études : 6 heures.

Dans ce milieu industriel on apprécie le ròle considérable du dessin dans toutes les branches de l'industrie; déjà à l'école le futur ouvrier doit acquérir une habileté et une science sérieuses dans toutes les branches du dessin sur lesquelles se développera son éducation professionnelle aux écoles spéciales de métiers. 
Comment trouver le nombre d'heures disponible sur un programme si chargé ?

Comme réponse à cette question nous reproduisons en regard le nombre d'heures consacrées aux différentes branches des écoles moyennes d'Iserlohn et de Schaerbeek.

ISERLOHN

(par semaine.)
Schaterbeek

(par semaine.)

\begin{tabular}{|c|c|c|c|c|c|c|c|}
\hline & $\begin{array}{c}\mathrm{I}^{\mathrm{e}} \\
\text { annéc }\end{array}$ & $=\overline{2^{\circ}}$ & $\overline{\begin{array}{c}3^{e} \\
\text { année }\end{array}}$ & & $\begin{array}{l}1 " \\
\text { année }\end{array}$ & $\begin{array}{c}2^{2} \\
\text { année }\end{array}$ & $\begin{array}{c}3^{\circ} \\
\text { année }\end{array}$ \\
\hline I. Religion & 2 & 2 & 2 & I. Religion & 2 & 2 & 2 \\
\hline 2. Allemand & 5 & 4 & 4 & 2. Français & 8 & 7 & 6 \\
\hline 3. Français & 5 & 5 & 5 & 3. Flamand & 6 & 6 & 6 \\
\hline 4. Arithmétique & 4 & 4 & 3 & 4. Arithmétique & 4 & 3 & I \\
\hline 5. Algèbre et géom. & 2 & 2 & 3 & 5. Algèbre et géom & ) & 2 & 5 \\
\hline 6. Histoire & 2 & 2 & 2 & 6. Histoire & 2 & 2 & 2 \\
\hline $\begin{array}{l}\text { 7. Géographie } \\
\text { 8. Sciences (Bot. et }\end{array}$ & 2 & 2 & 2 & $\begin{array}{l}\text { 7. Géographie } \\
\text { 8. Sciences (Bot. }\end{array}$ & I & I & I \\
\hline Zool.) & 2 & I & ) & et Zool.) & 2 & I & ) \\
\hline 9. Physique & $m$ & 2 & I & 9. Physique & ) & I & I \\
\hline Io. Chimie & ) & ) & 2 & Io. Chimie & » & 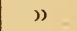 & I \\
\hline I I. Dessin (libre) & 4 & 4 & 4 & II. Dessin & 2 & 2 & 2 \\
\hline I I bis. Dessin (instr.) & ) & 2 & 2 & $. \quad . \quad$. & . . & ... & . \\
\hline . . . . . & . . & . & e & I I bis. Calligraphie & I & ) & ) \\
\hline 12. Chant & 2 & I & I & 12. Chant & I & I & I \\
\hline I3. Gymnastique & 2 & 2 & 2 & I3. Gymnastique & 3 & 3 & 3 \\
\hline & & & & 14. Allemand (facul- & ) & 3 & 3 \\
\hline & & & & & & & \\
\hline Totaux & 32 & 33 & 33 & Тот & 32 & 37 & 37 \\
\hline
\end{tabular}

Les Méthodes, le Programme, LES ModÈles.

La méthode est exclusivement individuelle 
pour le dessin à main levée (I) et la tendance franchement utilitaire.

\section{A Année d'Études}

(4 heures de dessin à main levée par semaine.)

Afin de rattacher le dessin aux études des classes préparatoires, les élèves reprennent les modèles plans : planches, dessins de feuilles, fleurs stylisées, d'ornements plans à base géométrique empruntés aux différents métiers. Quelques modèles à relief peu prononcé établissent une transition facile aux modèles solides limités par des surfaces planes. Faire un bon croquis, tel est le but du dessin à main levée.

Lorsque les élèves ont reproduit ou composé en contour (croquis), le dessin d'une rosace, d'un enroulement, d'un panneau, ils appliquent sur le fond et sur les motifs dominants des teintes unies, qui s'harmonisent entre elles. La pratique du lavis développe le sens de la couleur et de l'harmonie; elle inịtie les élèves à l'arrangement de motifs ornementaux simples.

\section{2 e Année D'Études}

I. Le dessin à main libre $\left(4 \mathrm{~h}^{\mathrm{s}}\right)$ exerce les élèves à la reproduction au trait d'objets

(I) Voir le chapitre consacré au dessin des écoles primaires. 
graduellement plus difficiles. Les modèles de la collection Stuhlmann, limités par des surfaces planes et courbes, et une série graduée de modèles ornementaux empruntés aux différentes époques, établissent les bases fondamentales du dessin. La collection de l'école fournit pour le surplus un matériel varié : des clefs, des serrures, des pentures artistiques, des organes simples de machines, des vases, des tissus historiés, des broderies, des assemblages de bois etc. dans lesquels l'élève choisit ses exercices sous la direction du professeur. Les objets en nature, feuilles, fleurs et fruits, rinceaux servent de point de départ à de petites compositions relevées de teintes unies en vue des applications variées de la gravure, de la ferronnerie, de l'ébénisterie, etc.

2. Le dessin à l'aide d'instruments $\left(2 \mathrm{~h}^{\mathrm{s}}\right)$. Simultanément avec le dessin à main levée, est enseigné le tracé des figures géométriques et leur mise en œuvre dans l'ornementation; les polygones, le cercle, les oves, spirales, volutes, leur raccordement, la réduction et l'agrandissement, le tout combiné avec la pratique du lavis.

3e Année D'Études.

I. Dessin à main levée $\left(4 \mathrm{~h}^{\mathrm{s}}\right)$. Les modèles 
Stuhlmann limités par des courbes (voir chapitre enseignement du dessin à l'Ecole primaire), des moulages gradués, les objets divers empruntés à la collection, constituent le matériel pour l'enseignement du dessin à la main libre.

L'étude de ces objets développe d'une manière générale le sens esthétique et les aptitudes manuelles.

A côté du dessin de pure reproduction, les élèves s'exercent à la copie d'objets artistiques de toute nature : de ferronnerie, de menuiserie et d'ébénisterie, des spécimens de tissage, d'incrustations de bois, de reliure, de sgrafitto, de gravures, et cela d'après les différents procédés : à la plume, au crayon, au fusain, au lavis à une ou à plusieurs couleurs. Les dessins sont aggrandis ou réduits d'après les objets auxquels ils s'appliquent.

Le cours de dessin à main levée conduit l'élève par des exercices de transformation, de substitution et de mémoire, à la composition décorative simple en vue des principaux métiers.

2. Dessin géométrique $\left(2 \mathrm{~h}^{\mathrm{s}}\right)$.

Le dessin par les projections orthogonales est étudié avec soin; il initie les élèves au mécanisme du dessin, à la lecture et à la 
confection du plan d'objets très simples : assemblages du bois, de la pierre, du fer, des fragments, de meubles, une porte, une fenêtre, des boulons, des écrous, des clous, le tout dessiné en croquis coté d'abord, puis en épure et lavé de teintes conventionnelles absolument comme un dessin d'atelier.

Cet enseignement est général; il n'étudie pas seulement la reproduction théorique de corps géométriques, mais les applications les plus simples aux objets des différents métiers; il initie les élèves aux rudiments du langage industriel. Tout en cultivant les facultés fondamentales, le goùt, l'intelligence, le raisonnement, le cours de dessin évolue vers le dessin professionnel et oriente les idées et les aspirations des jeunes gens vers les industries et les métiers.

\section{Salle DE DEssin.}

Parmi tous les avantages de la méthode individuelle pour le dessin à main levée, la simplicité du matériel de classe n'est pas le moins important : des pupitres à table large, légèrement inclinée.

Notre mobilier ordinaire pourvu d'une allonge pourrait à la rigueur suffire.

Certaines de nos écoles de dessin possèdent 
une salle de dessin bien outillée : chevalets et accessoires coûteux, des supports perfectionnés, le tout organisé sur le plan d'un atelier de peinture. Pas de traces d'objets d'industrie ni d'art industriel parmi les modèles. Il est vrai qu'un fragment de meuble, de ferronnerie, de machine, un outil d'artisan, quelque utiles qu'ils soient, feraient triste effet à côté de masques et bustes antiques et florentins et d'écorchés même, qui par une aberration grotesque garnissent exclusivement ces belles salles!

Quelle que soit la future profession des élèves, l'étude ombrée de ces modèles doit constituer à leurs yeux le nec plus ultra de la science et de l'art du dessin.

L'aspect de la salle d'Iserlohn est bien différent. Les murs sont couverts d'une collection complète de produits d'art industriel d'Allemagne et de l'étranger, soit en nature, soit en moulage ou en reproduction galvanoplastique. Une série d'objets sont reproduits dans leurs différentes phases de fabrication et montrent aux élèves comment la matière se transforme sous la main d'un artisan habile. Cette collection constitue l'histoire vivante de l'industrie artistique, elle fournit aux cours d'instruction un matériel d'études précieux et 
au cours de dessin des modèles concrets et pratiques, qui mettent l'élève en présence du travail.

L'aspect des salles de dessin caractérise bien les tendances contraires de l'enseignement du dessin chez nous et aux écoles moyennes d'Allemagne et d'Autriche : ici, les efforts stériles vers la culture absolue du sens artistique, là, une heureuse combinaison de l'éducation esthétique et de l'éducation professionnelle générale.

\section{Les Professeurs de dessin.}

Pour introduire efficacement une modification dans l'esprit du cours de dessin aux écoles moyennes, la question préalable et primordiale est le recrutement des professeurs.

Par le fait que les cours seraient ramenés au niveau des branches dominantes de l'enseignement, la situation des professeurs de dessin deviendrait plus importante et des conditions plus rigoureuses devraient être posées à l'octroi des diplômes.

Le candidat actuel doit fournir la preuve, qu'il possède une aptitude théorique au dessin exact et au dessin à main levée : tracer 
une épure de projections, faire le dessin de la feuille d'acanthe ou du masque de la Vénus de Milo, etc. Quelques questions anodines sur l'histoire des styles, sur l'esthétique et sur la méthodologie complètent l'examen. Nulle trace d'application industrielle ou décorative de ces notions théoriques.

Pour pouvoir enseigner le dessin avec quelques applications, il est indispensable, que le professeur sache mettre en œuvre ses connaissances théoriques en vue de la création de dessins industriels ou de projets décoratifs.

La question du recrutement des professeurs est l'objet de la plus constante préoccupation dans les pays étrangers. Des cours normaux pour professeurs de dessin sont organisés, non dans les Académies des Beaux-Arts, mais dans les principales écoles de métiers et d'art industriel d'Allemagne et d'Autriche.

Le programme de ces cours porte à l'Ecole d'arts industriels de Munich :

I. Le dessin linéaire et le dessin par les projections ;

2. le dessin du bâtiment;

3. le dessin ornemental; la figure;

4. le modelage.

Tous ces cours sont étudiés en vue du dessin industriel et décoratif; 
5. l'histoire de l'ornement;

6. la méthodologie du dessin - leçons pratiques.

Les questions suivantes, posées en I 893 pour l'octroi du diplòme de professeur de clessin, caractérisent la tendance des cours :

I. Arts graphiques. Projet de diplòme d'honneur à offrir à un architecte, qui a construit une église; dimensions : $\frac{0.60}{0.80} \mathrm{~m}$. Exécution au lavis.

2. Projet d'étui en cuir avec fermoir, initiales et appliques en métal; style : Renaissance allemande.

Les professeurs formés d'après pareilles méthodes, éduqués dans cet esprit du travail, sont capables d'enseigner, à côté des notions théoriques, les éléments graphiques des métiers; ils peuvent inspirer à leurs élèves l'amour des professions manuelles. 


\section{IV. - LE DESSIN DANS LES ÉCOLES PRIMAIRES ALLEMANDES}

La Prusse, les villes libres du Nord et quelques autres états ont adopté pour les écoles primaires un programme et des méthodes d'enseignement très caractéristiques, élaborés par M. Stuhlmann, directeur de l'Ecole des métiers et des arts industriels de Hambourg. En raison de sa simplicité et de sa tendance, ce cours peut offrir de l'intérêt, sinon de l'utilité pour nos écoles populaires. Nous rendons compte du dessin à la section préparatoire de l'Ecole normale de Hambourg où, sous les yeux de l'auteur, il doit certainement être enseigné dans son esprit pur.

L'école primaire compte 3 degrés et 7 années d'études.

$I^{\text {re }}$ degré (de 7 à 9 ans) I $^{\text {re }}$ et $2^{\text {e }}$ années d'études.

La méthode est śtigmographique; le dessin 
a pour but d'exercer les élèves à la reproduction, sur un réseau rectiligne, d'objets plans qui s'y adaptent facilement. C'est la méthode supprimée par notre programme de I893.

$2^{e}$ degré (de 9 à $\mathrm{I} 2$ ans), $3^{\mathrm{e}}, 4^{\mathrm{e}}$ et $5^{\mathrm{e}}$ années d'études.

Plus de méthode stigmographique. Les éleves dessinent, sur du papier blanc, les objets sans relief que le professeur montre en nature ou découpés en papier; celui-c1 explique le modèle aux élèves et exécute le dessin sous leurs yeux au tableau, en se servant de quelques lignes de construction. Ces objets et figures sont des ornements géométriques dérivés du carré, de l'octogone, de l'hexagone et du décagone : des rosaces et des encadrements, des panneaux, des trèfles, des ferrailles, des motifs d'incrustations.

Les formes empruntées à la flore sont expliquées sur des feuilles et fleurs en nature et dessinées d'après les mêmes feuilles et les mêmes fleurs stylisées; l'auteur estime que la feuille naturelle n'oblige pas suffisamment l'enfant à la copie exacte des formes, laisse trop de jeu à la fantaisie et présente souvent des défauts et des imperfections, que l'élève est tenté de reproduire.

La comparaison de la feuille naturelle et 
de la feuille stylisée montre dès l'abord, comment on simplifie et comment on synthétise les formes dans l'interprétation.

Vérification. Les élèves vérifient à la visée. Après avoir tracé une ligne, ils s'assurent de l'exactitude de sa direction et de ses proportions en la comparant à des lignes fixes, horizontales ou verticales.

La méthode est d'abord simultanée : un modèle, une planche pour toute la classe.

A mesure que les élèves avancent, elle tend à devenir individuelle en ce sens, qu'ils ont ensuite un modèle par groupe, puis, enfin, chacun un modèle différent.

$3^{e}$ degré, $6^{\mathrm{e}}$ et $7^{\mathrm{e}}$ années d'études (I3 à I4 ans).

Des modèles à faible relief forment la transition au dessin d'après des solides et des objets à 3 dimensions.

La méthode est individuelle et les exercices conduisent aux applications utilitaires.

Elle exerce une influence considérable sur l'enseignement à tous les degrés, tant dans les écoles moyennes, que dans les écoles des métiers; c'est pourquoi nous la décrirons avec quelques détails.

LES MOdÈles.

Les modèles sont en bois et ont une hau- 

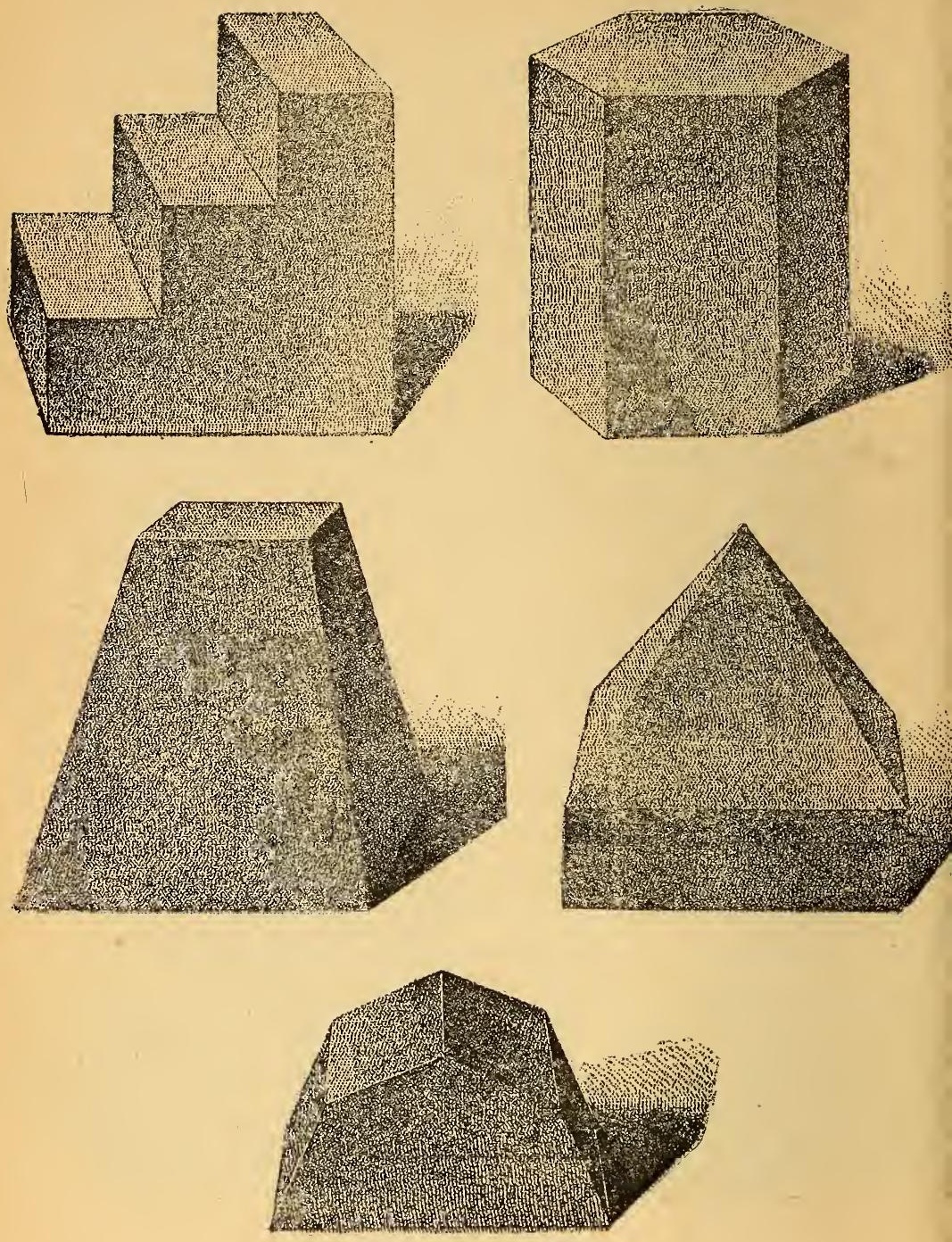

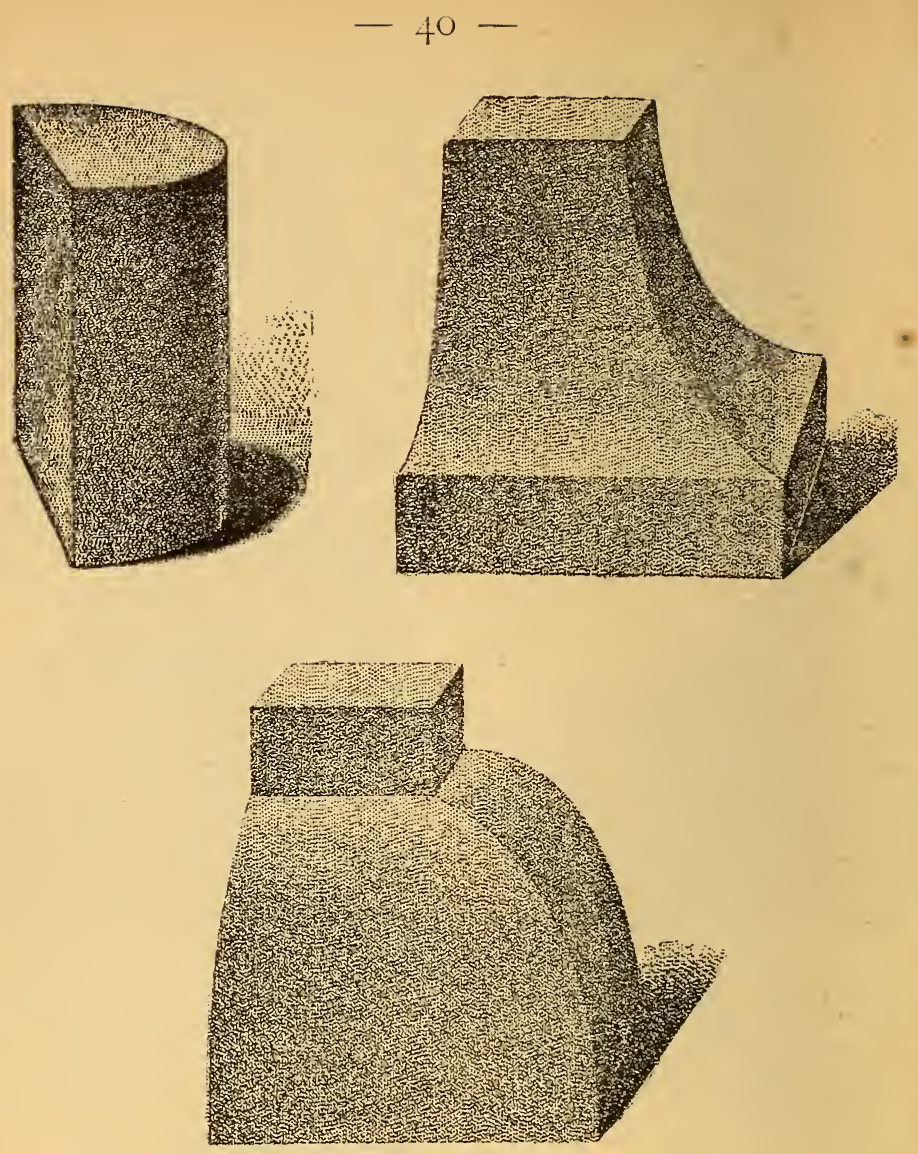

Les modèles ne sont pas, au point de vue esthétique, d'un choix remarquable, ils n'auront sur la culture du goùt qu'une médiocre influence; tel n'est d'ailleurs pas leur but principal; ils présentent sous une forme 


\section{- $4 \mathrm{I}-$}

mathématiquement graduée les difficultés fondamentales du dessin à main levée. L'étude de moulages simples et d'objets en nature développe plus spécialement le sentiment du beau chez l'élève.

GRoupe de 3 SOLIDES LIMITÉS PAR DES SURFACES COURBES :
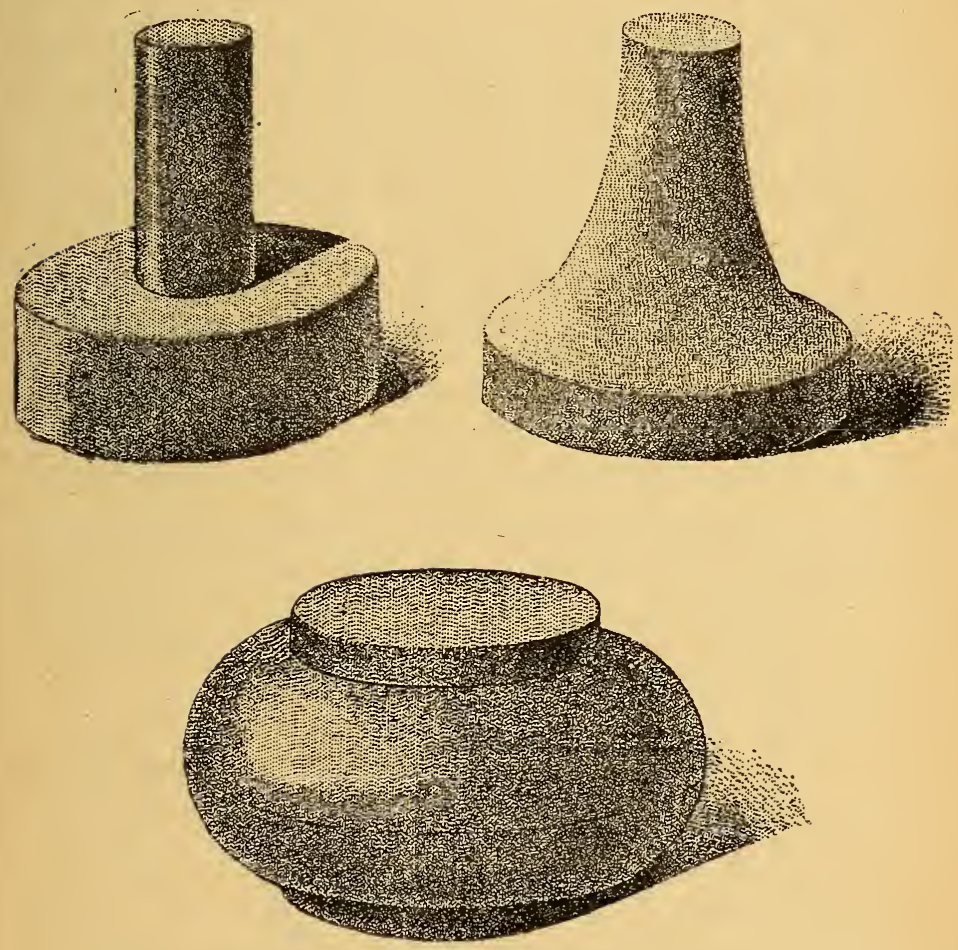
Seuls les plus avancés s'exercent au dessin ombré et à l'étude des couleurs. Des difficultés techniques considérables sont attachées au lavis, et pour ce motif il n'est qu'exceptionnellement pratiqué.

Fonctionnement de la méthode.

Les modèles sont placés à une distance de $0.80 \mathrm{~cm}$. à I m. de l'élève, soit sur un support fixé sur la table du pupitre, soit sur un support indépendant, muni d'une console et d'un crochet (croquis IV et V, page 43).

Le professeur distribue les modèles en tenant compte des aptitudes, du degré d'avancement et de l'habileté de chacun. Il surveille le placement, la position, la distance, se promène d'élève à élève et explique verbalement les défauts du dessin, la signification, les lignes caractéristiques du modèle.

Aussitôt qu'un élève a achevé son dessin, il reçoit un autre modèle et se remet au travail sans perdre du temps.

Les exercices de dessin d'après la méthode Stuhlmann sont alternés d'études d'après des moulages et des objets. en nature, tels que fleurs, feuilles, fruits, rinceaux. Les élèves les plus avancés s'essaient à de petites composi- 


\section{$-4^{3}-$}

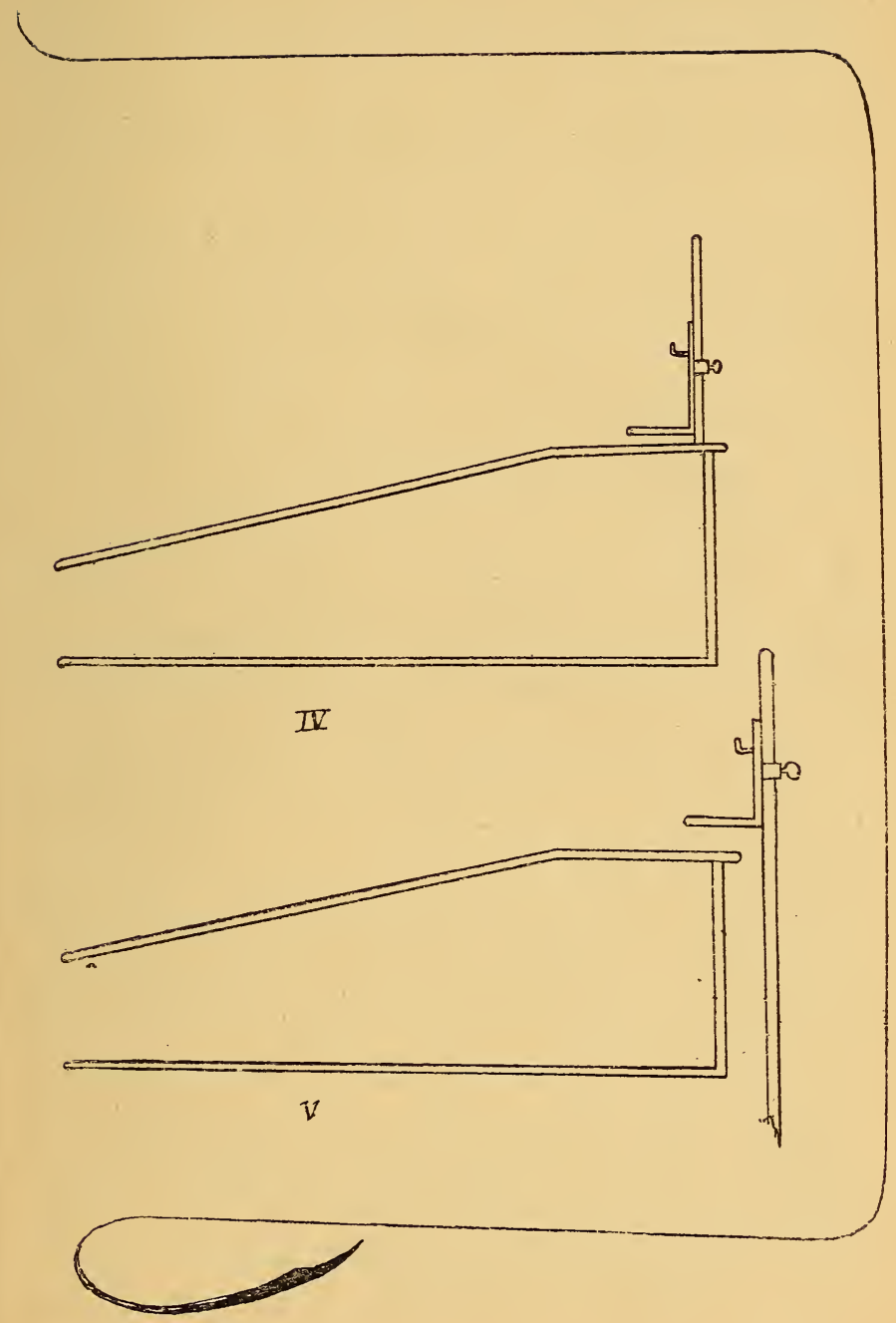


tions d'après un thème donné et relèvent leur dessin de teintes plates harmonisées.

\section{Avantages de la méthode individuelle.}

Si le professeur est obligé de montrer une vigilance et une activité soutenues, les élèves en tirent largement profit, parce que la méthode individuelle permet d'adapter soigneusement les exercices et les explications aux aptitudes et à la compréhension des élèves : sous ce rapport elle constitue l'idéal.

Nous avons tous observé que l'enseignement d'après le modèle unique a de grands inconvénients, dès que le dessin présente des difficultés réelles, comme le tracé des courbes, le dessin d'après le relief, etc. Les élèves les plus habiles perdent leur temps à attendre, que leurs condisciples moins doués aient achevé leur travail.

De plus, un modèle en relief, placé devant la classe se présente sous divers aspects aux élèves, les uns y remarquent des déformations perspectives auxquelles ils n'ont pas été préparés, les autres n'y voient qu'un simple contour à reproduire : manque de gradation dans les difficultés. Le cube (croquis VII) peut servir d'exemple.

La méthode simultanée suppose cette 


\section{$-45-$}

absurdité : mème aptitude, mème degré d'avancement chez tous; de là découragement des faibles, orgueil mal fondé des autres; elle tend à niveler les intelligences et à étouffer le caractère personnel, c. à. d. ce qu'il y a de plus précieux dans l'élève.

Comme la difficulté du modèle est mesurée au degré d'avancement, l'élève montre une salutaire activité au travail; il sait qu'en

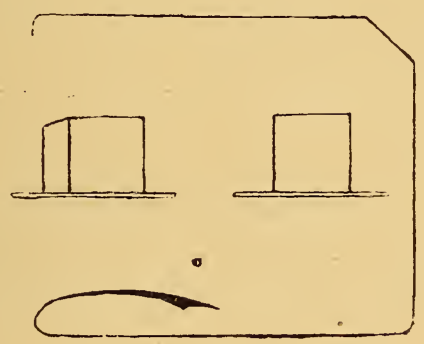

VII

s'appliquant de tout son zèle, il pourra dessiner l'objet qu'on lui soumet. Le succès du cours dépend du soin avec lequel le professeur choisit les exercices d'après les aptitudes de l'élève.

Avec la méthode individuelle l'élève doué se passe aisément des explications du professeur ; celui-ci peut en conséquence porter toute sa sollicitude sur les faibles. 
Le dessin est la seule branche d'enseignement qui peut, par la méthode individuelle, adapter les études au degré de développement de tous les élèves; cette méthode est logique, parce qu'elle tient compte des dispositions, du caractère, du tempérament de chacun en particulier, au plus grand bien de la culture de l'intelligence et de la personnalité.

Le cours de dessin enseigné d'après les modèles Stuhlmann est utilitaire et peut, en raison de son caractère positif, servir de base à l'enseignement professionnel.

Pour que l'instruction populaire contribue réellement à la prospérité du peuple, il faut qu'elle s'inspire des besoins de la vie sociale et s'harmonise avec les nécessités du travail actuel. Les écoles primaires et surtout les écoles moyennes ont saturé le pays de travailleurs intellectuels dont l'esprit est orné, certes, de toutes espèces de connaissances abstraites, mais qui sont dépourvus de tout sens pratique. Leurs forces intellectuelles ont été cultivées exclusivement en vue des examens à passer, leurs aspirations sont dirigées vers les administrations; ceux qui sont vaincus dans cette âpre lutte pour les emplois publics se 
trouvent désorientés, incapables de faire fructifier leurs connaissances théoriques, et ils vont grossir l'armée des déclassés (I). Ainsi l'enseignement moyen inférieur ravit aux industries et aux métiers toutes les forces vives, qui leur permettraient de se développer à la hauteur du travail étranger.

Le travail manuel est la base de la société actuelle; il faut que le travail soit la base des études et de l'éducation populaires : toutes les branches d'enseignement doivent tendre au développement des aptitudes en vue des professions manuelles; le dessin surtout doit acquérir une influence et une direction utiles aux études professionnelles.

La conséquence naturelle des réformes

(I) La catégorie d'ouvriers sans travail par suite d'absence de métier, d'aptitude, d'habileté, comprend le plus grand nombre des sans travail habituels. Quand les employés de la Bourse du travail leur demandent quelle est leur profession, ils répondent : garçons de course, commissionnaires, hommes de peine, concierges, colporteurs, femmes à journées! Autant dire qu'ils n'ont aucun métier; ils sont sans travail parce qu'ils ne savent pas travailler. C'est donc dans ces prétendues professions que se refugient tous ceux qui, par inaptitude, inhabileté, ignorance, ne connaissent aucun métier manuel. On peut y ajouter beaucoup de déclassés, qui s'intitulent commis, employés, magasiniers, placiers, commis-voyageurs, agents commerciaux, professions mal définies, propres à tous ceux qui, sachant tenir une plume, sont cependant incapables de tenir un livre de commerce. 


\section{$-48-$}

dans le caractère de l'enseignement primaire et moyen inférieur serait une vaste organisation d'écoles primaires des métiers et d'écoles secondaires industrielles et des arts industriels avec ateliers d'apprentissage. 


\section{I. - LES ÉCOLES PROFESSIONNELLLS ET INIDUSTRIELLES OBLIGATOIRES}

(jortbiloungidsulen)

Nos écoles d'adultes ne sont pas fréquentées et ne produisent guère de résultats, parce qu'elles ne s'attachent qu'à développer théoriquement et à confirmer l'enseignement des écoles primaires.

Les jeunes ouvriers n'ont que faire de la pédantesque théorie scolaire; il leur faut des études concrètes, directement utiles aux métiers. Toutes les branches des cours d'adultes devraient être enseignées dans leur rapport avec le travail de l'atelier; le dessin notamment demande à ètre développé dans un sens professionnel.

Le Gouvernement allemand a provoqué la création de cours d'adultes dans toutes les localités de plus de ıooo habitants, tant des régions agricoles que des régions industrielles. Cette institution est florissante et produit 
des résultats remarquables parce qu'on veille avec un soin extrême à ce que l'enseignement ne dégénère pas en un verbiage stérile.

Les élèves sont groupés d'après leurs métiers, par classes dans les grandes villes, par divisions dans les localités de moindre importance; ils reçoivent un enseignement scientifique et graphique basé sur des faits relatifs à leur occupation journalière.

Les matières de l'enseignement, les modèles, le langage du professeur, tout rappelle aux apprentis et ouvriers le travail à l'atelier, et excite vivement leur intérêt. Ces institutions caractéristiques constituent :

LES ÉCOLES PRIMAIRES DES MÉTIERS ET DES INDUSTRIES.

L'enseignement des écoles primaires des métiers et des industries est obligatoire, absolument comme l'enseignement populaire. Les enfants de 6 à I4 ans fréquentent obligatoirement les écoles primaires; ceux qui, ayant terminé leurs études primaires, commencent l'apprentissage d'une profession manuelle, sont oblicés dans la plupart des villes, de fréquenter jusqu'à l'âge de I 8 ans les cours de l'école des métiers et des industries : des milliers de jeunes gens y achèvent leur édu- 
cation morale, et y trouvent comme complément à leur travail pratique à l'atelier, les connaissances scientifiques et graphiques nécessaires à l'exercice intelligent de leur métier.

Faut-il être étonné de l'expansion qu'a prise l'industrie allemande dans ces derniers temps? Les produits, par leur exécution soignée, par leur bon marché et par leur aspect de plus en plus agréable, priment la fabrication française même sur les marchés français, et rivalisent avec l'industrie anglaise sur toutes les places du monde. Ce merveilleux développement industriel est le résultat tout naturel de l'enseignement logique des industries et des métiers.

Les écoles d'adultes obligatoires produisent plus spécialement de grands effets, parce que leur enseignement apporte aux plus humbles artisans l'art et la science nécessaires au travail moderne.

L'enseignement professionnel est une œuvre patriotique. Au lendemain de la guerre de I870, lors de l'inauguration du Musée des arts industriels de Berlin, le Kronprinz Frédéric prononça ces paroles historiques : "Nous avons vaincu sur les champs de bataille de la guerre, nous vaincrons sur les 
champs de bataille du commerce et de l'industrie! »

Cet appel a trouré son écho dans toute l'Allemagne : les Pouvoirs publics, les Associations ouvrières, les industriels, guidés par le Pouvoir central se sont mis à l'œurre arec enthousiasme; ils ont créé un enseignement complet des industries, qui amènera dans un temps rapproché, la supériorité de l'Allemagne dans le domaine du travail.

Le Régime de L'obligation.

L'article I20 de la " loi industrielle " porte :

" Les entrepreneurs d'industries et les patrons sont obligés d'accorder à leurs apprentis, âgés de moins de I 8 ans, le temps fixé par les autorités compétentes, pour fréquenter les cours d'une école d'adultes industrielle ou professionnelle. »

La loi délègue aux autorités communales le droit de décréter l'obligation en vertu de l'art. I40 qui porte :

"Par une disposition statutaire communale, les ourricrs industriels (gcwerbfiche 9rigeiter), âgés de moins de i 8 ans, peuvent ètre obligés à fréquenter les cours d'une école d'adultes industrielle ou professionnelle, ou de toute 
autre institution, reconnue comme telle par les autorités compétentes.

L'article I 48 formule la sanction :

'“ Peut être puni d'une amende de 20 marks maximum ou en cas d'insolvabilité, de 3 jours de prison, celui qui contrevient aux articles I 20 et I 40 .

Cette délégation n'a été accordé que provisoirement aux communes.

Cédant aux vœux exprimés à différentes reprises par des associations de commerce, d'ouvriers et de patrons, par des Conseils de l'industrie, le Gouvernement ne tardera pas à rendre l'enseignement professionnel obligatoire par la loi, dès que les écoles seront organisées et outillées d'une manière complète dans toute l'Allemagne.

En fait, plus de la moitié des communes industrielles de Prusse et presque toutes les communes des autres états allemands ont décrété l'obligation, d'une part, pour obéir aux instances des Associations pour le relèvement de l'industrie, d'autre part pour participer aux subsides, que le Gouvernement n'accorde en règle générale qu'aux écoles établies sous le régime obligatoire.

Quelques localités très importantes comme 


\section{$-5_{4}-$}

Berlin, Breslau et autres, qui peuvent se passer des subsides gouvernementaux, ont organisé l'enseignement professionnel facultatif; néanmoins les statistiques prouvent que $45 \%$ des apprentis industriels suivent les cours.

Locaux. - Heures.

Les écoles professionelles d'adultes sont, pour la plupart, établies dans les locaux des écoles primaires ou moyennes, dans les athénées disséminés dans les quartiers; une division centrale est installée à l'école des arts industriels.

La séparation d'après les métiers est un principe absolu : elle permet de donner aux élèves de chaque branche un enseignement scientifique et graphique approprié, intelligible et intéressant pour tous.

L'enseignement obligatoire des métiers de Hannovre, ville de province, se donne dans 6 écoles, sises aux différents quartiers de la ville; I 500 élèves-apprentis suivent les cours sous la direction de 5I professeurs. Le cours supérieur de dessin professionnel est enseigné à l'école d'art industriel, qui, avec un personnel de 39 professeurs, compte I4 à I50O élèves.' Au total, 3000 élêves, ouvriers et 
futurs ouvriers, s'appliquent à l'étude des métiers, sous la conduite d'un seul directeur et de 90 professeurs.

Les autorités communales fixent le nombre d'heures de cours obligatoires : dans certaines localités, il y a un minimum de 6 heures par semaine, dans d'autres de 8 et de I 2 heures même.

L'enseignement se donne l'après-midi, le soir et le dimanche matin, et se prolonge dans la plupart des communes pendant 43 semaines de l'année.

Les élèves des écoles obligatoires professionnelles ne paient aucune rétribution scolaire; les patrons peuvent être obligés, en vertu de la même loi industrielle, à payer une redevance scolaire pour leurs apprentis.

Caractère.

Les écoles d'adultes professionnelles et industrielles présentent dans leur organisation une telle variété, qu'il est difficile d'en décrire la physionomie d'une manière générale : cette variété correspond à la multiplicité des industries et des métiers locaux.

L'Etat, envisageant les besoins généraux de l'industrie, trace aux administrations les 
grandes lignes de l'organisation de ces écoles. Il veille, par ses inspecteurs, à ce que les études aient une direction utile, et donnent réellement aux apprentis les notions d'art et de sciences nécessaires à leur métier.

Contrairement à notre conception de l'enseignement pour adultes, les écoles allemandes n'ont pas pour but d'augmenter le savoir livresque des élèves. Le choix des matières est strictement limité aux besoins professionnels des apprentis et tout l'enseignement est pénétré de l'esprit du travail.

L'école d'adultes achève l'éducation morale et professionnelle des futurs ouvriers.

\section{Matières D'ENSEIGNEMENT.}

L'enseignement comprend 2 degrés :

A. Le degré inférieur, destiné aux apprentis de 14 à 16 ans, a pour objet d'enseigner les notions des sciences et du dessin qui forment la base des métiers et des industries.

I. La langue maternelle dans ses rapports avec la géographie industrielle et commerciale, les sciences naturelles, l'histoire, le style et la lecture.

2. Le calcul : la tenue des livres, l'arithmétique commerciale, la géométrie : les figures et les solides. 
3. Le dessin.

B. Le degré supérieur a pour objet de développer les connaissances professionnelles de l'élève apprenti. Dans les localités de grande industrie, les cours du degré supérieur prennent un caractère général industriel et alors l'école est appelée : école industrielle d'adultes (Siewerblidye jortbildungidfunte); dans les régions de la petite industrie, l'école enseigne le métier : on l'appelle dans ce cas l'école des métiers, (Jandweiterifgule); dans certaines villes, les deux genres sont réunies dans une mème organisation.

En tous cas, le dessin est quasi toujours l'élément principal du degré supérieur.

Ces branches constituent un minimum. L'école peut s'adjoindre des cours spéciaux, tels que les mathématiques, le modelage, la chimie inclustrielle, la dinanderie, la carrosserie, la construction de machines, etc. etc. d'après les besoins de l'industrie locale.

\section{LE COURS DE DESSIN.}

A. Degré infÉrieur. (I 4 a i 6 ANS).

I. Le dessin à main libre. Ce cours comporte des exercices variés développant le sens de la mesure et des proportions, le goùt et l'habileté 
manuelle. Les élèves dessinent, au trait, des objets variés d'après leurs professions respectives : des fragments d'objets d'ébénisterie et de menuiserie, des ferrailles artistiques, des pavements céramiques, des parties de machines, des outils et ustensiles, des vases, des fragments d'ornements de différents styles. Les modèles spéciaux initient les élèves au dessin largement ombré.

2. Le dessin à l'aide d'instruments a pour objet la représentation exacte des objets et les ressources considérables de l'ornement géométrique dans la décoration. Après quelques exercices de construction élémentaire, les élèves exécutent une série d'ornements géométriques dérivés des polygones, des cercles, et des courbes de sentiment.

3. Les projections : Plan, élévation; projection latérale, coupes de solides géométriques, d'objets et d'outils simples, d'assemblages usuels du bois, du fer et de la pierre.

Le dessin au premier degré a pour but de coordonner les connaissances éparses des élèves, et de jeter les fondements du dessin professionnel, qui fait l'objet du $2^{\text {e }}$ degré.

$$
\text { 2 } 2 \text { DEGRÉ (I6 A I } 8 \text { ANS). }
$$

4 heures, au minimum, sont assignées au 
dessin dans les écoles obligatoires, la plupart lui accordent 8 à Io hs par semaine.

I. Le dessin à main libre évolue graduellement vers les applications professionnelles. Chaque classe ou chaque division d'élèves, exerçant le même métier ou des métiers semblables, dispose de modèles appropriés, qui sont transformés et dessinés d'après les techniques et dans les proportions usitées dans ces métiers.

Les élèves bijoutiers, orfèvres, ciseleurs, graveurs, réduisent les ornements et les appliquent aux objets de leurs métiers; les lithographes, les graveurs en taille douce, les graveurs sur bois ou autres dessinent à la plume ; les charpentiers, charrons, carrossiers, menuisiers, ébénistes, dessinent d'après des objets se rapportant à leur profession : des assemblages, des fragments de meubles, ou d'après des meubles entiers, des détails de voitures etc.; les ferronniers, les forgerons d'art d'après des ferrailles artistiques en nature ou en reproduction.

Les élèves apportent à l'école les croquis des objets, à la fabrication desquels ils collaborent à l'atelier, et en font l'étude complète : les détails, une vue perspective, les coupes etc. Ainsi, les études à l'école servent directe- 
ment à favoriser l'apprentissage à l'atelier.

2. Le dessin gćométrique reprend le cours de projections du I ${ }^{\text {er }}$ degré et le développe dans le sens du dessin d'atelier; il comprend les projections orthogonales et obliques (perspective cavalière) arec les coupes et les pénétrations usuelles.

Les élèves s'exercent à lever exactement les objets de leur métier, à'en faire un croquis coté et le dessin exact d'après une échelle donnée; les détails sont dessinés en grandeur nature, le tout en vue de l'exécution à l'atelier. Le dessin d'atelier est généralement accompagné d'une vue perspective cavalière de l'objet.

Tous les artisans trouvent ainsi à l'école des études relatives à leur métier. Beaucoup de ceux qui y entrent à contrecœur en vertu de l'obligation, finissent par s'intéresser à l'enseignement, parce qu'ils sentent le lien étroit de l'école avec le travail à l'atelier; leur intérêt augmente arec les études; on remarque, que le sens de la forme, le goùt et l'aptitude professionnelle se développent simultanément; ils voient nettement et parviennent à reproduire proprement et exactement sur le papier ce qu'ils roient, ce qu'ils pensent et ce qu'ils sentent. 
Le Corps professoriL.

L'enseignement des écoles "des métiers se donne d'après une méthode spéciale; les professeurs des écoles ordinaires, autant que les artisans, qui désirent enseigner aux Fortbildungschulen, doivent connaitre à fond les besoins de l'industrie, afin de pouvoir rattacher leurs cours et leurs méthodes au travail de l'atelier.

En comparant les écoles entre elles, on remarque çà et là du tàtonnement, de l'arbitraire et du dillettantisme, pas seulement dans les cours de dessin, mais aussi dans les autres branches; le manque de professeurs entrave encore visiblement le développement de l'enseignement.

Pour obvier à tous ces inconvénients et pour former un corps professoral d'élite, le gouvernement se propose de créer un .enseignement normal, qui établira les méthodes sur des bases fixes et aura pour objet principal l'étude des besoins de l'industrie.

Cette école ne donnera aucune instruction scientifique; les aspirants devront justifier des connaissances fondamentales et apprendront seulement à enseigner les branches des écoles industrielles et des écoles de métiers. 
Jusqu'à ce jour les directeurs choisissent leurs professeurs en se guidant sur les travaux des candidats.

Les écoles d'arts industriels et de métiers de Berlin, de Hambourg, de Dusseldorf, de Hannovre, etc., ont organisé un enseignement temporaire, par lequel les professeurs de dessin peuvent s'initier aux méthodes d'enseignement spéciales aux métiers. Un nombre considérable de professeurs ont été formés dans ces cours.

\section{RESSOURCES FINANCIÈRES.}

L'organisation financière des écoles professionnelles, industrielles, et d'art industriel à tous les degrés est très complexe.

Beaucoup d'écoles sont entretenues par la commune, d'autres par les associations ouvrières et par les associations patronales, d'autres encore doivent leur existence à des legs et dotations.

Les villes prêtent toujours les locaux, pourvoient à l'éclairage et au chauffage; l'Etat fournit en général l'outillage et le matériel scolaire.

Les frais courants, déduction faite des sommes produites par les contributions scolaires, sont supportés normalement pour 
une moitié par l'Etat, pour l'autre par la commune. Ce principe n'a cependant rien de fixe; l'Etat tient compte des'ressources de la commune, de l'utilité plus ou moins générale de l'enseignement. Il agit sur les communes dans le double but d'établir l'obligation et d'augmenter le nombre d'heures de cours, là où il lui paraît insuffisant.

Le budjet de l'industrie de Prusse portait en I895 une somme de 700.000 marks, destinée exclusivement à l'enseignement primaire des métiers et de l'industrie (₹ortbildung= ¡dullen).

Telles sont, largement esquissés, le caractère, la tendance, l'organisation de l'enseignement primaire obligatoire des industries et des métiers en Allemagne.

Forcer tous les apprentis, âgés de moins de 18 ans, de ce vaste empire, à compléter leur apprentissage à l'usine ou à l'atelier par l'étude professionnelle ou industrielle à l'école, est une de ces idées grandioses et audacieuses, dont nous concevons à peine la réalisation dans l'état de nos mœurs et de nos idées.

L'Allemagne a des raisons impérieuses d'exercer cette tyrannie humaninitaire : pour 


\section{$-6+-$}

maintenir sa puissance militaire, elle doit à tout prix relever la situation économique de la nation, augmenter la richesse publique par le déreloppement de la productivité des travailleurs. Gràce surtout à son enseignement, la nation allemande est derenue un peuple industriel de premier ordre. Si les écoles primaires ont rendu les armeés victorieuses, les écolès industrielles et professionnelles obligatoires assureront la victoire de l'industrie allémande : elles forment, en effet, une armée industrielle d'élite, composée d'ouvriers, qui, par la souplesse de leur talent, par leur extrème habilité technique, par leur gout de plus en plus affiné, rivalisent arec les meilleurs travailleurs du monde. 


\section{VI. - LES ÉCOLES SECONDAIRES D'ART INDUSTRIEL AVEC ATELIERS}

Les patrons, contre-maîtres, chefs d'atelier, tous ceux qui sont chargés de conduire, de faire progresser le travail, devraient acquérir dans les écoles de dessin, dans les écoles d'art industriel et d'apprentissage une éducation esthétique et des aptitudes techniques plus avancées.

Telles qu'elles sont organisées, nos écoles de dessin ne sauraient donner qu'un enseignement élémentaire pour les apprentis et ouvriers adultes. Elles ne disposent ni du temps ni de l'influence nécessaires pour favoriser efficacement la culture professionnelle des artisans. Elles visent d'ailleurs au delà du but, en poursuivant le développement exclusif du sens du beau, de la sûreté du coup d'œil, de l'adresse de la main des élèves. Dans les expositions des travaux, on voit des études agréables par leurs contours, par leur variété 
ou par leur originalité. Les écoles de dessin s'évertuent à la composition décorative... sur papier. Sans souci des besoins de l'industrie, les élèves peuvent donner libre cours à leur imagination vagabonde et essayer de s'élever même jusqu'au grand art; ils ne tiennent aucun compte de la nature ni des propriétés de la matière, des conditions de fabrication ni du prix des matériaux. L'élève formé à pareille école est un théoricien, ignorant les conditions techniques et économiques de la fabrication, ambitieux au delà de ses aptitudes; mais, lorsqu'il est obligé de plier son crayon aux exigences si rigoureuses de l'industrie, une dure déception l'attend; avant de pouvoir collaborer à la fabrication, il doit commencer à faire son apprentissage technique.

Il est évidemment nécessaire de cultiver l'idéal chez l'élève, mais pas à l'exclusion des branches directement utiles.

Les écoles de dessin ne tiennent aucun compte de ce fait, que les industries et métiers artistiques sont autant une science qu'un art; le raisonnement, le calcul et le dessin scientifique entrent pour une forte proportion dans toute conception ou composition d'art industriel. 
Tous les métiers, excepté la pure décoration, procèdent de la géométrie descriptive.

Malgré la prédominance absolue du dessin scientifique dans le travail, même artistique, les écoles de dessin le négligent ou le réduisent à une importance tellement infime, qu'il n'exerce aucune influence sur la dircction générale des études : les programmes et les tableaux horaires en font foi :

$I^{r e}$ année d'études préparatoires : I h. de calcul et I h. de géométrie; 8 ou Io heures de dessin à main levée;

$2^{e}$ année d'études : $2 \mathrm{~h}^{\mathrm{s}}$ de géométrie, I heure de calcul, I heure de dessin géométrique, $8 \mathrm{~h}^{\mathrm{s}}$ de dessin à main levée.

Les ébénistes, menuisiers, maçons, plafonneurs, tailleurs de pierre, serruriers, ferronniers, etc. etc., qui travaillent exclusivement d'après des dessins exacts, ne trouvent pour ainsi dire rien dans les cours préparatoires, qui les prépare à la branche principale de leur métier : lire un plan coté et le dessiner.

Il est vrai, ils cherchent à reproduire péniblement les ombres de solides et d'ornements, sans profit aucun pour leur métier.

L'importance exagérée du dessin à main libre a pour effet d'éloigner de l'école les élèves-apprentis; il pousse les jeunes gens 
vers les métiers décoratifs, vers ce dessin aimable, qui nourrit toujours en eux le secret espoir de pouvoir s'élever à l'étude de la figure; peut-être à la haute peinture ou à la haute sculpture.

Les cours de sciences, qui doivent expliquer les phénomènes du travail et éclairer l'apprentissage, n'ont pas encore pu acquérir la moindre influence sur les autres branches, précisément parce que l'enseignement du métier.... sur le papier, n'exige l'application d'aucune notion scientifique. Les écoles de dessin enseignent le tracé ornemental théorique sans tenir compte des nécessités de l'exécution, des propriétés de la matière ni des techniques: nuances délicates que l'élèveartisan devrait apprendre à saisir, parce qu'elles sont capitales dans les industries d'art.

D'autre part en s'évertuant à enseigner la partie artistique d'une industrie ou d'un métier à des élèves, qui ignorent les fondements techniques de ce métier, on leur fait perdre un temps précieux.

A l'encontre de tout bon sens, on prépare le jeune homme, futur travailleur, à l'ébénisterie artistique, alors qu'il ignore la simple menuiserie; on l'initie à la compostion de la serrurerie, de la ferronnerie d'art, quand 
il n'a encore aucune notion de la forge ni de la serrurerie ordinaire; comme comble d'illogisme, on lui fait dessiner des façades, des plans d'habitations, alors qu'il ignore la reproduction géométrique d'une simple pierre ou d'un assemblage usuel; on lui fait modeler des ornements pour l'orfèvrerie, et il n'a aucune idée des manipulations de cette industrie! Pur gaspillage de temps pour les ouvriers! L'art doit être la floraison du métier : voilà pourquoi l'enseignement du dessin, sans application technique au travail à l'atelier, est stérile.

Pour avancer l'éducation professionnelle du futur artisan, il faut que l'Ecole de dessin soit complétée par des laboratoires et par des ateliers, où il puisse appliquer immédiatement les notions de dessin et sa culture artistique à la confection d'objets de son métier.

L'apprentissage technique doit marcher de front avec l'enseignement des sciences et du dessin théorique.

Telle est le rôle des écoles professionnelles et des écoles d'art industriel avec ateliers.

Les ÉColes D'APpRentissage.

Dans les localités où une industrie ou un 
groupe d'industries offrent un champ d'action assez vaste, la création d'écoles d'apprentissage s'impose.

Sur quelques points du pays, pareilles écoles ont été organisées selon les besoins les plus pressants de l'industrie locale. Les grandes villes, les Unions professionnelles consacrent à cet objet des sommes considérables, les sociétés privées ont installé des ateliers, institué des cours complets de dessin et de modelage, et semblent autant réussir dans leurs efforts que l'initiative officielle.

Lorsque l'enseignement primaire et moyen inférieur convergera vers les études industrielles et manuelles, la population ouvrière s'intéressera plus vivement encore à l'apprentissage des métiers d'art, et fera fructifier davantage les sacrifices de l'initiative privée et publique.

Les frais considérables qu'entrainent l'organisation et le fonctionnement des ateliers d'apprentissage sont un obstacle sérieux à leur développement: les budjets des écoles de bijouterie, d'orfèvrerie, d'horlogerie, d'ébénisterie, de menuiserie sont élevés, relativement du nombre d'élèves qui peuvent les fréquenter. Cela tient au système d'organisaton de ces ateliers-écoles. 
Il serait à la fois plus logique et plus économique de pròner, dans la mesure $d u$ possible, la création d'écoles d'apprentissage, qui embrassent, chacune, un groupe de métiers utilisant la même matière première.

Nous aurions ainsi une école d'apprentissage :

- pour le travail du métal : l'orfèvrerie, la bijouterie, la ferronnerie, la serrurerie, la ciselure, la gravure sur métaux, la fonte, la dinanderie, la galvanoplastie, la dorure, la teinture des métaux etc.

II. pour les tissus : la décoration, la teinture; la dentelle, le tissage, la tapisserie, la broderie, la passementerie, etc.

III. pour la céramique, l'émaillerie, le verre, peinture, décoration, modelage.

IV. pour le bois : la charpente, la menuiserie, l'ébénisterie, la carrosserie, etc.

$\mathrm{V}$. pour la pierre: la sculpture, la taille, la maçonnerie, etc.

Avantages de CE système.

L'avenir réserve aux écoles de métiers un développement considérable. Pour aboutir à une unité de tendance, il est nécessaire de tracer un plan général pour tout le pays; les Administrations locales organiseront l'école 
dans les limites du plan et en vue des besoins spéciaux de la région.

Bien des raisons plaident en faveur du système ci-dessus esquissé.

\section{Les Sciences.}

Les métiers de chaque groupe ont pour objet la transformation de matières premières, similaires par leurs propriétés générales. Les métaux, par exemple, s'extraient, s'affinent, se trempent, se soudent, s'allient d'après les mêmes principes; l'air atmosphérique, les agents chimiques ont sur eux une action sensiblement identique; les différents métaux exercent, par la nature de leur matière, une influence semblable sur la forme; le professeur de sciences physiques et chimiques, le professeur technique s'attachent à l'explication de ces phénomènes et leurs indications jettent une vive clarté sur le travail de tous les élèves indistinctement.

Dans nos écoles, il est totalement impossible de donner un cours utile et compréhensible de sciences, parce que le professeur a parmi ses auditeurs les artisans et apprentis les plus disparates; il doit conséquemment se borner à expliquer les phénomènes, qui forment le fond de tous les métiers et de 
toutes les industries : ce cours est donc nécessairement abstrait et théorique; le degré de développement intellectuel de l'ouvrier ne lui permet pas d'appliquer lui-mème les notions générales aux cas particuliers de sa profession, et il ne trouve pas dans ce cours les faits qui lui seraient directement utiles. C'est dans cette situation qu'il faut chercher la profonde aversion des artisans pour les cours de sciences dans les écoles de dessin et d'industrie.

\section{Le Dessin.}

Les inconvénients des écoles trop générales pour l'enseignement si utile des sciences existent, renforcés, pour le dessin et pour le modelage.

On peut dire qu'au moment actuel, l'enseignement du dessin aux écoles primaires et moyennes ne laisse aucune trace sur les élèves; ceux qui se présentent aux écoles de dessin doivent donc recommencer l'étude des éléments, comme s'ils n'avaient jamais tenu un crayon. Or, à cause de la méthode simultanée qui est en vogue dans bien des écoles de dessin, il ne saurait être tenu compte, ni du but, ni du degré d'avancement des élèves des classes inférieures; l'ébéniste, le menuisier, le lithographe, le 


\section{$-74-$}

maçon, le graveur, le charpentier, tous dessinent d'après des modèles semblables. Mais ces jeunes gens désirent immédiatement tirer profit de leurs études, et ils ne voient dans la copie de ces beaux modèles qu'un aimable passe-temps, où rien n'est en rapport, même éloigné, avec leur métier. Ne faut-il pas chercher dans la tendance trop générale de l'enseignement, la cause de l'indifférence des patrons et des ouvriers pour les écoles de dessin?

\section{Collections.}

L'école d'apprentissage, qui, d'après le système que nous préconisons, embrasse un groupe de métiers semblables, peut se créer une collection de modèles bien appropriés aux besoins professionnels spéciaux de chaque métier : un petit musée, résumant sous une forme concrète, l'histoire d'une branche spéciale du travail dans les plus brillantes époques.

Ainsi, la collection de l'Ecole d'apprentissage pour le métal, débuterait par un groupe technologique des matières premières dans leur différentes phases de préparation:

I. les minerais de fer, de zinc, de cuivre, etc. etc.;

2. les métaux à l'état brut; leurs alliages, leurs soudures; 
3. les métaux polis, trempés, émaillés, laqués, teints, dorés, argentés etc.

4. des spécimens, en nature, en moulage, en galvanoplastie, des travaux remarquables dans l'histoire du travail.

Une notice concise sur la provenance, les propriétés, la métallurgie, l'usage, etc. serait le complément heureux de cette collection.

Pour rehausser l'éclat de ce Musée $d u$ travail, pourquoi les Musées royaux, les Musées d'antiquités de l'Etat et des communes, rompant avec les plus saintes traditions du passé, ne prêteraient-ils pas leurs collections aux écoles, dans l'intérêt supérieur du travail national?

Les Musées de Kensington, de Berlin, de Vienne, de Nuremberg et tant d'autres, nous ont précédé dans cette voie et ont fait rentrer ainsi dans la circulation, les techniques et procédés oubliés et les formes charmantes, dont les artisans-artistes revêtaient autrefois les objets même les plus simples de la vie usuelle.

A l'aide de tous ces documents authentiques, l'école se créerait une série de travaux types démontables, qui montreraient les principes techniques de la décoration et qui constitueraient la base des modèles, tant pour 
le dessin que pour le travail à l'atelier.

L'école ainsi organisée serait impregnée d'une atmosphère propice au travail. L'intérêt de l'élève serait vivement excité, parce qu'il aurait sous la main, dès le début, des modèles qui, au point de vue ornemental et technique, lui apprendraient quelque particularité de sa profession.

\section{Les Professeurs.}

Lorsque le domaine de l'école professionnelle et des arts industriels sera circonscrit aux seuls métiers, semblables par la matière, il sera possible de recruter des professeurs de sciences, des dessinateurs techniques, des professeurs de modelage, qui dirigeront avec cohésion les études vers le travail manuel.

Dans nos écoles professionnelles de tissage, de sculpture, de bijouterie etc., la valeur d'artiste, seule, détermine le choix du professeur. L'artiste, qui ne saurait être omniscient, ignore souvent le métier, dont il est chargé d'apprendre l'ornementation; il enseigne le dessin, le modelage général et théorique, sans l'appliquer et ne résout donc pas la difficulté essentielle de l'enseignement des arts industriels : l'interprétation des formes d'après les procédés de fabrication, d'après la matière 
dont l'objet est confectionné et l'usage auquel il est destiné.

Si le professeur de décoration pour le tissage, par exemple, ignore la mise sur carton, s'il n'a jamais tissé, son cours ne portera certainement pas tous ses fruits; sous sa direction, les élevès feront peut-être de beaux dessins, mais l'exécution en sera impossible ou présentera des difficultés insurmontables pour le tisserand: une lutte est inévitable entre le professeur-ouvrier et l'artiste-dessinateur.

Il en est ainsi de tous les métiers d'art.

Pour que les efforts des professeurs produisent leur maximum d'effet, il faut que le professeur-artiste connaisse assez la technique de l'industrie, pour établir le trait d'union entre le dessin théorique et le dessin professionnel, entre l'art et le métier. C'est au véritable artiste industriel, c. à. d. à l'ouvrier-artiste qui a lutté avec la matière, que revient le rôle délicat et capital de faire sentir aux élevès, dans quelle mesure la forme est dominée par l'usage, par la technique et par la matière.

Dans les écoles de dessin, qui toutes tendent prétendùment aux métiers, l'ignorance technique du professeur de dessin a des 


\section{$-78-$}

conséquences plus grares encore. Il est déjà forcé, par la variété de ses auditeurs, de donner un enseignement général; s'il leur permet d'essayer des dessins relatifs à leurs métiers, il ne saurait ni contrôler, ni corriger les travaux, et le cours dégénère en un dessin de dilettantisme professionnel, qui fait hausser les épaules aux gens de métier.

L'artiste pur est à l'école de métiers, le professeur contemplatif et théorique; les élèves abandonnés à eux-mêmes, se désintéressent à l'enseignement et désertent l'école.

A défaut d'une réorganisation fondamentale, un groupement d'après le système exposé plus haut, devrait ramener sous la direction du mème professeur, des élèves, qui exercent des métiers relatifs à la même matière et donc soumis à des procédés de fabrication semblables. Dans ce cas le professeur de dessin pourrait développer son enseignement véritablement dans le sens professionnel.

5. Les Associations ouvrières.

Les écoles de dessin, des métiers, d'art industriel, arriveraient promptement à une grande prospérité, si, comme à l'étranger, toutes les associations syndicales, professionnelles et patronales leur réservaient une part de leur 
activité et si elles pesaient sur leurs membresapprentis pour les engager à fréquenter les cours.

Les Associations poursuivent l'amélioration du bien-être de leurs membres; elles doivent donc veiller à l'éducation des apprentis et favoriser développement de l'enseignement professionnel. Elles sont en outre compétentes, connaissent les lacunes, les défauts du travail. Pourquoi ne pourraient-elles pas avoir des délégués aux commissions administratives des écoles pour ouvriers? Nous sommes persuadé, que ces délégués-ouvriers y feraient bonne besogne; ils établiraient le lien entre l'école et l'atelier et ramèneraient les discussions vagues et académiques, sur le terrain pratique du travail.

L'enseignement de nos écoles de dessin et d'art industriel est général, il cherche à préparer à tous les métiers; aucune corporation n'y trouve une utilité assez directe pour lui prêter un appui. C'est ainsi que beaucoup de ces écoles, établies au milieu d'une population ouvrière, sont abandonnées à la seule protection officielle.

Pour préparer l'intervention des ouvriers dans la direction des écoles de dessin et d'apprentissage, il est nécessaire de limiter le 
domaine de l'enseignement à un groupe de métiers similaires par la matière première; dans les centres les plus importants de travail, il faut créer des écoles spéciales pour le travail du bois, du métal etc.: ailleurs, il faut grouper les élèves-apprentis d'une même école, d'après un principe identique.

Ces divisions correspondent aux groupes professionnels et syndicaux. Chacun de ces derniers porterait sa sollicitude sur l'enseignement de son métier, et les écoles professionnelles, sous l'impulsion des travailleurs et des patrons, pourraient réellement exercer une influence salutaire sur le relèvement du travail.

LES ÉCOLES D'APPRENTISSAGE

POUR L'INDUSTRIE DU MÉTAL D'ISERLOHN ET DE Remscheid.

(Fachjidjulent.)

Remscheid et Iserlohn sont assises au milieu du district minier de Westphalie. Leur population est presque exclusivement composé de travailleurs du bronze, du fer et de l'acier. Une infinité de petits ateliers sont éparpillés sur les différents points de la ville, et ils produisent des spécialités de l'industrie du métal : la quincaillerie, la serrurerie et la 
ferronnerie artistiques, la gravure, la fabrication d'étaux, de scies, de pinces, de ciseaux, de limes, de patins, etc. etc.

L'apprentissage à l'atelier initie à une série d'opérations mécaniques très simples; les manipulations les plus difficiles y sont exécutées par des jeunes gens, avec une dextérité merveilleuse. C'est d'ailleurs sur cette habileté mécanique que repose la prospérité de l'industrie spéciale de ces localités.

La base de toute l'industrie du métal est la forge. Peu d'apprentis peuvent s'y exercer, parce qu'elle constitue à l'atelier un travail spécial dans le travail total. Tout au plus peuvent-ils manier le marteau de devant, s'ils possèdent assez de force corporelle.

D'un apprentissage complet même dans les branches fondamentales de l'industrie du métal, pas de trace.

L'école de Remscheid ainsi que celle d'Iserlohn apportent aux ateliers l'intelligence du travail; elles ont fourni aux différentes usines des ouvriers habiles, dont le travail plus artistique et plus soigné qu'autrefois, fait une concurrence désastreuse à notre petite industrie du métal.

CARACTÈrE.

L'école de Remscheid a leaucoup d'analo- 
gie avec l'Ecole d'apprentissage pour le fer et le bois de Gand. Elle enseigne les connaissances fondamentales de tous les métiers du bois et du métal, elle cultive les aptitudes générales des élèves et les prépare à l'apprentissage d'une branche spéciale à l'atelier.

L'Ecole d'Iserlohn élève le métier jusqu'à l'art. Dès leur entrée à l'école, les jeunes gens doivent se décider pour une branche de l'industrie du métal. L'enseignement est double ; l'étude théorique du dessin ornemental et professionnel marche de front avec le travail pratique à l'atelier.

Quoique nos industries soient, en bien des régions, centralisées d'après la matière, nous ne possédons pas encore une seule institution qui enseigne les transformations et les manipulations d'une même matière première.

Lorsque le moment sera venu d'élargir la base trop étroite de nos écoles d'apprentissage et de restreindre le domaine trop vaste de nos écoles de dessin et d'art industriel etc., l'Ecole des arts du métal d'Iserlohn, unique par son organisation pratique et par son enseignement scientifique, pourra donner des indications précieuses. C'est pourquoi nous tâcherons d'en tracer à grands traits la physionomie caractéristique. 


\section{Les Elìves.}

Dès l'âge de $\mathrm{I}_{4}$ ans les jeunes gens qui ont fait des études primaires complètes peuvent y être admis. L'Ecole recrute surtout ses sujets parmi les élèves des écoles primaires et moyennes; les branches en général, et le dessin en particulier, dont nous avons esquissé le programme et les méthodes, y préparent admirablement les futurs ouvriers à l'apprentissage approfondi du métier.

La durée des études est de 3 années. Toutefois l'école est accessible à ceux qui sont déjà cultivés d'une manière générale dans des écoles d'apprentissage, telles que celle de Remscheid, et qui désirent se perfectionner dans une spécialité; elle est aussi ouverte aux futurs commerçants, qui désirent se mettre au courant de la fabrication des objets de leur négoce.

Redevances scolaires : I 5 marks par trimestre. Les indigents peuvent en ètre dispensés.

Le local est insuffisant pour y installer convenablement les So élèves. La construction d'un établissement nouveau de roo.000 mk., soit de I25.000 frs., a été décidée.

Les écoles de Remscheid et d'Iserlohn 
sont royales; leurs budjets sont inscrits au budjet de l'Etat prussien. (Voir annexe I).

Groupement des Élìves.

Les élèves sont divisés en trois groupes.

I. Groupe : les modeleurs, les ciseleurs, les graveurs;

II. Groupe : les ferronniers, les serruriers d'art et les fondeurs;

III. la galvanoplastie, la galvanostegie, métallochromie.

A. - COURS FONDAMENTAUX.

LE DESSIN.

Les cours de dessin et l'interprétation des formes ornementales d'après les besoins spéciaux du métal sont communs à tous les élèves de l'Ecole.

L'ornement est déterminé dans les métiers des 3 groupes, par les exigences de la même matière. Un même professeur dessinateurtechnique enseigne à tous les élèves l'application de l'ornement aux objets en métal, et ramène le cours théorique de dessin dans la voie utilitaire.

Iserlohn essaie de résoudre la difficulté capitale de l'enseignement de l'art industriel : 
l'invention et l'interprétation des ornements. Toute l'attention est concentrée sur ce cours, parce qu'il établit le lien ténu et délicat entre l'art et l'industrie.

Du reste, dans toutes les écoles d'apprentissage d'Allemagne, l'enseignement tend à former des créateurs, capables de rajeunir des formes guindées et banales que présente encore la fabrication.

Le double enseignement offre à l'école d'Iserlohn un intérêt particulier; le travail à l'atelier initie les élèves ouvriers à la manipulation du métal; le marteau, le burin, le ciselet, maniés par ces jeunes gens déjà habiles et cultivés, devient un instrument aussi intelligent et aussi obéissant que l'ébauchoir du modeleur et sert, comme lui, à traduire leurs pensées et leurs sentiments. Le cours de dessin ornemental met à la disposition des élèves la source inépuisable des formes de la nature, qu'ils apprennent à reproduire d'après leur observation directe, personnelle et sincère.

Le cours de dessin tend, avec une constance soutenue pendant les 3 années d'études, à cultiver l'imagination inventive des élèves et à appliquer avec intelligence les formes aux objets de leur métier. 
Les SCIENCES, COMMUNes A TOUS LES ÉLÈves.

LA PHysigue.

I $^{\text {re }}$ Année. - (2 $\mathrm{h}^{\mathrm{rs}}$ par semaine). Les propriétés générales des corps. Les effets principaux de la chaleur. Les machines simples.

$2^{\mathrm{e}}$ Année. - ( $\mathrm{I}$ heure). L'électricité et le magnétisme dans leurs applications à l'industrie du métal. Les éléments galvaniques. Les batteries. La loi d'Ohm. Les effets dynamiques, magnétiques, inducteurs du courant électrique. La tension et l'intensité des courants électriques.

3e Année. - (I heure). Les appareils pour mesurer et régler les courants électriques. Effets sur les solutions des métaux employés dans la galvanoplastie. Influence de la tension et de l'intensité du courant sur la qualité des précipités métalliques dans la galvanoplastie. - La machine dynamique.

\section{LA Chimie.}

$2^{\mathrm{e}}$ Année. (I heure par semaine). Les éléments chimiques de l'industrie du métal; les métaux, leurs alliages, leurs mélanges. La solubilité. Influence des agents atmosphériques sur les métaux; la fusibilité, la tenacité, la ductilité, la dureté. Influence des mélanges 
sur la fusibilité et sur les propriétés des métaux.

3e Année. - (I heure). Les notions indispensables de la chimie théorique. Les combinaisons les plus usuelles de l'industrie du métal. Nature et manipulation des bains galvaniques pour la teinture des objets en cuivre, en laiton, en bronze, en fer, en acier. But, importance, choix de la couleur et son influence sur la conservation de la surface des métaux.

Tel est, dans ses grandes lignes, l'objet des cours de sciences à l'Ecole d'apprentissage pour le métal.

Les cours scientifiques s'attachent à l'explication des phénomènes que présente la manipulation du métal. Les professeurs empruntent aux différentes branches, les notions strictement applicables à la matière première, maniée par les élèves. Ces notions concrètes sont compréhensibles pour eux, parce qu'elles tombent dans le cercle de leur observation journalière ; elles sont intéressantes et utiles, parce qu'elles rendent compte de la cause des mille phénomènes physiques et chimiques de leur profession.

Bref, tous les inconvénients que nous avons signalés pour les cours scientifiques de 
nos écoles, sont évités par le groupement des élèves d'après leur métier.

\section{B. - LES ATELIERS.}

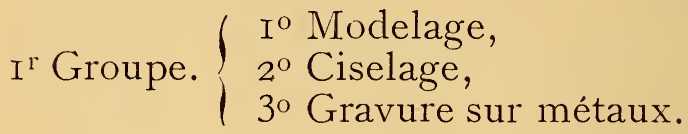

$2^{\mathrm{e}}$ Groupe. $\left\{\begin{array}{l}4^{\mathrm{o}} \text { Ferronnerie, serrurerie artis- } \\ \text { tique, } \\ 50 \text { Fonderie. }\end{array}\right.$ 3e Groupe. $\left\{\begin{array}{c}60 \text { Galvanostégie : renickelage } \\ \text { dorure, argenture, etc. } \\ 7^{\circ} \text { Métallochromie : teinture des } \\ \text { métaux. } \\ 80 \text { Laboratoire de chimie galva- } \\ \text { notechnique. }\end{array}\right.$

Les tours, les souflets, les étaux-limeurs, les machines à polir, les meules, etc. sont mûs par un moteur à gaz d'une force de 5 chevaux; les élèves sont chargés, à tour de rôle, de le diriger et de l'entretenir.

Les ateliers se prêtent un mutuel appui en préparant les matières premières nécessaires à chaque industrie du métal : le cuivre entre à l'état brut; la fonderie fournit des sujets de fonte aux ciseleurs, des feuilles aux repousseurs; la forge prépare les masses d'acier pour les graveurs sur métaux; les objets modelés 
en terre ou en cire dans l'atelier de modelage sont exécutés à la forge ou à la fonderie.

Le travail pratique.

En $I^{\text {re }}$ et en $2^{\mathrm{e}}$ année d'études, les élèves consacrent I6 heures par semaine aux travaux pratiques à l'atelier; en $3^{\mathrm{e}}$ année d'études, 24 heures.

Les cours de dessin et de modelage cultivent chez l'élève le sens de la forme et l'initient à la composition ornementale en vue de son métier; seulement, le disciple ne saurait se laisser aller à une fantaisie écervelée, parce qu'il est tenu d'exécuter sa composition à l'atelier ; il est forcé de concilier son art avec les exigences impérieuses de la technique et de la matière. Il deviendra un créateur de formes, un véritable artiste industriel, sachant allier intimement la maind'œuvre à la conception.

L'ENSEIGNEMENT DE LA GRAVURE SUR MÉTAUX.

Une description détaillée de l'atelier de gravure sur métaux complétera les études sur l'enseignement de la ciselure à l'Ecole d'art industriel de Vienne, de l'ébénisterie, de la peinture décorative, éparpillées dans nos différents rapports insérés ci-après. 
Les méthodes sont unes; elles procèdent toutes du même principe : l'enseignement pour l'atelier.

Le domaine de la gravure sur métaux est très vaste; l'enseignement comprend la gravure de médailles et d'émaux, de cachets, la gravure d'initiales et d'attributs héraldiques, la gravure en creux de matrices pour les fabriques d'objets estampés en métal pour les fabriques d'orfèvrerie, de plaques, de boutons de livrées etc. etc.

\section{Marche de L'Enseignement.}

I re AnnéE.

Le dessin et le modelage marchent de front.

Le dessin comporte des exercices généraux : la reproduction en contour des modèles en plâtre et en nature (fleurs, feuilles, fruits, rinceaux, oiseaux), et des exercices plus professionnels : la reproduction d'objets du métier. L'élève ramène constamment les formes à la proportion et à la technique de son métier; il les copie d'abord au trait, puis, avec les effets de lumière. Insensiblement il s'affranchit du modèle en appliquant au canevas de l'ornement un autre motif dominant. En somme, il développe par des exercices appropriés et gradués, l'habileté sévère de la 
main, l'idée du groupe et de l'arrangement; il recherche des ensembles et des oppositions heureuses et cultive son imagination créatrice dans le sens de sa profession.

Le modelage ( 6 $\mathrm{h}^{\mathrm{s}}$ par semaine). L'école possède une bonne collection d'objets gravés des différentes époques et de toutes les spécialités. C'est cette collection, qui forme la base du matériel d'étude. L'élève débute par le modelage en terre en grandeur nature; après avoir acquis quelque habileté, il copie, en cire, des monogrammes et des lettres de tout style, des fragments de pièces d'orfèvrerie et s'applique à l'invention et à l'arrangement de simples sujets de gravure.

Les cours obligatoires de physique $\left(2 \mathrm{~h}^{\mathrm{s}}\right)$, d'algèbre $\left(2 h^{\mathrm{s}}\right)$ et de géométrie $\left(2 h^{\mathrm{s}}\right)$, dans leurs applications à l'industrie du métal, complètent les études de la I $^{\text {re }}$ année.

Total, 38 heures par semaine.

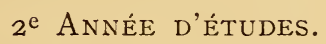

Les branches sont :

I. le dessin ornemental, $9 \mathrm{~h}^{\mathrm{s}}$ par semaine;

2. le dessin professionnel, $7 \mathrm{~h}^{\mathrm{s}}$;

3. la chimie appliquée, I heure;

4. la physique (électricité), I heure;

5. l'algèbre et la géométrie, 2 hs; 
6. le travail pratique, I6 $\mathrm{h}^{\mathrm{s}}$.

Total : 36 heures.

La Ire année d'études a donné à l'élève l'habileté au modelage et au dessin, la culture esthétique et scientifique nécessaires pour aborder avec succès l'apprentissage technique.

\section{LE DESSIN.}

Le dessin ornemental (9 $\mathrm{h}^{\mathrm{s}}$ ) complète l'éducation esthétique de l'élève. Ce dernier reproduit, en exécution plus achevée et en réduction, des ornements appartenant aux meilleures époques, et s'initie ainsi pratiquement aux ressources ornementales des différents styles.

L'Ecole s'est créé une collection de modèles, qui établissent avec élégance la transition entre le dessin ornemental et le dessin professionnel. Après que l'élève a étudié le modèle général, le professeur lui soumet un objet, un fragment en métal, auquel cet ornement a été appliqué. Cette comparaison, continuée avec persévérance, apprend aux élèves à traduire un dessin général en un dessin de métier, et à lui donner la forme caractéristique, imposée par la nature du métal et par l'usage, auquel l'objet est destiné. 
3e AnNÉE D'Études.

\section{Branches :}

I. le dessin - composition ornementale $8 \mathrm{~h}^{\text {s }}$.

2. le dessin professionnel, 4 heures.

3. la géométrie, I heure.

4. la chimie, I heure.

5. l'électricité, I heure.

6. le travail pratique à l'atelier, 24 heures par semaine.

Total $3 g h^{s}$.

LE DESSIN ORNEMENTAL ET PROFESSIONNEL.

La collection d'objets en nature ou en moulage : services d'orfèvrerie, médailles, bijoux, armes et armures gravées et damasquinées, etc. fournit, avec la bibliothèque, des documents complets aux études de composition. L'élève arrange et crée des ornements et des objets ornés de son métier; il compose des monogrammes dans les différents styles, des pièces d'orfèvrerie, des ornementations appliquées aux objets de toute nature, dont il pourrait être appelé plus tard à graver les matrices pour l'estampage. Les esquisses et les dessins sont exécutés en aquarelle ou en grisaille dans un album, qui reste la propriété de l'élève. 


\section{Le traVAil PRATIQUE.}

Le dessin professionnel est intimement relié au travail à l'atelier. Chaque élève exécute les dessins des objets, qu'il devra réaliser en métal à l'atelier.

Après que l'apprenti a acquis par le tracé de droites, de courbes, de feuilles, etc. quelque habileté au burin et au ciselet, il grave dans le métal des lettres simples en creux, puis graduellement, des monogrammes en creux et en relief, des cachets agrémentés d'un ornement géométrique et d'ornements plus compliqués; il s'exerce à fouiller l'acier et à reproduire en creux des manches de couteaux et de cuillers, des boutons de livrées, des parties de pièces d'orfèvrerie de toute nature, que la presse hydraulique foule en métal dans les fabriques d'estampage.

Pas à pas le travail technique à l'atelier suit le dessin professionnel. Cette étude simultanée hâte l'apprentissage manuel de l'élève.

L'apprentissage de la gravure est extrêmement laborieux et long à l'atelier, et cependant l'Ecole d'Iserlohn fournit, après 3 années d'études, des graveurs passablement habiles, dont l'éducation n'est certes pas achevée, 
mais qui sont déjà capables de gagner un bon salaire.

L'école professionnelle d'Iserlohn forme des apprentis d'élite, qui apportent à l'atelier l'influence bienfaisante de l'enseignement; elle met en vogue des éléments de décoration et des procédés techniques, basés sur la science, qui permettent à l'industrie artistique de sortir de la fabrication banale.

L'enseignement n'est pas étroitement dirigé vers le métier; il s'efforce de raffiner l'idéal artistique des élèves par l'étude de beaux modèles empruntés à. la nature et aux monuments du passé; le dessin professionnel et le travail pratique en font l'application.

Les résultats rapicles et remarquables que produit cette école prouvent, que l'étude de la décoration doit être constamment accompagnée d'exercices d'application pratique; c'est seulement lorsque l'élève connaît les propriétés de la matière par les cours de sciences et par les manipulations, qu'il peut faire des compositions rationnelles et observer les finesses propres à son métier.

L'atelier est le complément nécessaire de l'Ecole d'art industriel.

A mesure que l'estampage se développera 


\section{$-96-$}

dans l'industric artistique du métal, la gravure en relief et en creux deviendra plus florissante.

En examinant nos objets estampés de fabrication courante, il n'est pas difficile de constater, que le goût en est banal et médiocre; on peut en conclure que la culture esthétique comme l'éducation technique de nos graveurs est étroite et routinière.

Le cours d'apprentissage de la gravure est très important; il est appelé à rendre à l'art ses droits dans l'industrie du métal et pas seulement dans les travaux supérieurs : médailles, attributs héraldiques, émaux, armures, mais dans ceux où le goût et le conception tiennent moins de place que l'apport mécanique, notamment, dans les objets estampés.

L'artisan habile contribuera ici encore à circonscrire le domaine de la machine.

En outre, il y là un admirable moyen d'instruction et de propagation du goût du beau dans le peuple : la distinction de la forme, la pureté des profils de ces mille objets modestes, qui passent dans les mains de tous et qui se mêlent aux nécessités de la vie, contribuent presque mécaniquement, à l'éducation esthétique du public. 


\section{VIII. - LES ÉCOLES D'ART INDUSTRIEL DE HANNOVRE ET DE HAMBOURG}

(ふunjtgemerbejchulen.)

Les écoles d'art industriel de Hannovre et de Hambourg sont, dans leur organisation générale, semblables à celle de Berlin.

Le promoteur de l'Ecole de Hambourg, M. Jessen, en abandonna la direction en I88I, et fonda l'Ecole de Métiers de Berlin, d'après les méthodes nouvelles et sur les principes expérimentés par lui avec tant de succès.

Les écoles de Berlin et de Hambourg réalisent le type parfait et ont servi de modèle à l'organisation de toutes les institutions similaires d'Allemagne; Hannovre s'en inspira lorsque, en 1877 , elle décida de transformer son école d'art en une école de métiers artistiques.

Une exposition des dessins de toutes les écoles de la province de Hannovre avait 
prouvé aux autorités, combien est stérile l'enseignement du dessin qui ne s'appuie pas directement sur les besoins de l'industrie. L'Administration de la ville décida, sur la proposition du Ministère de l'industrie et du commerce, de fonder une école de métiers artistiques avec ateliers d'application, assez vaste pour recevoir I200 élèves.

La superbe construction a coûté un demimillion de francs; l'école est installée et aménagée avec un confort d'une modernité absolument remarquable.

\section{Situation .}

Les écoles de Hannovre et de Hambourg sont situées le long du plus agréable boulevard. Chose digne de remarque, dans la plupart des localités que nous avons visitées, les écoles d'art industriel, d'apprentissage, etc. sont construites avec une véritable luxe dans les quartiers les plus attrayants de la ville. Les Allemands sont symbolistes : par le choix de l'emplacement ils montrent l'importance de l'enseignement : ils veillent avec soin à ce que ces temples du travail soient installés dans un millieu riant, et reçoivent à profusion l'air et la lumière. 
Éclairage.

La question de la lumière, si importante dans les écoles de dessin, est brillamment résolue à Hannovre : il y a là un raffinement d'éclairage électrique, qui fait le plus grand honneur à l'industrie allemande. Nous esquisserons rapidement les divers systèmes de lampes et d'écrans qui y sont employés :

$$
\text { Figr VIII }
$$

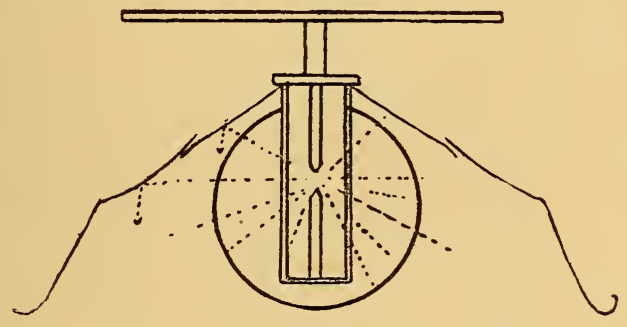

Le globe : éclairage central. Une seule lampe puissante est appendue au plafond de la salle de modelage : lampe à arc avec globe en verre mat et écran en toile blanche. La lumière est très vive; les ombres et la lumière tranchées, donnent aux modèles et aux travaux un relief très prononcé, favorable aux études (croquis VIII).

Le réflecteur à lamelles. Autour d'un foyer 
central (lumière à arc) sont placées, en forme de cône tronqué renversé, une série de lamelles de verre mat, entre lesquelles la lumière

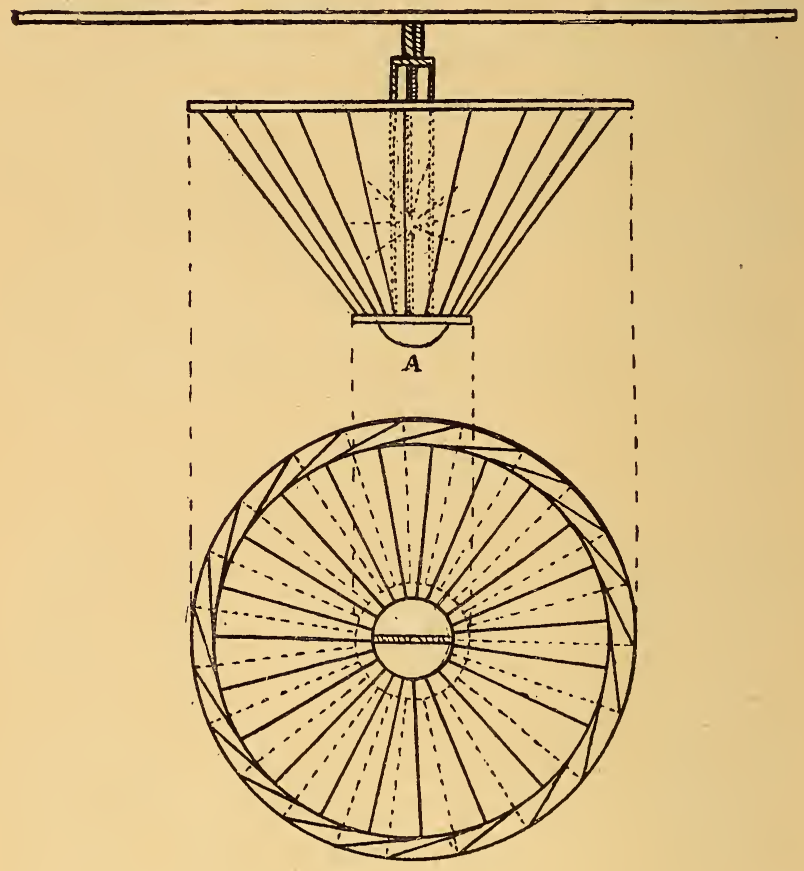

$$
\text { Fig. Ir }
$$

électrique se joue et se réverbère de manière à descendre diffuse et calme sur les modèles. Cette lumière remplace presque avantageusement le jour pour le dessin et pour la 
peinture; elle est agréable à la vue, ne produit évidemment qu'une chaleur minime et enveloppe les modèles d'une douce atmosphère propice à l'étude (croquis IX, p. IOO).

Le réflecteir de la lampe (croquis $\mathrm{X}$ ) se compose d'un squelette en fil de fer, tendu d'une toile blanche $(\mathrm{E})$. Une demi sphère $(\mathrm{A})$ et 2 petits prismes $(\mathrm{P})$ en albâtre tamisent

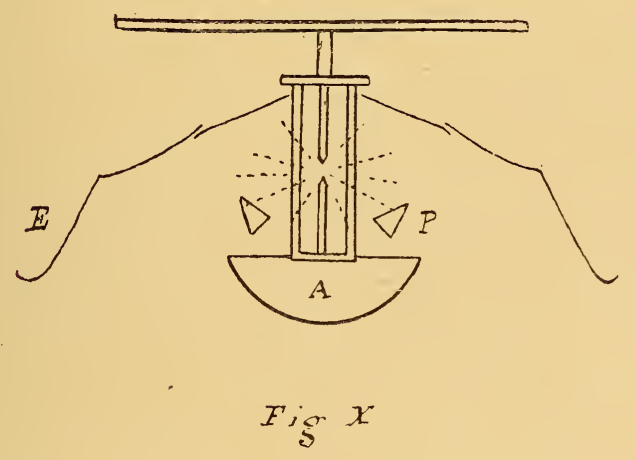

les rayons dirigés vers le bas : une partie de ces rayons les traversent, d'autres sont réflétés et jetés sur l'écran en toile, qui les renvoie dispersés dans la salle.

Le réflecteur latéral (croquis XI p. IO2) se compose de deux écrans, en forme de cône tronqué ( $\mathrm{E}$ et $\mathrm{V})$.

Les rayons lumineux qui tombent sur le petit écran, en verre mat assez transparent, 
sont en partie réflétés et rejetés sur le grand écran, qui les dirige dans tous les sens.

Tous ces réflecteurs rendent la lumière uniforme et diffuse. Le système entier a l'aspect d'un corps lumineux, d'où rayonne une clarté agréable dans toutes les directions.

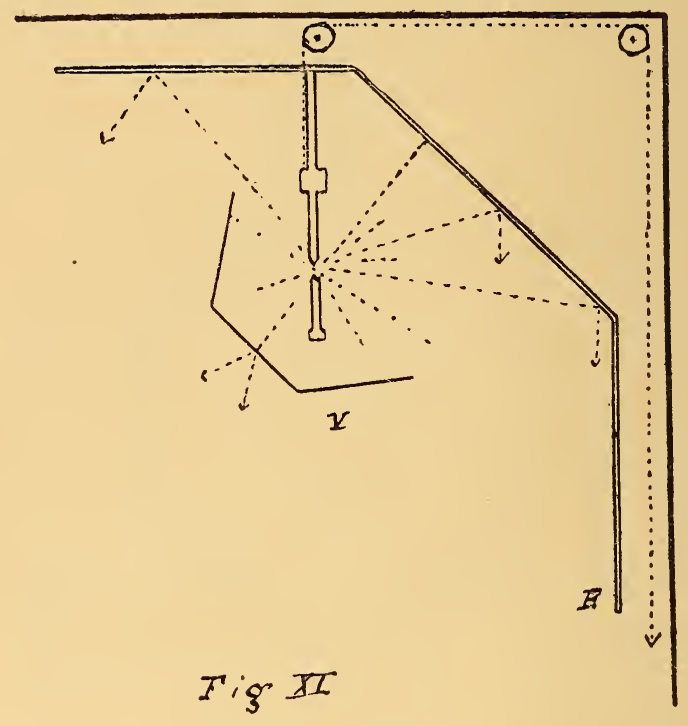

Heures des Cours.

Cours du soir, de $5 \mathrm{I} / 2 \mathrm{~h}$. à $9 \mathrm{I} / 2$.

Le dimanche de 7 à $9 \mathrm{~h}$. (en été), de $7 \mathrm{I} / 2$ à $9 \mathrm{I} / 2$ du matin (en hiver) et de I I à I2 I/2. 
Cours du jour : de 7 à I 2 h. (en été), de 8 à I2 (en hiver), et de 3 à $7 \mathrm{~h}^{\mathrm{s}}$ du soir.

Un enseignement spécial pour les élèves des écoles générales est donné le mercredi et le samedi, de 2 à $4 h^{\text {s }}$ (jours de congé des élèves).

\section{PLAN DES ÉTUDDES.}

Un aperçu général, mais succint de tous les cours de l'établissement de Hannovre donnera une idée de l'organisation solide et logique de l'enseignement professionnel.

Tout l'enseignement est divisé en 3 degrés. Pour chaque branche du dessin, le degré inférieur établit d'une manière générale les bases graphiques et scientifiques de tous les métiers, il cultive l'idéal artistique, le goût esthétique et les aptitudes manuelles des élèves, sans trop tenir compte de leur profession; les exercices des degrés moyen et supérieur sont adaptés aux besoins de l'industrie exercée par l'élève, tant par la technique du dessin, que par le choix des motifs ornementaux.

\section{LE DESSIN A MAIN LEVÉE.}

a/ Dessin général.

Les matières des cours suivants sont réparties sur 3 années d'études. 
I. Dessin d'après des ornements plans très simples : formes géométriques et végétales.

2. Dessin d'après les solides, dérivés de la géométrie (modèles Stuhlmann). Ce cours est le complément du précédent en ce sens, qu'il développe chez l'élève le sens de la perspective et des proportions.

3. Le dessin ornemental plan relevé de tons plats, initie l'élève au groupement de motifs ornementaux dérivés des figures géométriques, avec application de l'a flore.

4. Dessin ornemental en relief. Ce cours comprend la reproduction, an trait, de modèles empruntés aux différents styles et l'étude de ces modèles dans leurs relations avec les formes de la nature.

5. Dessin ombré d'ornements géométriques - usage du fusain, du crayon et des teintes d'ombre.

6. Dessin d'après les plantes vivantes ou séchées, d'abord en contour, puis interprétation et arrangement de motifs ornementaux - lavis aux couleurs unies conventionnelles - composition ornementale.

7. Etudes et esquisses d'après nature : ustensiles, coquillages, oiseaux empaillés, animaux (bronzes), tissus isolés ou groupés sous la direction du professeur. 
8. Dessin de la figure : masques, bustes, torses, d'après des moulages - ensuite d'après le modèle vivant. Ce cours est strictement limité aux applications de la figure dans la décoration.

9. Etude à l'aquarelle, d'ornements et de petits sujets décoratifs avec figures, vases, draperies, etc.

Io. Compositon décorative, encadrements, panneaux, frises, etc., avec la flore, la faune, la figure humaine comme éléments décoratifs. - Ensembles.

\section{B/ Dessin professionnel.}

Les cours de dessin professionnel se développent parallèlement avec le dessin général : ils exercent les élèves au dessin technique et les mènent à la composition d'objets de leur profession. L'emploi des instruments n'est pas exclu d'une manière absolue, quoiqu'il s'agisse, en général, de dessin à main levée.

Le dessin professionnel comprend :

I. Le dessin pour tourneurs, memisiers, ébénistes.

Les exercices se succèdent dans l'ordre suivant : dessin d'ornements plans et d'incrustations; reproduction en contour, à l'aide du 
crayon ou du fusain, d'ornements en relief appliqués aux objets en bois, tels que : balustres, colonnettes, piédestaux, panneaux et dessus de portes, fragments de meubles sculptés etc. Etudes au crayon, à la plume, en peinture, en aquarelle, de modèles empruntés au Musée. - Composition.

2. Le dessin pour serruriers, ferblantiers, dinandiers et autres ouvriers du métal.

Les aspirants à cette classe doivent avoir suivi avec fruit le cours de dessin géométrique et de projections.

Une série complète de modèles en métal constitue, pour chaque métier de cette classe, la base des études graphiques.

Le Musée de l'école met à la disposition des élèves sa collection variée d'ouvrages artistiques, un spécimen de tout ce que les travailleurs du métal ont produit de plus ingénieux et de plus charmant aux différentes époques et surtout pendant la Renaissance.

L'élève les étudie au crayon et au pinceau; lorsqu'il possède assez de dextérité. il s'essaie aux arrangements décoratifs et à la composition.

3. Le dessin pour maçons, tailleurs de pierre, plafonneurs, et contre-maîtres de l'industrie du bàtiment. 
Le dessin ornemental plan est le point de départ du cours. Les élèves dessinent en contour, en exécution plus achevée, à la plume et au pinceau, l'ornement architectural, les moulures et les profils caractéristiques des différents styles.

4. Le dessin professionnel pour lithographes, xylographes et graveurs.

De sérieuses études préalables du dessin ornemental plan permettent aux élèves de cette classe d'aborder, à la plume ou à l'aquarelle, la reproduction d'une série de planches fournies par la bibliothèque : des gravures sur bois, des lithographies, des gravures en taille-douce et des eaux-fortes des meilleures époques. Lorsque par ces études ils se sont fait une idée des moyens employés dans les différents procédés de gravure, ils s'appliquent à l'arrangement et à la composition de motifs décoratifs, tels que, entêtes de pages, culs-de-lampe, planches, lettres, diplômes, etc.

5. Le dessin pour tapissiers et garnisseurs comprend l'étude à la plume et à l'aquarelle de passementeries de toute nature, d'étoffes pliées et drapées, de portières et de rideaux, de meubles de tous les styles, empruntés à la collection de l'école. Tous ces exercices 
tendent à la composition d'ensembles avec devis estimatifs.

6. Le dessin pour orfèrres, bronziers, bijoutiers.

Les travaux les plus précieux et les plus remarquables de l'industrie artistique des métaux précieux appartenant aux différentes époques et aux différents pays, sont mis à la disposition des élèves sous forme de moulages, de copies galvanoplastiques, de gravures ou d'objets authentiques. L'élève orfèvre ou bijoutier les reproduit à la plume, en grisaille, à l'aquarelle; il puise dans les formes de la nature, dans la flore et dans la petite faune (papillons, insectes), des sujets de composition, qu'il arrange en se guidant sur les modèles du Musée; l'élève-bronzier s'attache à l'étude de pendules et de vases, d'accessoires de meubles, de candélabres, de girandoles, de bronzes d'art etc., que - le professeur analyse au point de vue de la technique et du style.

\section{Le dessin pour relieurs.}

Pour la bouquinerie de luxe, le goùt de l'ouvrier est un facteur important dans la valeur de la reliure, mais pour le brochage ordinaire le travail est tellement divisé, qu'il est réduit à quelques opérations purement 
mécaniques. Les exercices de copie au trait et à l'aquarelle, de reliures anciennes et modernes, en nature ou en imitation, épurent le goût des relieurs-artistes et doublent le travailleur mécanique d'un ouvrier intelligent.

\section{LE DESSIN A L'AIDE D'INSTRUMENTS.}

Le dessin exact constitue l'écriture de la plupart des industries même artistiques; les ébénistes, menuisiers, tourneurs travaillent d'après des dessins d'atelier géométriques, les ouvriers du bâtiment, doivent tous puiser au plan de l'architecte les clonnées exactes pour leur travail; le plus simple objet est exécuté dans l'industrie d'après un plan coté, avec coupes et vue perspective ; c'est pourquoi l'enseignement professionnel graphique est stérile, s'il ne procède pas du dessin à l'aide d'instruments.

Ce cours comprend à Hannovre ct à Hambourg une division générale et une division professionnelle.

a/ Division générale.

I. Le dessin géométrique. Ce cours a pour but d'exercer les élèves au maniement des instruments usuels (la règle, le compas, le tire-ligne), et à la pratique du lavis; ils 
étudient une série graduée d'ornements géométriques plans, limités par des droites, par des lignes mixtes, par des courbes, auxquels ils appliquent des couleurs unies.

2. Le cours de projections est enseigné avec un soin extrême, parce qu'il forme la base du dessin professionnel de la plupart des métiers : L'école possède une série complète de modèles, qui résument sous une forme théorique, les cas usuels et les principales difficultés du dessin par les projections : les solides géométriques avec leurs coupes intéressantes et leur développement, la pénétration de deux prismes, de deux cylindres, le plan incliné en hélice, la vis, etc.

La géométrie descriptive étudie d'une manière plus générale les propriétés des figures géométriques : le point, la ligne, le plan; elle fortifie le cours concret des projections et mène à certaines applications, aux projections des ombres, à la perspective parallèle, à la perspective centrale.

B/ LE DESSIN GÉOMÉTRIQUE PROFESSIONNEL.

Le cours de cette division complètent le dessin professionnel à main libire et étudient les applications caractéristiques pour chaque métier. 
LE Bors. - I. Classe des ébénistes. Les modèles impriment à tous les cours et principalement à la classe des ébénistes une tendance absolument pratique.

Les élèves ont à leur disposition une abondance de fragments de meubles, tels que, consoles, colonnettes, corniches, coins de portes démontables, assemblages, etc. et une série complète de moulures et de profils. Ils les dessinent, en grandeur nature et en réduction, d'après une échelle donnée et parviennent, suivant une méthode synthétique naturelle, à faire le lever et le tracé de meubles entiers.

2. Classe des memisiers, charrons, charpentiers et tourneurs.

Les projections et la géométrie descriptive sont étudiées dans leurs applications à ces différents métiers.

Les memisiers étudient plus spécialement le tracé d'assemblages de bois, des châssis, des portes, des lambris, des plafonds, des volets etc.; ils dessinent d'après les modèles en nature ou d'après des croquis cotés, des fragments d'escalier : limons, main-courante, balustres etc. de différents systèmes, pour aboutir au dessin complet et à la composition de boiseries et d'escaliers. 
3. Les charrons et les carrossiers procèdent d'après une méthode semblable. Après avoir dessiné les éléments des différents systèmes de voitures, il composent des projets d'ensemble avec devis estimatifs.

Les écoles de Hannovre et de Hambourg comblent une véritable lacune en enseignant la charpente. Plus que les autres artisans, la nombreuse corporation des charpentiers applique mécaniquement les recettes routinières de l'atelier. L'étude sur nature de fermes, de plafonds, etc. reproduits en réduction, la composition d'après des problèmes et des devis donnés, élargit l'horizon professionnel des. élèves et leur permet de comprendre et d'exécuter fidèlement la pensée des architectes et des constructeurs.

4. Les toumentrs, qui occupent une place importante dans l'ébénisterie, s'attachent au tracé ëxact des objets usuels et de tous les fragments tournés de meubles : supports, pieds de tables, de chaises, consoles, rosettes, balustres.

Toutefois, pour étendre le plus possible le domaine de leur étroite spécialité, les élèvestourneurs dessinent des parties de meubles et des meubles entiers, dans lesquels le tournage entre comme élément décoratif. 
Les Métaux. - 5. Classe des ferronniers d'art.

Les élèves débutent par l'étude d'une série de motifs géométriques dérivés du cercle, de la volute, de l'ove, de l'ellipse, etc., qui entrent comme élément dans la construction ou dans la décoration des travaux en ferronnerie. Ces exercices concrets mènent au dessin d'ouvrages complets, empruntés aux Musées, tels que, épis et couronnements de toiture, grillages, lanternes et candélabres, accessoires de l'ébénisterie et de la menuiserie : plaques d'entrée de serrure, poignées, pentures etc. L'étude de la flore ornementale donne aux élèves la culture esthétique et les formes nécessaires à la composition; la copie des modèles, et le travail pratique à l'atelier leur fournissent les notions techniques indispensables pour appliquer logiquement ces formes aux objets de ferronnerie.

6. Classe des sernuriers et des constructeurs. Cette classe a une importance considérable à cause de l'emploi progressif du fer dans la construction.

Des modèles gradués déterminent encore la marche de l'enseignement dans ce cours. L'étude commence par le lever et le dessin exact de simples objets dérivés de ${ }_{8}^{\text {la }}$ 
géométrie : boulons et écrous, verrous, crampons, assemblages usuels de fer, clous, gonds, grillages etc. Bientôt le lever simple se combine avec la représentation graphique par les projections, d'objets variés : des cassettes, serrures, toitures, châssis de fenêtres, ventilateurs, casiers, auvents; le cours s'élève ainsi graduellement de la simple copie à la composition de dessins d'atelier, suivant des données exactes : vérandahs, poulaillers, grillages, serres, etc. Les ornements et les assemblages sont dessinés en grandeur nature et teintés d'une couleur conventionnelle.

Parallèlement à ces exercices graphiques, l'élève étudie la nature, les prix, la préparation des matériaux employés dans son métier; il possède ainsi les connaissances nécessaires pour exécuter des dessins complets avec dévis estimatifs.

7. Classe des mécaniciens, des constructeurs de machines.

Un cours pratique de projections et de géométrie descriptive sert de point de départ au dessin technique pour mécaniciens, ajusteurs, etc. Les contre-maitres des ateliers de construction jouent un rôle important dans le travail; ils constituent l'intermédiaire entre l'ingénieur et les ouvriers. Aussi, ils ne 
doivent pas seulement comprendre le dessin technique qu'on leur soumet pour exécution, il faut qu'ils aient des aptitudes suffisantes pour tracer à main levée l'esquisse exacte des objets de leur métier, et pour faire, à l'aide de ces esquisses, des dessins complets, compréhensibles par les ouvriers. Tel est le double but du cours.

L'élève reproduit, d'après nature, des objets démontables et des outils, des clefs, des boulons, des assemblages, des roues dentées, des moufles et des organes de machines. A l'aide de ces esquisses cotées, il exécute des dessins complets, avec coupes et vues perspectives à l'appui, relevés de teintes conventionnelles.

LA Pierre. - 8. Classe des tailleurs de pierre. Pour entrer dans cette classe, les élèves doivent fournir la preuve qu'ils ont fréquenté avec fruit, un cours sérieux de projections et de géométrie descriptive.

Le cours de dessin pour tailleurs de pierre est essentiellement concret et débarrassé de toute la théorie au delà de la compréhension des ouvriers; les cas usuels sont résumés, en réduction, en une série de modèles, qui figurent parfaitement les systèmes d'appareillage couramment employés. Guidés 
par ces modèles, les élèves font le tracé de plates-bandes, de frises, de couronnements, de consoles, de supports, d'encadrements de portes et de fenêtres, ordinaires et biaises, de différents systèmes de voûtes (plates, sphériques, à arête etc.) de descentes droites, d'escaliers, en un mot, de toutes les constructions, qui ne nécessitent pas les connaissances supérieures de la géométrie descriptive.

Ils font l'application pratique des principes dans les dessins, qu'ils exécutent d'après certaines données et sur des devis imposés.

9. La classe des céramistes. La céramique avec ses nombreux procédés de décoration, forme une classe spéciale très intéressante, ce qui ne doit guère étonner en Allemagne, terre classique des porcelaines et des poêles en faïence.

La peinture, le tournage, le moulage de la porcelaine, les faïences et leurs applications décoratives dans l'art de bâtir sont étudiés par tous les élèves-céramistes, quelle que soit la spécialité de leur profession.

Malgré la multiplicité et la variété des travaux, les études présentent une cohésion parfaite : l'ornement s'applique à la même matière, la décoration est exécutée d'après 
des procédés semblables, le cours de dessin et le cours de composition tendent donc au même but pour tous les élèves.

L'étude générale du dessin ornemental a donné aux élèves la culture esthétique et l'habileté manuelle; il a mis à leur disposition les ressources de la flore et de la faune. La reproduction d'objets de choix en nature, empruntés au Musée, complète leur éducation esthétique dans un sens professionnel; en effet, ces exercices leur font sentir le caractère spécial de l'ornement appliqué, la subtilité du modelé propres aux travaux céramiques.

Les documents en nature, fleurs, branches, fruits, oiseaux, ou les ornements de style, servent de base aux arrangements et à la composition.

Nous remarquons une belle collection de dessins de frises, médaillons, bas-reliefs, panneaux de faïence, fontaines, pavements, carreaux de revêtement, poêles de faïence, services de porcelaine etc. L'arrangement ingénieux, le caractère original de certains dessins dénotent un esprit d'observation curieux, un goùt sùr et une tendance décorative très moderne. 
Io. LA CLASSE DES MÉCANICIENS

(Instruments de précision, d'optique, d'électricité et de physique).

Parmi tous les cours enseignés aux Ecoles de Hambourg, de Hannovre et de Berlin, la classe de dessin technique pour mécaniciens offre un enseignement, intéressant au plus haut point, qui mérite une mention spéciale.

L'élève a suivi un cours complet de projections:les solides, leurs développements, les pénétrations usuelles; sur cette base scientifique s'établit son éducation professionnelle.

\section{Ire AnNÉe D'Études.}

Les premiers exercices portent sur les applications des projections aux objets du métier : écrous, vis, trépieds, supports etc. pour aboutir au lever et au dessin de fragments d'instruments et d'appareils.

Ces exercices sont gradués avec le plus grand soin : l'élève commence par l'étude de fragments d'objets en métal tournés ou limés, présentant des accidents et des surfaces faciles à reproduire graphiquement; puis il aborde les sujets plus difficiles.

Les exercices de dessin débutent généralement par l'esquisse de l'objet. L'esquisse ainsi obtenue, est cotée; puis le modèle 
disparaît et l'élève fait le dessin complet, d'après une certaine échelle, à l'aide des cotes indiquées sur son esquisse.

Les élèves reproduisent d'après la même méthode, les appareils et instruments complets : tracer l'esquisse, coter l'esquisse et exécuter le dessin.

Les écoles possèdent une série d'instruments et d'appareils démontables, sur lesquels les élèves étudient en détail la structure et l'agencement des fragments. Cette étude préparatoire leur donne l'aptitude nécessaire pour dessiner les instruments compliqués.

Soutenus par les cours de sciences, ils peuvent commencer l'étude approfondie et la composition d'objets de leur métier : tel est le programme de la $2^{\mathrm{e}}$ année d'études.

\section{$2^{\mathrm{e}}$ Année D'Études.}

Les élèves possèdent les sciences fondamentales de leur métier et ils y puisent les éléments de leurs études graphiques : ils dessinent au trait, de mémoire, des fragments semblables de différents appareils : systèmes d'axes, régulateurs, montures de lentilles, de prismes, de réflecteurs, etc.

Lorsque le professeur a vu et, le cas échéant, corrigé les esquisses, l'élève les classe et exécute le dessin de l'objet entier. 
Les opticiens-constructeurs poussent ainsi leurs études jusqu'à la composition d'objets du métier.

Comme application à la physique, qu'ils étudient à fond, ils résolvent dans leurs constructions, des problèmes d'optique, tels qu'ils peuvent se présenter dans la pratique de la profession.

Un cours, conduit de cette façon, élargit le cercle intellectuel des élèves, leur donne la capacité nécessaire pour diriger un atelier de construction, et réagit contre la division excessive du travail qui sévit dans les industries d'instruments de précision.

\section{Les SCIENCES.}

Les études de dessin sont étayés de cours sérieux de sciences: les mathématiques, la physique, la mécanique, la technologie.

Les mathématiques alimentent les études graphiques; dans le dessin professionnel, les élèves résolvent les problèmes et étudient les principes de la géométrie, qui constituent la base du dessin de projections.

L'algèbre (I he), s'étend jusqu'aux logarithmes et à leur emploi dans le calcul de résultats indiqués.

La trigonométrie $(2 \mathrm{~h}$ s). Fonctions d'un angle, 
leurs rapports, le calcul des éléments des triangles rectangle et scalène, les formules.

La mécanique statique est étudiée d'unemanière graphique : les forces, parallélogramme, polygone des forces. Equilibre, stabilité. - Les machines simples.

Comme les autres branches des mathématiques, la mécanique n'a pas seulement pour but de faciliter la solution des cas particuliers relatifs aux professions; elle a un but éducatif plus élevé : elle inculque aux élèves des vérités générales et développe en eux le sens de la stabilité.

La physique a pour objet spécial d'avancer l'éducation technique des mécaniciens; l'enseignement est double : l'étude générale des phénomènes, et la vérification de ces phénomènes à l'aide d'instruments et d'appareils.

Les faits fondamentaux : la réfraction, la réflection etc. ne sont pas seulement étudiés au point de vue expérimental, par les opticiens, mais vérifiés et généralisés dans les cours de mathématiques; les conclusions sont appliquées au dessin professionnel.

Dans cette classe, on cherche d'une manière constante à établir une relation intime entre la physique mathématique et expérimentale d'un côté, et la technique de l'autre; la science 
et le métier, intimement unis, constituent la base de l'éducation professionnelle des opticiens et des électro-techniciens.

Nous décrivons en détail, dans les différentes "Etudes ", l'atelier de sculpture sur bois de l'Ecole d'art industriel de Vienne, l'atelier de gravure de l'Ecole d'Iserlohn, la peinture décorative de l'Ecole des métiers de Berlin. Comme il n'y a aucun élément nouveau à Hambourg ni à Hannovre, il nous sera permis de nous borner à la simple indication de ces cours et ateliers.

\section{LE MODELAGE. \\ IV. Les Ateliers.}

A/ Atelier de sculpture sur bois.

B/ Atelier de ferronnerie artistique.

C/ Atelier de dinanderies et de ferblanterie.

D/Atelier de peinture décorative.

E/ Atelier de peinture de lettres, d'attributs.

\section{STATISTIQUE.}

Les écoles de métiers et d'art industriel, avec leurs bibliothèques et leurs musées du travail artistique, font partie intégranté de la vie industrielle et professionnelle en Allemagne. Tous les métiers y trouvent des leçons 
directement utiles; c'est à cette organisation pratique qu'il faut attribuer la fréquentation facultative extraordinaire de ces écoles.

L'Ecole d'art industriel et professionnelle de Hambourg, avec les écoles divisionnaires établies dans les différents quartiers de la ville comptait, en hiver I894-95, une population de 4755 élèves; notamment :

Industriels établis.

Ouvriers et artisans.

Apprentis.

Métiers indéterminés.

Professeurs.

Aspirants-instituteurs.

Etudiants.

720

Ecoliers(division générale).

Ouvriers du bâtiment (maçons

et charpentiers) (division). $\quad 484$

Mécaniciens (division).

\section{Total : 4755 élèves.}

Cette légion d'élèves étudient sous la conduite d'un seul directeur, M. Stuhlmann, et de 189 professeurs! Sans commentaires.

Le chiffre de 4577 élèves ne constitue que le relevé approximatif des jeunes gens, qui, à Hambourg, complètent l'apprentissage par 
l'étude à l'école : les écoles des corporations (Innumgiduren) et d'autres institutions privées enseignent aussi les métiers, et reçoivent un nombre assez considérable d'élèves.

Nous ne saurions rendre l'impression de réelle grandeur que produit l'aspect de ces salles immenses remplies d'élèves, calmes, studieux et tout au travail; les professeurs, l'élite du monde ouvrier, transmettent à ces apprentis avides de savoir, les principes artistiques et scientifiques du métier; ils circulent entre les rangées, encouragent, expliquent, approuvent, redressent les erreurs. Une lumière abondante, tamisée par des écrans, savamment combinés, descend du plafond et donne à ces salles un air de fête.

On emporte la conviction, que l'étude du travail, ainsi ennobli par l'art et la science, contribue au relèvement moral des artisans, augmente leur force productive, et développe la puissance industrielle du pays.

Nous possédons aussi un enseignement du dessin : la moindre petite ville se glorifie de son " académie ». Le cours de " nature » qui la couronne, en général, y constitue l'arche sainte, le summum de la décoration sculpturale et picturale. Le cours de dessin exact, 
qui devrait modestement établir les fondements de la plupart des métiers, s'intitule pompeusement "classe d'architecture ». Les pauvres ouvriers ou apprentis ont vite le jugement faussé; au fond, ils désirent acquérir à l'école cette bribe de sciences, cette lueur d'art, qui leur permettrait de monter d'un degré dans la hiérarchie des travailleurs, mais on y fait tant de belles choses! Ils se mettent aussi à dessiner des façades, à tracer des plans d'habitations, alors même qu'ils sont encore incapables de lever; de dessiner exactement l'objet le plus simple de leur métier!

Les sciences, ce cauchemar de toutes les écoles de dessin, sont soigneusement isolées et cantonnées; elles pourraient dissiper par leur inexorable exactitude, l'aimable fantaisie d'un enseignement si éloigné des besoins réels de la population ouvrière. 


\section{VIII. - CONCLUSION}

ROLE DES POUVOIRS PUBLICS.

Une large extension de l'enseignement professionnel, la transformation des écoles de dessin et des écoles d'art industriel, sont une nécessité urgente pour la prospérité de notre industrie.

Sur tous les points du pays une vive réaction se manifeste contre la tendance exclusivement théorique et esthétique de nos écoles ouvrières : on est d'accord pour désirer, que l'enseignement soit plus intimement adapté aux besoins réels des travailleurs.

Sans centraliser à outrance, le Pouvoir central peut stimuler l'initiative des administrations publiques, provoquer la création d'écoles nouvelles et privilégier dans l'octroi des subsides celles, qui ont une direction et une tendance utiles. C'est en effet le Pouvoir central qui régit et surveille le travail national, qui connaît ses besoins, ses défauts 
et ses lacunes. C'est lui, qui concentre entre ses mains les statistiques des importations et des exportations, les informations des inspecteurs de l'industrie, qui s'inspire des vœux des Chambres de commerce, des Commissions du travail, des Corporations et Unions professionnelles et syndicales. Il peut donc déterminer dans quelle branche de l'industrie, d'après quel système, dans quelles localités, des écoles doivent être organisées, quel doit être leur but et leur tendance.

Ne dispose-t-il pas, en outre, de puissants moyens d'encouragement, des subsides et des concours, qu'il a, il est vrai, réservés jusqu'à ce jour aux artistes? Ces faveurs, étendues aux artisans et travailleurs-artistes, auraient certainement la meilleure influence sur le relèvement de notre travail.

\section{LES SUBSIDES.}

Pour déterminer la part des subsides qui revient à l'enseignement des métiers et des industries, il suffit de considérer la signification de cet enseignement au point de vue du bien-être national, son importance pour la consommation intérieure et pour le commerce extérieur, ses effets sur la répartition harmonique de toutes les forces travailleuses parmi 
les différentes professions et sur la consolidation de l'existence sociale.

Malgré l'importance reconnue par tous, l'Etat n'accorda à l'enseignement du travail qu'une somme de 650.000 frs. en I894; tandis que les subsides consacrés à l'enseignement en général s'élevèrent à 7.892 .000 fr., et à l'art en particulier, à I.87I.4Ig fr. Qui donc pourrait soutenir, qu'une telle répartition répond aux besoins économiques de notre pays?

2. Les Concours et les Expositions.

La sollicitude des Administrations publiques s'est portée trop exclusivement sur les arts purs : les concours de toute nature, pour l'obtention du prix de Rome, des bourses d'études etc. viennent périodiquement stimuler l'ardeur des jeunes artistes. Les efforts louables de la "Société pour l'art à la rue », dans le domaine de l'embellissement des villes, montrent, par leurs résultats, ce dont notre travail artistique est capable, lorsqu'il est encouragé et guidé. Des concours organisés par les provinces et par l'Etat, seraient un encouragement puissant et permanent pour les travailleurs de toutes les branches des métiers d'art. 
Chaque année un appel, fait aux écoles professionnelles, aux écoles d'art industriel, et aux artisans, provoquerait l'émulation parmi l'élite des ouvriers et cles futurs ouvriers.

Si l'on jugeait un concours annuel trop vaste et trop fréquent, on pourrait y convier annuellement et successivement les travailleurs artistes du bois, du tissus, de la pierre, etc.

Projets et travaux seraient exposés, et le public apprendrait à connaître nos industries nationales; les artisans pourraient comparer les industries entre-elles et en apprécier la valeur et les procédés. Ces concours et ces expositions renseigneraient, sur la situation exacte des industries et des métiers d'art, les Pouvoirs publics, qui pourraient suivre attentivement le développement du travail et régler l'enseignement et l'apprentissage qu'ils patronnent, d'après les défauts et les lacunes, que présenterait la fabrication.

Les lauréats devraient être bien récompensés; à l'aide de leur primes, ils seraient chargés de continuer leurs études professionnelles, pendant un temps déterminé, dans un établissement d'art industriel belge ou étranger. Rentrés dans l'industrie, ces jeunes gens apporteraient de nouvelles connaissances 
dans les ateliers, et contribueraient à stimuler et à améliorer la fabrication.

Il est certain, que ces concours révéleraient des talents supérieurs dans le travail artistique, et permettraient de recruter à bon escient un personnel d'élite pour les écoles professionnelles et d'art industriel.

Les objets primés seraient acquis par l'Etat et serviraient à constituer peu à peu un Musée du travail artistique moderne, complément utile aux Musées des échanges et d'antiquités. Les provinces et les communes de même, pourraient se créer une collection de productions industrielles intelligemment embellies par l'art.

Les Musées du travail artistique ancien et moderne de l'Etat, des Provinces et des Communes serviraient, en premier lieu, à alimenter les musées des écoles; ils compléteraient le matériel d'études, et exerceraient ainsi directement une grande influence sur le goût public et sur l'éducation esthétique et technique des artisans.

Quelle influence morale ces expositions et ces concours n'auraient-ils pas, en outre, sur la population ouvrière!

Les entrepreneurs et fabricants ne seraient plus les seuls à recueillir les honneurs et les 
avantages attachés au succès; les travailleurs méritants, anonymes maintenant, ne resteraient plus ignorés; l'œuvre porterait le nom du véritable auteur, et ainsi renaîtraient la responsabilité, la personnalité, l'orgueil professionnel et par suite une salutaire émulation parmi ceux, qui collaborent dans une si large mesure à la prospérité industrielle.

Enfin, pour montrer que l'art appliqué n'est pas moins digne de considération que le Grand art, il importerait que des récompenses honorifiques fussent accordées aux artisans qui se distinguent, soit par leurs travaux, soit par les modèles élaborés pour les ateliers.

\section{LES RÉFORMES.}

Pour aboutir, par l'enseignement, aux merveilleux résultats obtenus en Allemagne, en Autriche et en Angleterre, de grandes réformes s'imposent.

Le régime mixte des écoles de dessin et d'industrie est, en premier lieu, nuisible au point de vue de l'unité et de la tendance des études.

Ces écoles enseignent comme des branches isolées, le dessin artistique et les sciences : la partie industrielle est du ressort du Ministère de l'Industrie et du Travail ; l'élément 
artistique, toujours prédominant, est du domaine du Département des Beaux-arts.

Ce dualisme a pour effet de séparer les deux branches du travail, qui devraient, au contraire, se pénétrer et s'enchainer pour constituer l'enseignement des métiers.

Le progrès dans l'industrie poussera,certes, les écoles à fusionner plus intimement l'art et la science, bases essentielles du travail moderne. Mais pour réaliser cette unité en harmonie avec les besoins commerciaux et industriels du pays, il sera nécessaire de ramener sous les attributions du Département de l'Industrie, les écoles de dessin, les écoles de dessin et d'industrie, les écoles professionnelles, d'art industriel, et toutes les institutions, qui, en dehors des Académies des Beaux-arts, s'appliquent à perfectionner le travail.

La décentralisation en matière d'enseignement professionnel et industriel trace une limite à l'ingérence directe de l'Etat. Mais, il reste le dispensateur des subsides; lui seul, en outre, dispose de tous les renseignements concernant les besoins du travail, ses lacunes et ses défauts. Il peut donc en connaissance de cause, guider et stimuler l'initiative des Administrations publiques et des Associations 
privées, et réaliser, en matière d'enseignement les progrès, qui ont provoqué l'efflorescence de l'industrie à l'étranger, notamment :

Io Transformer notre enseignement pour adultes en un enseignement industriel et professionnel primaire, destiné aux artisans, aux ouvriers et aux autres auxiliaires des industries ;

$2^{\circ}$ Créer dans les centres plus importants des écoles secondaires professionnelles et industriclles et des écoles de métiers artistiques avec ateliers, dans lesquelles les contre-maîtres, les directeurs, les industriels et les négociants puiseront les vrais principes du travail;

3o Organiser pour les créateurs d'industries et pour les inventeurs de formes décoratives, un enseignement supérieur de l'industrie et des arts industriels qui, tout en s'inspirant de la science et des grands prrncipes de l'art décoratif, soit ramené dans la voie du travail par les applications pratiques dans les ateliers ;

$4^{\mathrm{o}}$ Annexer à une ou à plusieurs écoles de chaque degré, des cours normaux, destinés à former des professeurs.

Le Musée du travail est le complément 
indispensable de toutes ces écoles : il fournit des modèles et un matériel parfaits, et permet aux apprentis et aux ouvriers de compléter leur éducation professionnelle par leurs études particulières.

Là, où le Musée est insuffisant, la Bibliothèque doit venir à la rescousse, et offrir des documents décoratifs (gravures et estampes), de toutes les époques et de tous les pays.

Autour de ces écoles, les Syndicats et les Unions frofessiomelles, qui unissent leur influence à celle des professeurs, pour conserver à l'enseignement son caractère pratique, pour fouetter l'émulation des élèves, pour les protéger et pour les guider, lorsqu'ils auront achevé leurs études.

Pour amener des élèves préparés dans ces écoles, il faut que toutes les branches d'enseignement des écoles primaires et moyennes soient imprégnées de l'atmosphère du travail, que le cours de dessin surtout soit dirigé concrètement vers les applications décoratives et industrielles, sans cependant perdre son caractère éducatif général.

Objection.

Des esprits hésitants objectent : “ si par 
l'enseignement utilitaire des écoles populaires, par la tendance professionnelle des écoles moyennes, trop d'ouvriers affluent brusquement aux écoles de métiers, à la situation si lamentable des travailleurs intellectuels succédera la dépréciation du travail manuel et la misère chez les artisans, mêmes les plus habiles et les plus cultivés. "

La prospérité industrielle de l'Allemagne, conséquence de l'enseignement professionnel obligatoire pour tous les travailleurs, doit dissiper cette crainte.

Quel que soit, du reste, le nombre des écoles, il n'y a toujours qu'une infime fraction du nombre total des travailleurs manuels, qui jouit des bienfaits de l'enseignement.

A cause des études laborieuses de l'apprentissage approfondi des métiers, les jeunes gens formés dans les ateliers-écoles ne font pas une brusque irruption dans les usines et chantiers; ils s'y infiltrent insensiblement et y apportent l'habileté technique et le sens artistique nécessaires au relèvement du travail. Ces ouvriers d'élite exercent une influence salutaire sur leurs compagnons, ils vivifient la production, contribuent à la culture du goût public et provoquent ainsi une reçru- 
descence dans la consommation intérieure; leurs produits supérieurs mettent un frein à l'importation étrangère pour le plus grand bien de l'industrie nationale.

Nous sommes loin, d'avoir élevé l'industrie et les métiers d'art à leur apogée.

Le bien-être croissant permet mieux qu'autrefois, d'utiliser un travail plus parfait et plus artistique; de nouvelles industries prennent naissance, dans d'autres, les chefs d'atelier, les contre-maîtres font défaut pour diriger la fabrication; ailleurs encore il manque des ouvriers-dessinateurs, des aidesconstructeurs, capables de seconder utilement les architectes et les ingénieurs; partout se fait sentir la pénurie d'ouvriers complets ${ }^{\circ}$ et d'artisans-artistes.

D'autre part, le négociant belge et le représentant de commerce, ignorent souvent l'industrie dont ils écoulent les produits ; l'étude sommaire des industries et des métiers compléterait avantageusement les cours de commerce des instituts; les intermédiaires apprendraient, au moins, la structure, le maniement, les perfectionnements possibles des objets de leur négoce, et ils se feraient les auxiliaires éclairés des fabricants.

Si l'apprentissage à l'école parvient à déve- 
lopper intégralement les aptitudes des élèvesouvriers, pour les rendre aptes à satisfaire aux besoins si changeants de l'industrie actuelle, ils y acquerront un gagne-pain assuré, à l'abri des chômages provenant des fluctuations et des transformations dans la fabrication.

Les ouvriers complets constituent, au point de vue économique général, des éléments précieux de prospérité : ils ont l'intelligence et le talent assez souples pour opérer la transition d'une industrie périclante à une autre plus vivante, pour sauver une industrie menacée et l'existence sociale de beaucoup de travailleurs.

Mais pour que les écoles produisent ces effets bienfaisants, il faut qu'elles forment réellement des travailleurs, des artisans, sachant manier la matière et la forme, et non des messieurs, tout au plus capables de faire un tracé sur le papier.

Rien ne serait plus désastreux, si, par une fausse organisation, les écoles de métiers et d'apprentissage multipliées dans tout le pays, continuaient le système actuel de la plupart de nos écoles de dessin, et contribuaient à leur tour, à former, en grand, des artistes dévoyés, à côté des déclassés intellectuels 
déjà si nombreux, qui sortent des autres écoles.

Pour éviter cet écueil, il est nécessaire de fixer le but final de tout l'enseignement: l'atelier, et de préciser les méthodes et les moyens : développer les facultés intellectuelles et esthétiques, et les aptitudes manuelles dans l'esprit du travail.

Il règne dans les méthodes d'enseignement des écoles ouvrières un empirisme, une indécision et un désarroi très préjudiciables aux études: il importe pour les dissiper, d'étudier les méthodes d'une manière approfondie, et de dégager de ces études une Méthodologie de l'enseignement professionnel, basée sur les lois de la psychologie. Ce n'est que par une méthode scientifique, adaptée à l'état d'esprit de l'adolescent, qu'on trouvera le chemin de son intelligence, et que les exercices tourneront au profit de sa culture intégrale.

Les écoles professionnelles et industrielles ne produiraient pas tous leurs fruits, si elles visaient uniquement au perfectionnement de la machine humaine; elles doivent relever la valeur intellectuelle et morale de l'ouvrier, faire renaitre en lui la personnalité, l'individualité et la vanité professionnelle, qui ont 


\section{- I39-}

actuellement une tendance trop prononcée à se perdre dans le tourbillon de la grande industrie et dans les collectivités syndicales et professionnelles. 
ANNEXE I.

\section{BUDJET DE L'ÉCOLE DE REMSCHEID.}

\section{RECETTES :}

Contribution scolaire.

Chauffage de la loge du concierge.

Subside de l'Etat.

Subsides de la ville et de Westphalie

$\begin{array}{cr}\text { mk. } & 5.500 \\ " & 35 \\ " & 28.900 \\ " & \text { I I.700 } \\ \text { mk. } & 46.135\end{array}$

DÉPENSES :

Directeur.

4 Professeurs techniques - 3 I 50 à 4500

mk. 6.000

2 Contre-maîtres - $2800 \mathrm{mk}$.

2 Assistants - I80o mk.

Le Concierge.

Subsides : pour l'habitation du Directeur, de deux professeurs, $540 \mathrm{mk}$. chacun; de deux professeurs, $360 \mathrm{mk}$. chacun ; total : "

2.340 Pour l'entretien des machines et des outils " Matériel scolaire et bibliothèque. Le mobilier classique (entretien). Matériaux pour le travail aux ateliers. Le chauffage.

Lumière et eau.

Nettoyage et aides aux ateliers

Frais de bureau, matériel de dessin, imprimés, imprévus, etc.

mk. $\frac{\text { I.960 }}{46.135}$

La ville fournit le local et le matériel, et pourvoit à leur entretien. 


\title{
L'ÉCOLE SUPÉRIEURE D'ART INDUSTRIEL DE VIENNE
}

\author{
LES ÉCOLES DE MÉTIERS ARTISTIQUES
}

DE DRESDE ET DE MUNICH 



\section{IX. - AVANT-PROPOS}

\section{SITUATION DE NOTRE INDUSTRIE ARTISTIQUE.}

Le travail artistique belge traverse une crise intense, qui se traduit par un grand malaise chez les ouvriers et chez les fabricants d'objets d'art.

Les affaires sont rares et de médiocre importance: la concurrence étrangère, de plus en plus redoutable, met en danger notre industrie artistique, et rend très précaire la situation de l'élite de nos travailleurs.

Le tableau statistique du mouvement commercial belge mentionne pour I892, quelques chiffres, qui révèlent avec une éloquence brutale, une des causes fondamentales du malaise dans lequel se débattent les artisans-artistes. 
MOUVEMENT COMMERCIAL DE LA BELGIQUE AVEC LA FRANCE ET L'ALLEMAGNE

\begin{tabular}{|c|c|c|c|c|}
\hline & PAYS. & Importation & Exportation & $\begin{array}{l}\text { L'importation } \\
\text { dépasse l'ex- } \\
\text { portation de }\end{array}$ \\
\hline Qıincaillerie & $\begin{array}{l}\text { (Allemagne } \\
\text { ( France }\end{array}$ & $\begin{array}{l}20,729,000 \\
2 \mathrm{I}, 6 \mathrm{I} 6,000\end{array}$ & $\begin{array}{l}6,300,000 \\
9,600,000\end{array}$ & $\begin{array}{l}\text { I } 4,429,000 \\
\text { I } 2,016,000\end{array}$ \\
\hline $\begin{array}{l}\text { Bijouterie, or- } \\
\text { fèvrerie, argent }\end{array}$ & $\begin{array}{l}(\text { Allemagne } \\
\text { ( France }\end{array}$ & $\begin{array}{l}\mathrm{I}, 356,000 \\
\mathrm{I}, 036,000\end{array}$ & $\begin{array}{l}\text { I } 87,000 \\
367,000\end{array}$ & $\begin{array}{r}1,169,000 \\
649,000\end{array}$ \\
\hline Or . & $\begin{array}{l}\text { (Allemagne } \\
\text { (France }\end{array}$ & $\begin{array}{l}\mathrm{I}, 433,000 \\
\mathrm{I}, \mathrm{I} 93000\end{array}$ & $\begin{array}{l}\text { I } 6 \text { I, }, 000 \\
\text { I } 90,000\end{array}$ & $\begin{array}{l}\mathrm{I}, 272,000 \\
\mathrm{I}, 003,000\end{array}$ \\
\hline Meubles . & $\begin{array}{l}\text { (Allemagne } \\
\text { (France }\end{array}$ & $\begin{array}{l}3,500,000 \\
4,200,000\end{array}$ & $\begin{array}{r}965,000 \\
\text { I,639,000 }\end{array}$ & $\begin{array}{l}2,535,000 \\
2,5 \text { I I, OOO }\end{array}$ \\
\hline Totaux . & $\mathrm{fr}$ & $55, \mathrm{O}_{4} 3,000$ & I $9,459,000$ & $35,584,000$ \\
\hline
\end{tabular}

Voilà la situation dans son affligeante réalité! La quíncaillerie, l'ébénisterie, l'orfèvrerie et la bijouterie, empruntent certes à l'art et au travail presque toute leur valeur; or, pour ces seuls articles, l'importation d'Allemagne et de France dépasse l'exportation de $35 \mathrm{I} / 2$ millions de francs! Pour 35,500,ooo francs de travail importé par an, comme si notre pays, surpeuplé, manquait de bras! Combien de malheureux artisans inoccupés pourraient être employés à confectionner ces objets, que l'insuffisance de notre industrie nous force de demander à l'étranger?

Le niveau professionnel de la masse de nos artisans est trop bas, pour que leurs produc- 
tions soient à même de soutenir la concurrence étrangère sur le marché universel. La main-d'œuvre artistique fait défaut dans tous les métiers : telle est la plainte unanime des fabricants d'objets d'art industriel. Ainsi, les bijoux et les objets ciselés, les meubles, les papiers peints et tous ces articles de luxe, que nous admirons dans les magasins de la capitale, ne sortent généralement pas des mains de nos travailleurs. Nous sommes incapables de produire chez nous ce que le luxe réclame; l'étranger y supplée, malheureusement, en nous envoyant ses fabricats et ses ouvriers, qui se créent de superbes positions dans nos industries.

Il est bien vrai que, malgré le glorieux. passé artistique dont nous pouvons être fiers, malgré le goût inné de nos populations, qui donne déjà à nos produits un certain cachet caractéristique, nous ne pouvons nous suffire à nous-mêmes; nous subissons l'onéreuse tutelle de l'étranger. Notre amour-propre national devrait nous pousser à entrer dans la voie suivie par nos redoutables voisins; grâce à un enseignement pratique et rationnel des métiers, ils ont réalisé des progrès immenses dans le domaine des industries d'art. 


\section{- I+6-}

\section{CAUSES.}

I. L'ENSEIGNEMENT INSUFFISANT DES MÉTIERS

Un régime douanier défavorable à notre industrie, le goût exagéré du bibelot insignifiant, l'engouement inconsidéré pour les produits étrangers, telles sont les causes accessoires de cette regrettable situation; l'apprentissage défectueux et incomplet en est la cause fondamentale.

La généralité de nos artisans apprennent leur profession d'une manière tout empirique; initiés peu à peu aux traditions routinières de l'atelier, ils ignorent absolument les principes généraux de la décoration et les sciences exactes qui forment la base de tous les métiers; ils appliquent l'ornement d'après une recette invariable et ne lui infusent aucune pensée originale. Ils sont rares, ceux qui savent travailler d'après un plan, plus rares encore ceux, qui savent modifier des données graphiques, introuvables ceux qui seraient capables de créer un objet de leur métier.

L'enseignement des métiers artistiques, si prospère en Allemagne et en Autriche, n'existe pas, à vrai dire, dans notre pays. Les efforts louables, mais isolés de l'initiative 
privée et publique ne répondent pas aux besoins si pressants du moment. Les pseudoacadémies, entretenues à grands frais dans les plus petites villes, sont plutôt nuisibles à l'éducation professionnelle et n'entrent pas en ligne de compte. De l'innombrable phalange de jeunes Belges, qui cheminent sur la route charmante du grand art, il n'y en a pas deux par an, qui parviennent à s'imposer à l'attention publique et à se créer une existence assurée. Et de cette foule dévoyée, sacrifiée à l'ambition des professeurs, les uns s'en retournent avec dégoût aux métiers manuels, les autres échouent piteusement dans quelque " bureau ", d'autres encore, vont grossir l'armée du prolétariat intellectuel.

Les partisans du régime existant disent : "L'enseignement académique forme des dessinateurs, des leaders de l'art industriel, donc il est utile. "

Pareille objection dénote une ignorance absolue de l'industrie artistique actuelle. Une enquête assez minutieuse dans les ateliers de l'agglomération bruxelloise, nous a permis de faire à ce sujet des constatations intéressantes : à de rares exceptions près, une manufacture ne compte qu'un dessinateur-créateur, le patron généralement. 
Telle orfèvrerie, telle fabrique de meubles, telle ferronnerie qui occupent jusqu'à 200 ouvriers, travaillent d'après les dessins d'un seul homme. En admettant même que les " académies ) préparent à cette branche fondamentale de l'industrie, elles fourniraient mille fois trop de dessinateurs.

Les " académies » ne poursuivent pas ce but et les patrons sont bien édifiés à ce sujet. Le grand art et la décoration d'objets d'art sont deux choses essentiellement différentes. Un artiste, très habile dans la composition, fera bien des dessins charmants de meubles, de ferronnerie, de quincaillerie, de papiers peints, etc., mais ignorant les nécessités matérielles de l'exécution et la relation intime qui, dans toute œuvre d'art, doit exister entre la forme, la matière et l'usage, il fera le plus souvent des dessins inexécutables; si ses projets sont réalisés, il verre son œuvre dénaturée, son idée détruite ou tout au moins le caractère général changé.

Ainsi le dessin d'un lustre, d'un papier peint ou d'une dentelle, fait par un artiste, ne rendra généralement pas, en exécution, l'effet cherché par l'auteur. Des rangs mêmes des travailleurs, qui ont lutté avec la matière, doivent sortir les créateurs, qui possèdent 
assez de subtilité de sentiment pour concevoir la forme propre à cette matière.

La pratique du métier doit marcher de pair avec les études théoriques : l'atelier doit être le couronnement de l'école des métiers artistiques.

Les études aux "académies» ne sont donc pas directement utiles à l'industrie d'art.

2. L'Apprentissage défectueux a L'Atelier.

L'apprentissage professionnel se fait uniquement d'après la tradition routinière de l'atelier. Les chefs de manufacture ont négligé totalement la question du travail des apprentis, parce que, jusqu'à ce jour, l'offre et la demande a réglé la situation, et parce que l'expérience leur a prouvé, que les jeunes gens quittent leur atelier, aussitôt qu'ils peuvent gagner plus dans un autre.

Quelque incomplet et quelque rudimentaire qu'il soit, l'apprentissage à l'atelier offre le grand avantage de donner aux apprentis, sans perte de temps, une précieuse habileté manuelle; ils n'y apprennent pas les vrais principes del'art décoratif, mais leur intelligence s'ouvre, en voyant fabriquer des objets semblables, de différentes façons selon la manière de chaque ouvrier. 
Malheureusement, tous les ateliers ne produisent pas ce travail varié et parfait, si propice à l'éducation professionnelle de l'artisan et cette bienveillance patriarcale du patron envers les ouvriers, qui était autrefois la règle, est maintenant l'exception. Malgré les amères critiques, il y a encore maint atelier où les apprentis passent des journées entières à traîner la charrette, comme auxiliaires du ménage, ou à des corvées étrangères au travail. C'est une chose profondément regrettable et immorale que d'employer les apprentis comme manœuvres, alors qu'ils devraient être à l'établi. Il faut qu'ils possèdent de réelles qualités de persévérance et un grand désir du métier poưr se soumettre à une épreuve aussi clure.

Est-il dès lors étonnant, que les jeunes gens montrent si peu d'empressement à apprendre un métier, fût-il artistique?

\section{LA DIVISION DU TRAVAIL.}

Un autre obstacle qui s'oppose à l'éducation intégrale de l'artisan à l'atelier, c'est la division extrème clu travail.

L'ouvrier collabore au travail total; il est cantonné dans sa spécialité et ne possède pas les notions de l'ensemble. Dans l'ébénisterie, 
par exemple, le patron-dessinateur, le menuisier, l'ouvrier en moulures, le sculpteur sur bois, l'ajusteur et tant d'aides accessoires contribuent à la fabrication du meuble. Le jeune apprenti, moins encore que les artisans accomplis, ne peut jamais travailler le meuble dans toutes ses parties; il est une machine tenant le rabot, la scie, la varlope, etc.; son éducation est donc nécessairement très incomplète.

Malheureusement, il n'est pas possible dans l'état actuel de l'industrie, de reprendre totalement le procédé si intelligent des siècles passés; l'ouvrier concevait et exécutait son œuvre; il avait une idée de l'ensemble et des détails et était assez libre, pour pouvoir mettre un accent personnel dans son travail.

L'école doit suppléer à l'insuffisance de l'atelier, cultiver les facultés créatrices de l'apprenti et lui donner cette diversité d'idées, qui serait le fruit d'un enseignement idéal dans un atelier parfait.

\section{La Mécanisation du travail.}

Une innovation envahit de plus en plus les métiers artistiques et les ménace dans leurs bases; c'est la mécanisation du travail. Sous des apparences d'un travail manuel est caché 
un travail mécanique. Il y a encore des ateliers où le travail est resté purement manuel, mais il en est beaucoup plus dans lesquels les pièces principales et uniformes sont fournies par les machines. Les ouvriers spécialistes ajustent, soudent, polissent et achèvent.

Le travail mécanique est froid et raide et ne détrônera jamais totalement le travail manuel, parce que l'artisan habile et cultivé y met son cachet personnel, son âme, enfin, ce qui fait tout le charme de l'œuvre. Néanmoins la machine entame fortement le métier et rend l'apprentissage quasi impossible dans les ateliers où elle fonctionne.

Telle est, rapidement esquissée, la situation de l'apprentissage des métiers artistiques dans notre pays. L'exploitation indigne de l'apprenti, le travail routinier de l'atelier, la mécanisation et la division du travail éloignent les jeunes gens des carrières professionnelles. Or, pas d'apprentissage, pas de travail. C'est donc dans l'organisation pratique et complète de l'apprentissage, que l'on doit chercher le salut des industries d'art, et les moyens de lutter victorieusement contre la concurrence étrangère.

\section{Les PRÉJugés.}

Toutes ces causes réunies ont donné nais- 
sance à la prévention d'un autre âge, qui règne encore contre le travail, même ennobli par l'art et éclairé par la science. Les parents, soit par égoïsme, soit par vanité, ne veulent plus consacrer, ni le temps, ni l'argent nécessaires à l'apprentissage professionnel de leurs enfants, ils préfèrent jouir immédiatement de leur travail et se soucient trop peu de leur avenir.

En agissant ainsi, ils obéissent d'ailleurs, surtout dans nos grandes villes, à leur antipathie, à leur dédain pour le travail manuel. Le jeune homme qui, à l'école primaire ou à l'école moyenne, montre quelque disposition au savoir scolaire, est invariablement proclamé trop instruit pour se faire artisan, et est destiné à l'Administration ou aux "bureaux " de commerce. Là au moins, il aura un gain facile et immédiat, il sera en outre employé, c'est-à-dire dans une situation en apparence plus brillante que celle du modeste artisan.

\section{LES REMĖDES.}

Il y a une vingtaine d'années les industries artistiques allemandes et autrichiennes se trouvaient dans une situation analogue de manifeste infériorité vis-à-vis de celle des autres 
pays. On connaissait à peine le mot "art appliqué », " art industriel », et encore moins la chose. Le public avait la conviction, d'ailleurs fondée, que, pour posséder un objet de goùt, il fallait se le procurer à l'étranger ; des millions de francs de travail furent ainsi annuellement enlevés à la population ouvrière de ces deux pays.

Quelques hommes clairvoyants et énergiques se sont émus de cette situation humiliante, et ont créé par la parole et par les écrits un mouvement d'idées en faveur de l'art industrièl national. Ils ont convoqué des congrès a austro-allemands d'artistes, d'artisansartistes, de fabricants et de particuliers et y ont dévoilé la vérité. Une vaste agitation nationale s'est fait jour et sous la puissanté impulsion des Souverains et des Gouvernements, appuyés par les industriels; quantité d'académies ont été transformées en écoles de métiers artistiques, et de nouvelles écoles ont été créées dans les centres de production.

L'Allemagne et l'Autriche possèdent actuellement un enseignement admirable des arts appliqués. La moindre ville située sur l'immense territoire, qui s'étend de la mer Baltique à l'Adriatique, possède son école, dont dépendent un musée et une bibliothèque. 
Des associations d'artisans, de fabricants, d'artistes et d'amateurs fonctionnent autour de ces institutions, les poussent dans la voie du travail pratique, par la discussion des question relatives aux métiers et par l'organisation d'expositions locales. Le peuple germanique a une confiance absolue dans ses écoles. L'école primaire a relevé le niveau intellectuel du peuple; les écoles de métiers relèvent le niveau professionnel des artisans et le travail national; elles peuplent les ateliers d'artisans de goût, qui connaissent toutes les ressources de leurs métiers; les musées et les bibliothèques cultivent le sens esthétique du public en lui donnant, par l'intuition, une notion saine du beau dans le travail. Ces pays peuvent depuis lors se suffire à euxmêmes; il n'existe aucun objet artistique, qui ne puisse étre bien confectionné dans leurs ateliers. En rattachant leur décoration à la Renaissance de la période de Dürer et à la Renaissance italienne, ils sont parvenus à donner un cachet propre à leurs produits.

Le développement énorme de l'art industriel, la recherche scrupuleuse de la forme, l'habileté à se servir de certains moyens de gravure, d'émail, de ciselure, la concurrence sans merci qu'ils font aux produits similaires 
de tous les pays, prouvent, que l'enseignement commence à sortir ses effets, et que leurs efforts sont couronnés de succès.

Cependant le peuple allemand n'a pas, en général, une plus grande disposition que nous pour les arts. Très sensible aux beautés de la musique, très amoureux des sciences et de leurs applications, son génie ne semble pas, en général, trouver une expression caractéristique dans les arts plastiques. Ses productions décoratives ne pétillent ni d'esprit ni de grâce, mais sa main d'œuvre est excellente. Les artisans et ouvriers acquièrent par une étude méthodique et acharnée, ce que la nature leur a refusé et les résultats sont merveilleux.

Nous autres, Belges, nous ne devons imiter l'art d'aucun pays, nous possédons un art national superbe, grandi sur notre sol et en harmonie avec le caractère de notre race.

L'étude de l'enseignement des arts industriels de l'étranger nous est néanmoins particulièrement utile : il nous apprend par quels moyens, d'après quels principes, et suivant quelles méthodes nous devons enseigner le métier à nos artisans, pour que le goût artistique inné, éclate dans leur travail. 


\section{X. - LES ÉCOLES DE DRESDE ET DE MUNICH}

Fondements de l'Enseignement :

LE DESSIN, L'INDUSTRIE ET LES MÉTIERS A L'ÉCOLE PRIMAIRE.

L'enseignement des métiers a ses racines à l'école populaire.

Il règne dans les écoles autrichiennes et surtout dans les écoles allemandes un esprit utilitaire très caractéristique, tangible surtout dans les différents cours de l'école primaire. Le mot 2olfs;dule n'est pas une vaine appellation; l'école prépare effectivement les enfants au rôle qui leur sera assigné dans le commerce, dans l'industrie et dans les métiers. Son enseignement est imprégné du prosaïsme commercial et industriel qui règne dans les masses, et inspire aux enfants l'amour du métier et le respect des artisans. 
Nulle part on ne trouve dans les écoles populaires ou moyennes inférieures des traces de ce régime étroit, par lequel des élèves sont préparés aux bureaux de commerce ou aux administrations; les anciens militaires occupent d'ailleurs presque tous les emplois publics, et ainsi, toutes les forces, tous les talents sont conservés à l'industrie et aux métiers.

L'enseignement primaire jette les bases d'une large éducation professionnelle, commerciale et industrielle.

Parmi les branches, destinées spécialement à développer les facultés de l'enfant dans un sens pratique, figurent en première ligne le dessin, le cours d'intuition et les tratanx manuels.

LE DESSIN.

Dans les centres comptant plus d'une école primaire, le cours de dessin est généralement confié à un professeur spécial, formé à unie école de métiers artistiques, et capable d'enseigner, outre le dessin théorique, ses applications aux professions manuelles et aux industries locales. Il en résulte une admirable unité, qui se manifeste surtout dans les expositions périodiques, où les écoles de tous les degrés soumettent les dessins de leurs élèves à l'appréciation du public. 


\section{$-159$}

Le dessin est plan pour les enfants de 9 à I I ans. Les élèves des classes supérieures de I I à I4 ans - dessinent d'après une série de solides, dérivés des formes géométriques, qui résument les premières difficultés du dessin à main levée. Les leçons de géométrie et de formes géométriques trouvent leur application dans le dessin à l'aide d'instruments, qui apprend aux élèves la maniement du tire-ligne, de l'équerre, du compas, de l'échelle des proportions, etc.

Le programme assigne quatre heures par semaine au dessin à main levée.

L'élève qui étudie avec soin la série des modèles, possède, à la fin de ses études primaires, une aisance remarquable à prendre les croquis des ornements, à quelque métier qu'ils se rapportent.

\section{MÉTHOde.}

La méthode est individuelle dans les deux classes supérieures. Chaque élève a devant lui un objet qu'il mesure et manie en le dessinant. Le professeur surveille, fait rechercher les erreurs, donne des conseils et encourage ; ainsi chaque élève reçoit un enseignement intime en harmonie avec ces aptitudes et son tempérament. Lorsque le dessin 
en contour est achevé dans un cahier spécial, le modèle disparaît et l'élève doit reproduire sur une feuille et de mémoire, le dessin fait dans le cahier. Cet exercice cultive à un haut degré la mémoire des formes, si indispensable à l'artisan, et meuble l'esprit de l'élève d'une provision d'éléments choisis, qu'il peut utiliser dans ses petits essais de composition.

Le dessin occupe à l'école primaire une place en rapport avec son importance éducative et utilitaire; il est d'ailleurs le langage universel des artisans, sans lequel ils ne sauraient travailler avec intelligence ni développer leurs aptitudes professionnelles.

\section{Cours d'intuition : L'INDUSTRIE}

ET LES MÉTIERS.

Parallèlement au dessin, qui forme l'œil et la main en vue des professions, est enseigné un cours d'intuition, qui forme l'intelligence de l'enfant dans le sens de la vie matérielle. Les leçons d'intuition, d'abord de simples causeries sur les plantes et sur les animaux, s'épanouissent à mesure que l'enfant avance en âge, et dans les deux classes supérieures (I2 à I4 ans) cet enseignement prend l'allure d'un véritable cours d'industrie et de métiers (quatre heures par semaine). 
Le programme porte entre autres : ${ }^{\circ}$ Ressources industrielles du pays; $2^{\circ}$ lecommerce: les voies de communication, les débouchés : exportation, importation; 3o les métiers locaux.

Cet enseignement est absolument intuitif; chaque école primaire possède une collection de produits industriels et artistiques, complétée par une série de planches coloriées, qui représentent des vues d'ensemble et de détail des différentes industries et manufactures. C'est sur ces objets en nature et sur ces planches que le professeur montre les différentes phases de la fabrication, et initie les élèves aux procédés de l'industrie locale.

La spécialité de chaque région forme le noyau de la collection et le pivot de l'enseignement intuitif : la porcelaine à Dresde, les arts de l'imprimerie à Leipsig, les tissus à Crefeld, etc. Pour compléter ces leçons dans un sens purement pratique, les élèves consignent dans un cahier, les croquis des outils, des appareils et des fabricats qui s'y prêtent.

A des intervalles réguliers, ils sont conduits dans les usines et dans les ateliers de fabrication artistique. Le spectacle de cette puissance industrielle, de l'habileté et du savoir 
des artisans les impressionne vivement, et éveille leur vocation. Une préférence se manifeste bientòt en faveur du métier pour lequel ils se sentent des dispositions et du goùt, et en connaissance cle cause, ils embrassent la profession de leur choix.

\section{Les tRavaUx MANUELS.}

Le dessin et les notions d'industrie trouvent leur application immédiate dans le travail manuel. Le modelage, le travail du bois, et, dans certaines écoles, le travail du fer, font partie intégrante de l'éducation générale.

Ces travaux n'ont pas uniquement pour but d'apprendre aux élèves les rudiments des professions; bien plus, ils sont destinés à favoriser le développement du corps, de l'esprit d'observation, de l'habileté manuelle; en outre, ils leur procurent une source de jouissances par la confection d'objets utiles. Des ateliers sont annexés à presque toutes les écoles primaires des villes de Munich, cle Dresde et de Vienne.

Le mobilier se compose d'établis, d'étaux, de tables de modelage, et d'un menu outillage pour ces différents exercices. Un nombre considérable d'élèves peuvent travailler en 
même temps à l'atelier, grâce à un roulement, qui fait succéder une heure de menuiserie et de travail du fer à une heure de modelage.

Quoique facultatifs, les cours sont suivis très assidûment. A voir l'ardeur et le savoirfaire que ces petits artisans de I3 à I4 ans déployent dans leur travail, l'entrain et le cœur qu'ils mettent à raboter, à limer, à modeler, on acquiert la conviction intime, que cette activité physique et intellectuelle répond à un besoin inné de leur nature d'enfant. Ils modèlent, d'après les formes géométriques et d'après les combinaisons élémentaires qui en dérivent, d'après des feuilles, des fleurs et des fruits en plâtre ou en nature, qu'ils arrangent en ornements courants ou en petits sujets décoratifs très simples.

Le bois est fourni par l'école, découpé dans toutes les dimensions désirées.

Les élèves s'exercent au maniement du rabot et du ciseau en dressant des planchettes, en mettant leurs faces en équerre, et les découpant en carrés, en hexagones et en cercles. Ils pratiquent des ouvertures carrées, hexagonales et circulaires dans des planchettes et $\mathrm{y}$ ajustent les pièces correspondantes. Ils appliquent alors ces notions, dans la 
construction des assemblages les plus simples de la menuiserie et de la charpente : entures à tenon et à mortaise, à enfourchement, assemblages en queue d'hironde, à emboitement, etc., et confectionnent de petits objets utiles, tels que : boites, porte-manteaux, coffrets, équerres, etc.

La marche des exercices pour le travail du fer est sensiblement la même.

L'école primaire dirige les vues des jeunes gens vers les industries et les professions; elle ouvre à leur intelligence le vaste champ du travail et leur inspire le respect du métier manuel; elle fournit aux écoles d'apprentissage des éléments préparés et contribue ainsi dans une large mesure au développement de l'industrie et des métiers. 
PRINCIPES FONDAMENTAUX DES ECOLES D'ART INDUSTRIEL

DE VIENNE, DE DRESDE ET DE MUNICH.

Les écoles d'art industriel et les écoles des métiers ne sont pas des écoles préparatoires aux académies. Nulle part en Allemagne ni en Autriche ces écoles ne sont réunies aux classes préparatoires des écoles des beauxarts.

Elles ont une existence, un but, des modèles et des méthodes propres; leur enseignement n'est nullement influencé par l'enseignement académique; elles ne donnent. pas comme appât l'art, mais le travail artistique.

Elles ne dédaignent aucunement le grand art; si une nature artistique supérieure se révèle, elles l'entourent de sollicitude pour favoriser son éclosion.

L'école est considérée comme une dépendance du Musée du travail.

Elle base son enseignement sur la nature. Le ciseleur, l'orfèvre, le bijoutier travaillent d'après des objets authentiques ou d'après des copies galvano-plastiques; l'ébéniste exerce 
ses aptitudes en étudiant des modèles de choix des plus belles époques empruntés au musée. La bibliothèque vient à la rescousse et fournit des reproductions et des documents, chaque fois que le musée est insuffisant.

L'action de la bibliothèque et celle du musée ne se bornent pas à l'école. Leur influence rayonne jusque dans les plus infimes ateliers du travail artistique. Les objets, les gravures, etc., peuvent être étudiés sur place même; moyennant l'accomplissement de légères formalités, la bibliothèque met à la disposition des intéressés des reproductions, des gravures et des livres, et le musée leur prête les objets de ses collections.

\section{Conférences et Expositions.}

Une salle de conférences est annexée à la bibliothèque; des savants vulgarisateurs et des professeurs entretiennent le public des sujets, compris dans la vaste sphère des arts industriels; ces causeries populaires sont hebdomadaires et destinées, pour une moitié, au public cultivé, aux consommateurs, et pour l'autre, aux artisans et industriels; elles ont trait aux questions du jour, aux acquisitions du musée ou de la bibliothèque, 
acquisitions qui sont alors exposées pour la circonstance.

Une salle du musée est réservée à des expositions spéciales trimestrielles. Si un nouveau produit apparait, si une nouvelle tendance se manifeste dans le domaine des arts appliqués, l'Administration réunit tous les documents et les expose. Le Bulletin : Communications du Musée impérial et royal autrichien, mentionne notamment des expositions de l'ivoirerie, des arts graphiques, du costume au xvili ${ }^{\mathrm{e}}$ siècle, des travaux de femmes, du rinceau, de l'application du dessin aux métiers, etc.

L'école fournit aux ateliers des artisans accomplis; le musée et la bibliothèque sont des moyens puissants de vulgarisation; les trois institutions sont connexes et concourent à l'éducation esthétique du public et à la culture des artisans dans toutes les branches de l'art industriel.

\section{LES ASSOCIATIONS D'ART INDLSTRIEL.}

L'âme de ces institutions est l'Association des Arts industriels. On se forme difficilement une idée de l'activité que ces associations ont pu imprimer aux écoles et à leurs dépendances, mème dans les localités les plus isolées 
de l'Allemagne et de l'Autriche.

Le malaise toujours grandissant dù à la concurrence étrangère, joint au désir ardent d'affranchir leur pays de la tutelle de l'étranger en matière de travail artistique, a groupé les hommes d'initiative : artistes industriels, fabricants et amateurs en de vastes associations appelées Runitgewerbevereine, dont les ramifications s'étendent partout. Ces associations se sont assigné pour mission de relever le niveau du travail national, en établissant entre le Musée, l'école et les artisans artistes des relations intimes, en vue du développement de l'art dans les ateliers. Elles influent sur. l'enseignement et sur la fabrication.

L'Association viennoise est un modèle du genre. Les membres se réunissent périodiquement pour discuter leurs affaires sociales, les perfectionnements et les tendances des arts industriels, pour se communiquer les renseignements relatifs à la concurrence étrangère et au régime douanier, pour étudier en commun les procédés de fabrication, les méthodes d'enseignement et les desiderata des fabricants et des artistes industriels, en un mot, pour agiter toutes les questions intéressant leurs industries.

Une exposition permanente des sociétaires 


\section{- I69 -}

est établie dans une des salles du Musée. Nous eumes, lors de notre visite, le grand plaisir de voir exposés les remarquables travaux que l'Association destinait à l'Exposition universelle d'Anvers. M. le professeur Klotz, aidé de ses élèves, donnait le dernier coup de ciseau à l'immense cartouche en bois sculpté, qui devait orner l'entrée du compartiment viennois.

La sollicitude de l'Association s'étend sur les élèves.

Elle distribue annuellement, à titre d'encouragement, des subsides considérables aux jeunes gens doués, mais peu favorisés par la fortune.

Furent distribués en I893 : Ig subsides de 20 florins, 5 de 55 florins et 3 de ro florins par mois; un élève reçut une bourse unique de Ioo florins, et un autre élève, 20 florins, soit en tout $: 2.025$ florins en une année.

Les élèves des classes supérieures sont admis, par groupes, dans les ateliers des sociétaires, et ils peuvent s'y perfectionner en collaborant à des travaux destinés au public; très fréquemment, les industriels organisent des concours parmi tous les élèves, pour la création de modèles nouveaux; en outre, les lauréats sont sủrs de trouver, après l'achève- 
ment de leurs études, une position lucrative chez leurs protecteurs.

Quoique l'Association n'ait aucune action directe sur la marche des études, dont le directeur et les professeurs seuls sont responsables, le corps professoral est trop heureux du précieux concours de ces spécialistes généreux, pour ne pas s'inspirer de leurs idées et de leurs tendances.

\section{L'ÉCOLE DE MUNICH.}

Le bâtiment de l'école est de construction récente et offre cette particularité curieuse, que toute l'ornementation a été créée par les élèves; les peintures décoratives, les ferronneries, les vitraux, les ornements sculptés sur pierre et sur bois, ont été projetés et exécutés à l'école même, sous la direction des professeurs.

Un principe très fécond a guidé l'architecte dans la distribution des salles.

Les classes et les ateliers se développent autour d'une grande salle centrale, prenant jour par un toit vitré, dans laquelle les travaux de l'école sont exposés en permanence. A l'entrée et à la sortie, les élèves ont sous le regard les sculptures sur bois, les émaux 
et pièces d'orfèvrerie, les projets de décoration, etc., exécutés à l'école, et la vue de ces objets fait naître en eux une salutaire émulation.

Mieux que par des affiches, les parents se rendent compte par les travaux des élèves, du but visé par l'école et des métiers qui y sont enseignés; les autorités peuvent constamment contrôler la tendance de l'école et juger celleci d'après son œuvre.

\section{LE MOBILIER.}

Nous reproduisons en croquis (fig. I) une ingénieuse disposition de bancs à gradins de l'auditoire. Les tables des pupitres ont une largeur moyenne, et sont pourvues alternativement d'une planchette d'allonge, mobile autour d'une charnière. Lorsque le cours oral est accompagné d'exercices de dessin, la planchette peut être levée (A B) pour élargir la table; lorsqu'elle est baissée (A C),- elle s'efface dans le dossier.

Remarqué aussi un banc-chevalet assez original, que nous reproduisons en plan et en élévation. L'élève s'assied en califourchon sur le banc et se trouve dans une position telle, que son regard tombe perpendiculairement sur le centre de la feuille (fig. 2). 


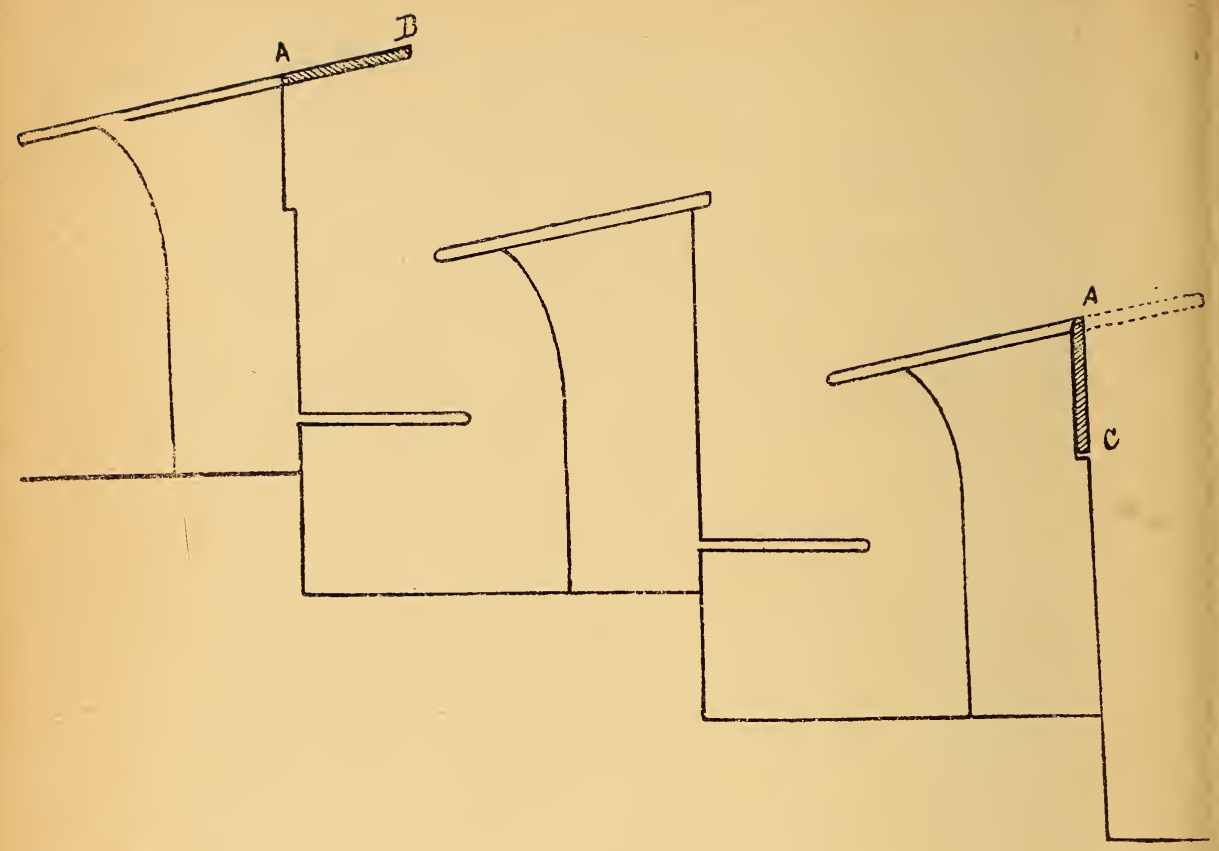

Fig. I
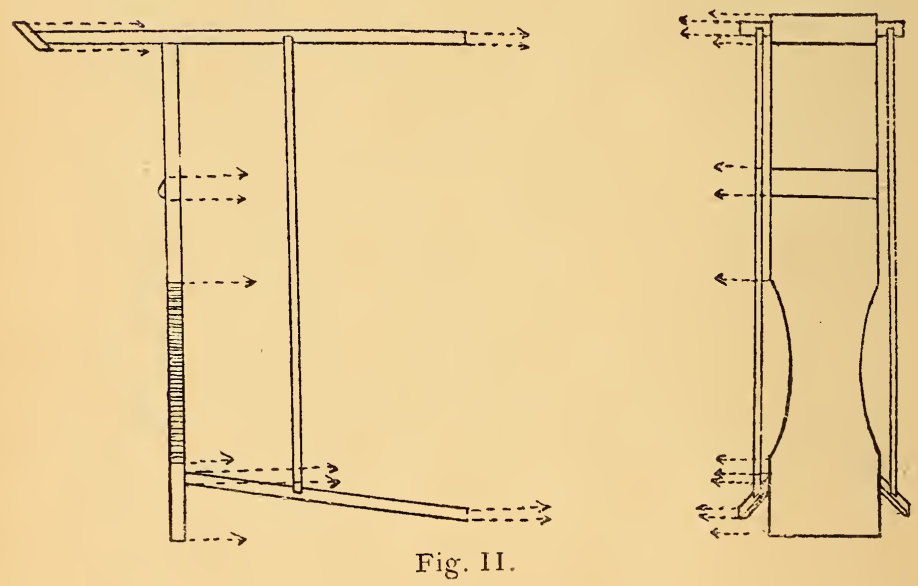


\section{XI. - L'ÉCOLE SUPÉRIEURE IES ARTS INDUSTRIELS ET DÉCORATIFS DE VIENNE}

\section{LE MUSÉE.}

SON ORIGINE ET SON FONCTIONNEMENT.

I64.055 personnes visitèrent le Musée des arts industriels en I8g3. Ce chiffre se passe de tout commentaire.

Ce Musée ne doit pas la faveur clu public à une réclame effrénée, ni à des curiosités de nature à émerveiller les désœuvrés et les touristes les plus blasés. Non, il n'offre que du travail modèle, qui par la technique, la forme ou le coloris, est digne d'ètre étudié et de rentrer dans la circulation, empreint du cachet moderne. Sous forme d'une collection de produits authentiques ou de copies de toutes les périodes remarquables, le Musée montre l'histoire complète du travail artistique de toutes les races, depuis la plus haute 


\section{- I74 -}

antiquité jusques et y compris l'époque actuelle.

Le noyau de la collection a été formé par des achats et par des dons. Chaque nouvelle acquisition est annoncée, discutée, analysée dans les journaux, et les amateurs et les artisans intéressés s'empressent de venir l'étudier. Le Musée a comblé les lacunes par l'échange de copies galvanoplastiques ou autres de ses œuvres, avec les collections du monde entier.

Grâce à la munificence de la Maison impériale, il possède une collection très complète de bijoux, de pièces d'orfèvrerie et d'ivoirerie. Les particuliers, les communautés religieuses et des membres de la noblesse, mettent volontiers à la disposition du Musée des objets ou des collections, qui offrent de l'intérêt au point de vue du travail.

Enfin, quantité d'œuvres d'anciens élèves ou d'élèves actuels ont été exécutées aux frais du sooftitelfonds, fonds formé par une redevance de 300 florins, que doivent verser les commerçants, qui désirent s'intituler “fournisseurs de la Cour ».

\section{Ròle.}

Le musée s'est fait l'auxiliaire de l'industrie artistique locale en prètant les objets, qui ne 


\section{$+175-$}

peuvent se détériorer par la manipulation, aux intéressés reconnus solvables ou versant en garantie la valeur de l'objet. Le régistre du Musée de Drescle signale, pour I893, l'emprunt de $9.45 \mathrm{I}$ objets; il est vrai que toutes facilités sont accordées dans les Musées mêmes de Dresde et de Vienne, pour dessiner ou pour peindre sur place des objets ou des groupes décoratifs; il est loisible au visiteurs et aux artisans de déplacer et de manier les objets qui ne peuvent en souffrir; ils y trouvent des tables, des chevalets, et les accessoires nécessaires à l'étude.

Ces musées sont des foyers puissants de culture artistique, ils exercent en collaboration avec l'école et arec la bibliothèque une influence considérable sur la production des arts appliqués locaux, en remettant en circulation des techniques et des procédés oubliés et les gracieuses formes, dont les artisans revêtaient aux belles époques les cbjets les plus ordinaires de la vie usuelle.

Comme celui de Berlin, le Musée de Vienne est une institution nationale, et comme tel il répand son enseignement si vivant et si salutaire dans toutes les régions de l'Empire. Il fournit des modèles à toutes les écoles d'art appliqué; le laboratoire de 


\section{- I76-}

galvanoplastie et l'atelier cle moulage copient les séries d'objets, qui emportent avec eux l'esprit de l'institution centrale; le Musée dirige les écoles avec une remarquable énergie vers l'affranchissement et l'indépendance dans l'art industriel.

L'Association des arts industriels ne reste pas inactive; elle fait participer tous les pays de la Couronne aux bienfaits du Musée central, en organisant des expositions particulières, à l'aide d'objets empruntés au Musée, là, où une industrie naissante doit être guidée, où une tendance erronnée doit être combattue.

Animés d'une ardeur admirable et avec une ténacité toute germanique, les écoles d'arts industriels, le Musée et l'Association travaillent à la régénérescence du travail artistique austro-allemand : l'école, en peuplant les ateliers d'artisans, et les écoles similaires de professeurs imbus de ses idées; le Musée, par ses modèles et par sa publication : Communications du Musée pour l'art et l'industrie, qui répand au loin ses doctrines; l'association, par l'organisation d'expositons locales, là, où la production artistique les appelle.

Cette institution modèle guide glorieuse- 
ment le travail autrichien dans la voie de l'art appliqué moderne.

\section{Le batiment du Musée.}

L'école et le Musée sont établis dans deux bâtiments symétriques, contigus, construits en Renaissance italienne, sobre et de belle allure. Au nord, le Stubenring, à l'est, au sud et à l'ouest, le parc, dont les larges trouées ouvrent des échappées sur la ville et laissent affluer une abondante lumière.

Une entrée monumentale conduit dans une spacieuse salle centrale, ornée d'une ordonnance de colonnes, qui portent une galerie au niveau dú premier étage; la salle prend jour par un toit vitré. Le rez-de-chaussée, dont nous donnons ci-dessous le dessin (fig. 3), est occupé par les collections, le premier étage par la bibliothèque, par la salle de lecture et par les salles des expositions trimestrielles et des expositions permanentes de l'Association.

\section{LES COLLECTIONS.}

\section{Classification.}

Une des principales causes de la vogue toujours croissante du musée est certes la 


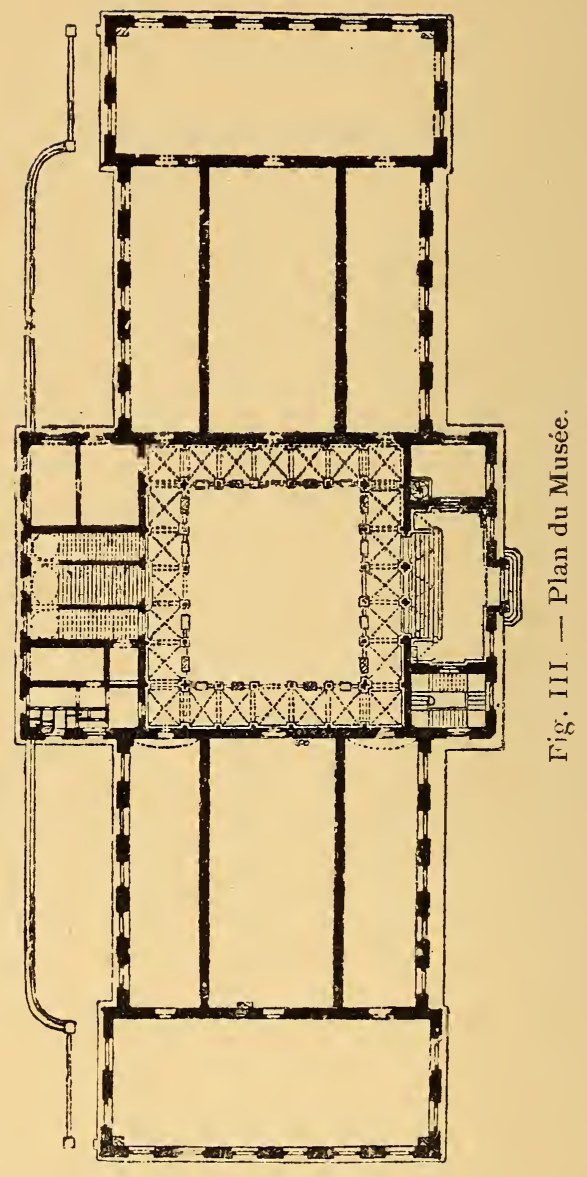


classification aussi simple que logique des objets des collections.

Les divisions sont établies, autant que possible, d'après la matière; quelques collections, telles que l'intérieur oriental, sont rangées d'après leur usage. Ce classement permet au visiteur de retrouver l'objet de son désir, sans perte de temps, et de comparer d'un coup d'œil, le travail similaire de toutes les époques et de tous les pays.

Le groupement chronologique, prenant comme point de départ la matière, dont les objets sont confectionnés, permet de se rendre compte, par comparaison, de la technique dans les différentes époques, de saisir la marque caractéristique de l'ornement à une époque spéciale et ses transformations successives suivant les besoins, ou les caprices du luxe et de l'usage.

Groupe I.

\section{a) Tissus, b) Dentelles, c) Broderies, d) Tapis.}

Collection remarquable par sa variété et par sa qualité. Elle fournit à l'école de Vienne un matériel d'étude considérable; l'industrie entière si florissante vient y puiser la technique et l'ornementation des superbes brocarts d'or et d'argent de l'Inde, des étoffes 
persanes et japonaises, des broderies orientales, turques et chinoises; le "cours central» de dentelles de Vienne, les écoles de dentelles des Erzgebirge et des régions des Alpes, lui empruntent les admirables dentelles nationales, brabançonnes, vénitiennes, sudaméricaines, etc.

On attribue avec raison à l'influence de cette collection, la transformation avantageuse de l'industrie de la dentelle, de la broderie et du tissu autrichiens.

\section{Groupe II.}

\section{Le cuir.}

Les formes multiples, que le moyen-âge avait données au cuir pour les usages du meuble et de la décoration, sont rentrées dans l'industrie viennoise. Ce sont encore les collections du Musée : cassettes, étuis, reliures, meubles ornés de cuir sculpté, repoussé et estampé des $\mathrm{XVI}^{\mathrm{e}}$ et $\mathrm{XVII}^{\mathrm{e}}$ siècles, qui ont servi de point de départ aux applications intéressantes, dont la maison Pollack de Vienne s'est fait une spécialité universellement renommée.

Groupe III.

Le bois.

La tendance des organisateurs se manifeste 
clairement dans l'ameublement. A en juger par le nombre prépondérant de meubles sculptés et incrustés des xvi e et $\mathrm{xvII}^{\mathrm{e}}$ siècles, ils ont eu en vue de rattacher l'ébénisterie à la Renaissance. Les meubles italiens et français de la première période, au dessin élégant et aux sculptures merveilleuses, les meubles flamands à la structure architectonique sobre et pondérée, les meubles portugais aux applications si originales de colonnettes, de pieds, de pilastres et d'ornements tournés, sont largement étudiés dans la classe d'ébénisterie; ils sont entrés par cette voie dans l'industrie et dans le goût du public, mis en harmonie avec les idées et les usages modernes.

Groupe IV.

\section{La céramique.}

Le Musée a trouvé dans l'industrie de la céramique viennoise des matériaux d'une richesse inouie, qui forment avec les produits si réputés de Saxe, de France, de Hollande, avec les majoliques italiennes, avec les poteries turques, égyptiennes, grecques, orientales, etc., l'histoire complète et vivante de cette branche si intéressante de l'art industriel. Les sujets décoratifs - véritables miniatures - l'ornementation si élégante, à base 
d'or discrètement mis en œuvre, donnent à la céramique viennoise une vogue de bon aloi, dont le Musée et l'école peuvent revendiquer l'honneur.

Groupe V.

Le verre.

Les produits vénitiens, allemands et bohémiens des $\mathrm{xvI}^{\mathrm{e}}, \mathrm{xvII}^{\mathrm{e}}$ et $\mathrm{xvII \textrm {I } ^ { \mathrm { e } }}$ siécles, forment le noyau de cette remarquable collection; autour d'eux viennent se grouper les verres modernes, émaillés, taillés, incrustés, gravés, de France, d'Angleterre, de Russie, etc. Tous ces objets, intéressants par la forme, par la couleur, par la taillè, par la gravure ou par l'émail, ont exercé sur l'industrie une influence salutaire, et l'ont élevée, après bien des alternatives de déclin et de prospérité, au premier rang de la production artistique autrichienne.

Groupe VI.

Les Métaux précieux. - Les travaux d'émaillerie.

La collection contient, à côté d'objets originaux, des reproductions galvanoplastiques, obtenues par échange; elle présente une image assez complète de l'orfèvrerie et de la bijouterie, surtout de la Renaissance italienne, française et allemande. 
Quantité de bijoux et de pièces d'orfèvrerie ont été acquis, aux frais de la cassette impériale, dans les dernières expositions universelles. La générosité de la Cour, le produit de quelques fondations, et l'intervention de l'Association des arts industriels ont permis de faire exécuter à l'école les " concours " primés des élèves.

Les collections privées, que des amateurs bienveillants exposent temporairement, ajoutent un puissant attrait à cette branche si caractéristique du Musée.

La présence prépondérante des œuvres des $\mathrm{xv}^{\mathrm{e}}$ et $\mathrm{xvI}^{\mathrm{e}}$ siècles, confirme l'opinion, que les organisateurs cherchent aussi à ramener cet art à la Renaissance.

La finesse exquise de l'orfèvrerie et de la bijouterie actuelles, jointe à son caractère ornemental caractéristique, montrent à l'évidence, que cette industrie d'art a su s'affranchir des vieilles formules et entrer dans la voie nationale.

L'émaillerie que M. Macht, professeur, a remis en honneur à Vienne, est représentée par quelques œuvres du moyen-âge, par quelques objets persans anciens, et surtout par une belle série de travaux modernes que nous avons pu admirer partiellement dans le 
compartiment autrichien de l'Exposition d'Anvers.

\section{Groupe VII.}

Les métaux non précieux.

Cette collection se compose d'une infinité d'objets de toute époque et de tout style, subdivisés d'après la matière et groupés par ordre chronologique.

Les bronzes comprennent des médaillons, des candélabres, des sonnettes, des heurtoirs, des objets de toilette, etc., une collection admirable d'animaux, des panneaux décoratifs et des statuettes de M. König, professeur: de sculpture à l'Ecole.

L'étain et le plomp. - Les plats, cruches, assiettes, potiches et menus ustensiles de ménage forment un ensemble très instructif.

Le fer. - Les grillages, croix funéraires, enseignes, pentures, heurtoirs, serrures, cassettes et armes de toute provenance, constituent une collection très complète, dont l'industrie du bâtiment surtout tire un parti considérable à Vienne.

Les constructions nombreuses en Renaissance italienne, française et allemande, qui ornent le grandiose Ring, sont revêtues de tous les accessoires en ferronnerie, dont les architectes du moyen-âge embellissaient si 
artistement les façades, les portes et les châssis des fenêtres.

Groupe VIII.

Les objets sculptés.

Les sculptures sur bois, sur ivoire, sur pierre, très nombreuses, de tou tes les époques, sont subdivisées d'après la nature des matériaux.

La sculpture sur ivoire a reconquis une vogue considérable depuis que les Européens se sont installés en Afrique, et ont amené du continent noir, sur nos marchés, les stocks importants de pointes d'ivoire.

Les antiques comme les gothiques et les artistes de la Renaissance ont reconnu le mérite de son grain serré, de son poli et de sa couleur chaude, et l'ont employé à la confection de menues sculptures ou d'objets de toilette et pour les incrustations de l'ébénisterie. Les nombreuses expositions spéciales d'ivoirerie, organisées dans beaucoup de villes d'Allemagne et d'Autriche sous les auspices des Associations d'art industriel, notamment en I892 à Dresde et dernièrement à Vienne, ont attiré l'attention des artisans-artistes sur les ressources décoratives qu'offre l'ivoire; les Musées ont profité de ces expositions pour 
enrichir leurs collections d'ivoirerie par l'achat de produits et d'applications modernes.

Nous remarquons à Vienne, des revêtements de livres, et des fourreaux d'épée très fouillés, des objets de piété, des cassettes en ébène incrustée d'ivoire, des paravents en laque avec appliques de fleurs, d'oiseaux, d'animaux, d'une légèreté extrême, des éventails montés sur ivoire avec des incrustations diverses, etc.

Les collections du Musée, les conférences, la participation aux expositions locales, exercent une influence considérable sur l'enseignement et sur l'industrie artistique; c'est ce qui nous a engage à nous étendre sur leur organisation et sur leur fonctionnement. Le Musée a stimulé l'ardeur des artistes et a ramené l'enseignement dans la vraie voie, en montrant, sous forme d'une brillante exhibition, ce que la nation autrichienne a produit de plus parfait aux époques où elle puisait son art en elle-même.

Les modèles du Musée, au service d'un enseignement théorique et pratique, ont provoqué la renaissance des arts industriels allemands et autrichiens. 


\section{LA BIBLIOTHÈQUE.}

La bibliothèque est le complément indispensable du Musée et elle est, comme lui, un auxiliaire précieux des écoles et des industries. Elle prête ses livres et ses reproductions à l'école et aux personnes, qui désirent les consulter dans la salle de lecture; moyennant certaines garanties, elle leur permet même de les emporter, pour les examiner chez eux.

La bibliothèque est un organisme vivant. Tout comme le Musée, elle a sa tendance, qui se manifeste par le choix des ouvres, par les conférences au sujet des nouvelles acquisitions. Elle combat les déviations du goùt public en fournissant aux ateliers des reproductions d'objets d'art irréprochables au point de vue de l'esthétique.

\section{ORGANISATION.}

Nous avons de la peine à nous faire une idée de la promptitude et de l'exactitude avec lesquelles un personnel, relativement restreint, parvient à servir la nombreuse clientèle de gens de métier, qui se pressent dans la salle de lecture. L'accès de la bibliothèque est d'ailleurs si aisé, le livre ou l'estampe 
désirés s'obtiennent si facilement, que l'artisan n'a pas peur d'y étaler sa maladresse ni son ignorance; il ose s'y rendre. Cette organisation simple et logique est une des causes de la vogue considérable des bibliothèques d'art industriel.

La statistique signale pour I8g3, à Dresde, 45.820 visiteurs, dont I0.450 ayant emprunté des objets : livres ou reproductions.

Le but de l'institution est donc largement atteint; elle met en circulation les reproductions gravées, photo- ou lithographiques des objets qui intéressent l'artisan, et augmentent ainsi le stock des formes en usage dans les industries d'art.

\section{CLASSEMENT.}

La bibliothèque comprend :

Io les volumes;

$2^{\circ}$ les estampes, reproductions et dessins originaux;

3o les périodiques.

LES VOLUMES.

Un premier catalogue énumère les volumes à texte continu d'après leur sujet, par ordre alphabétique. Ex.: Aigles, Bronzes, Costumes, etc. 
Ce premier catalogue renvoie à un second, qui reprend les mêmes groupes et les détaille, en prenant pour base l'ordre alphabétique de la matière, dont les aigles, par exemple, sont confectionnés. Le groupe Aigle, notamment, comprend : Bois, Bronze, Cuir, Cuivre, $P$ ierre sculptée, etc.

\section{LES GRAVURES}

sont classées d'après le même système ; toutes les gravurcs concernant l'Aigle sont enfermées dans une série de boîtes, et dans chacune de celles-ci, elles sont rangées par ordre chronologique, c'est-à-dire d'après les styles.

Elles sont attachées avec un soin méticuleux, par des languettes de papier gommé sur des feuilles en carton blanc.

Un visiteur désire-t-il consultcr, par exemple, les documents relatifs aux aigles armoriés, sculptés sur pierre $\mathrm{du} \mathrm{xv}^{\mathrm{e}}$ siècle, il cherche au catalogue I le chapitre Aigle, en regard duquel il remarque un numéro, qui renvoie au catalogue II. Là il trouve sous la même rubrique : - Aigle - Pierre sculptée - les indications nécessaires à la confection de son bulletin.

L'employé met sans aucun tâtonnement la main sur l'estampe désirée, et épargne ainsi au visiteur un temps précieux. 
LES PÉRIODIQUES.

Les deux cent-vingt périodiques sont renseignées par ordre alphabétique dans un catalogue spécial.

Les gravures ordinaires, prêtées, sont placées dans un passe-partout en carton, les gravures plus précieuses ou plus rares sont glissées dans un passe-partout en bois, sous verre. Cette disposition évite l'endommagement de la feuille, et, quoiqu'elle permette aux élèves de l'examiner en détail, elle leur empêche de la copier servilement.

La bibliothèque de l'Ecole des Métiers d'art de Dresde, supérieurement organisée, possède, outre la salle de lecture, un vaste auditoire, où se donnent périodiquement des conférences. Les murs sont revêtus de 45 mètres carrés de châssis dans lesquels on expose les nouvelles acquisitions et les documents relatifs à quelque spécialité du jour.

Dès qu'une œuvre importante paraît, elle est exposée dans l'auditoire, et des conférences son organisées pour en faire ressortir le caractère, la valeur et le parti que les différents métiers peuvent en tirer. La direction prévient, par une notice aux journaux, les 
artisans et les amateurs, qui ne manquent pas de répondre à l'appel.

Une description plus complète pourrait sembler méticuleuse. Elle ne serait certes pas inutile pour notre pays, où une bibliothèque des arts industriels est chose inconnue. Les documents les plus précieux sont enfouis dans les rayons, sous une couche de poussière, tandis qu'en Allemagne et en Autriche ils circulent entre les mains des artisans et des amateurs.

La bibliothèque s'est conquis une place importante dans la vie industrielle; elle exerce, grâce à son organisation parfaite, une influence considérable sur la culture esthétique de la masse des artisans. Mieux encore que le Musée, et à moindre frais et risques, elle fait pénétrer jusque dans les plus humbles ateliers, la reproduction de toutes les œuvres qui illustrent le travail artistique de tous les pays.

En stimulant les travailleurs à se perfectionner, la bibliothèque des arts industriels concourt au relèvement du niveau professionnel des artisans. 
Le Batiment.

Le bâtiment de l'Ecole est exactement semblable à celui du Musée. Une entrée monumentale conduit à un vestibule orné de sculptures décoratives. Le bâtiment se développe en quadrilatère autour d'une cour intérieure; les classes et les ateliers prennent jour sur le parc et sur le Stubenring.

\section{But de L'ÉCOLE.}

L'Ecole des arts industriels est une institution centrale supérieure, destinée à former des ouvriers artistes, capables de s'affranchir des anciennes formules et d'exprimer leurs sentiments et leurs pensées dans la conception et dans la décoration des objets de leur métier.

Une école normale pour professeurs de dessin des écoles moyennes et des écoles d'arts appliqués y est annexée.

Cours normaux POUR LES PROFESSEURS DE DESSIN.

Les gouvernements allemand et autrichien 
se sont appliqués, dès le début du mouvement actuel, à former pour les écoles de tous les degrés, des professeurs capables d'enseigner, outre le dessin ornemental et théorique, les éléments graphiques des métiers. Dans ce but les écoles d'art industriel de Tienne, de Dresde et de Munich, comme celles de Berlin, de Leipsig, etc., tant de l'État impérial que des États fédérés, ont organisé des cours normaux.

L'enseignement normal moyen du dessin, créé à Vienne, par arrêté ministériel du 7 aoùt 1872 , comprend trois années d'études.

Pour être admis à ces cours, il faut :

I E Etre âgé de 16 ans accomplis; $2^{\circ}$ avoir terminé ses études moyennes; 30 posséder le degré d'aptitude au dessin, correspondant au programme des écoles moyennes.

Le programme porte :

a) Le dessin de l'ornement en relief et l'étude de l'ornement polychrome; exercices de composition.

b) L'étude de l'ornement et des styles; exercices d'application; dessin du bâtiment.

c) Les éléments des projections, y compris les projections des ombres; la perspective ; cxercices. 
d) La théorie des couleurs ; pratique du lavis.

e) L'anatomie pittoresque.

f) Exercices pratiques d'enseignement.

Les professeurs sont pénétrés des méthodes pratiques du travail qui règnent dans les écoles ; ils orienteront l'esprit de leurs élèves vers les métiers et leur montreront le chemin des écoles professionnelles.

\section{L'ADMISSION DES DAMES.}

Les dames sont admises, dans la mesure des convenances, à participer à l'enseignement. Leurs travaux de broderie, de dentelle, d'émail, de peinture sur porcelaine et sur verre démontrent à l'évidence la supériorité du sexe féminin pour ces métiers, dans lesquelles la femme peut appliquer ses qualités naturelles : l'imagination, la persévérance et la grâce.

Le manque de place dans les classes préparatoires limite encore le nombre d'admissions. Le principe pourra recevoir une application complète, lorsqu'un local spécial pour les cours généraux aura été créé; plus de jeunes filles pourront alors être admises aux études et se faire une position honorable dans une des carrières relevant des arts décoratifs. 


\section{Plan des Études.}

L'enseignement se divise en :

I. Cours préparatoires;

II. Cours professionnels;

III.Ateliers.

\section{COURS PRÉPARATOIRES.}

Pour ètre admis comme élève régulier il faut :

Etre âgé de I4 ans, avoir terminé les études de l'école moyenne, prouver une certaine aptitude au dessin, payer une taxe unique de 2 florins à l'entrée, une taxe annuelle fixe de 3 florins, en outre une rétribution scolaire annuelle de is florins.

Les élèves qui possèdent une éducation technique ou artistique plus complète, peuvent être admis d'emblée aux cours professionnels.

L'enseignement de la division préparatoire a pour but de donner aux élèves le degré de culture artistique, l'aptitude manuelle au dessin et au modelage et les connaissances théoriques nécessaires, pour approfondir avec succès l'étude d'un métier d'art. 


\section{- I96 -}

\section{BRANCHES.}

Les branches principales sont le dessin et le modelage; les cours théoriques comprennent les projections, la perspective, l'étude de l'ornement et des formes architecturales y compris le dessin des ordres, - les élèves, qui se destinent à l'industrie textile, étudient l'ornement textile, - enfin la chimie industrielle et l'anatomie pittoresque.

\section{LE DESSIN.}

Les méthodes se rapprochent sensiblement de celles en vigueur aux écoles des métiers artistiques de Berlin.

Quand l'élève a copié en contour et en exécution achevée quelques bons spécimens d'ornements caractéristiques pour chaque période remarquable, et qu'il a ainsi récapitulé pratiquement les notions théoriques de l'historie de l'ornement et des formes architectoniques; quand, en outre, il a acquis une certaine habileté au dessin de la flore et de la faune, et que ses dispositions pour une profession déterminée commencent à se révéler, il s'applique plus spécialement à l'étude des modèles, conduisant au métier rers lequel il se sent attiré.

Le ferronnier et l'orfèvre, étudient alors des 
modèles en nature de ferronneries et de pièces d'orfèvrerie des différentes époques, qu'ils empruntent au Musée; ils dessinent, en contour, les fleurs et les animaux, qui, par leur caractère ou leur forme peuvent entrer dans la décoration des objets de leurs métiers respectifs. Les futurs graveurs se préparent à leur profession par les exercices de dessin à la plume, d'après de menus objets, tels que: insectes, fleurs, bourgeons, etc., présentés sous tous leurs aspects, et d'après des ornements en plâtre; ils s'exercent entretemps à la copie réduite ou agrandie de gravures des différents procédés et des différentes époques.

Les peintres-décorateurs acquièrent une sùreté suffisante dans le dessin ombré par la reproduction de l'ornement, du masque, du buste et du torse; ils accroissent leur provision de formes et leur habileté manuelle par l'interprétation de la flore et de la faune; ils développent la mémoire et l'imagination créatrice par la composition, et complètent leur éducation esthétique par l'étude de l'anatomie pittoresque.

Les ébénistes, menuisiers et sculpteurs sur bois trouvent au Musée des modèles admirables pour l'étude des éléments de leurs professions. Ils copient en croquis, en grandeur 
nature ou d'après certaines proportions, des parties de meubles de tous les styles, et se rendent ainsi compte des ressources inépuisables qu'offrent les collections.

Les dessinateurs en tissus et en dentelles, les peintres sur porcelaine et sur verre, les céramistes et les émailleurs sur métal utilisent, de même, les objets du Musée, dans le double but d'étudier le caractère et l'ornement spéciaux à leur métier dans tous les temps et d'exercer leurs facultés dans le sens professionnel.

\section{LE MODELAGE.}

Dans les cours généraux, le modelage marche de front avec le dessin. Les élèves modèlent d'après une série de moulages minutieusement gradués : des fragments simples d'ornements architecturaux, des rinceaux, des panneaux avec figure, etc.; ils entremêlent ces exercices d'études d'après la flore et la faune, qu'ils appliquent à des petites compositions. Ils traduisent des hauts-reliefs en bas-reliefs et réciproquement, et s'appliquent au modelage d'après des dessins et des photographies.

Lorsqu'ils ont fait le choix d'une profession, ils étudient des sujets plus en rapport avec 


\section{- 199 -}

leur but et d'après les procédés en usage : les orfèvres-ciseleurs et les repousseurs modèlent, en cire, des bijoux et pièces d'orfèvrerie ou de petits objets gracieux, tels que carabes, papillons, fleurs, fruits, coquillages, etc.; les ferronniers, d'après des dessin de ferrailles, les sculpteurs d'après des modèles intéressants de toutes les époques classiques.

\section{Les cours oraux. a) Les Projections.}

L'école de Vienne assigne une importance considérable au cours fondamental des frojections. L'étude de cette branche des mathématiques apprend aux élèves de représenter sur une surface, les formes, la position, la structure, les dimensions d'un objet dans toutes ses parties.

Pour être exécuté à l'atelier, le dessin d'un meuble, d'une ferraille, d'une pièce d'orfèvrerie, etc., doit renseigner exactement toutes ces données, et être complété d'une vue d'ensemble, qui donne une idée de l'aspect et de la décoration de l'objet: le dessin pittoresque procède de la perspective.

$$
\text { b) La Perspective. }
$$

Le cours de perspective est le complément 
indispensable au cours de projections. Il est plutòt éducatif et a pour but, à en juger par les travaux que nous avons pu voir, de donner aux élèves le sens du relief et des directions des lignes, de les familiariser avec les déformations apparentes que subissent les lignes d'après le point de vue du spectateur. En effet, dès que l'élève a étudié les constructions fondamentales de la perspective, il se borne à faire les croquis des objets et à vérifier par des constructions de plus en plus simples, si la direction des grandes lignes est conforme aux lois de la perspective.

\section{c) Histoire de l'Ornement.}

Le cours de l'ornement et des formes architecturales est l'étude raisonnée et intuitive des transformations quel'ornement et les éléments architecturaux ont subis chez les différents peuples à travers les époques remarquables de leur histoire.

Le Musée offre encore à cette étude un matériel d'enseignement parfait. Sur des objets en nature, complétés au besoin par des reproductions, le professeur examine le caractère et l'importance de l'ornement géométrique, de la flore, de la faune et de la figure humaine dans la décoration; il montre d'une 
manière palpable, comment l'ornement réflète les idées et les mœurs de son époque et sous quelles influences les éléments architecturaux (moulures, profils) se sont transformés dans le cours des siècles.

Cette étude ouvre l'esprit des élèves sur les ressources décoratives, considérées comme l'expression caractéristique des idées et du sentiment; elle tend à prouver, que l'art industriel moderne doit, pour se développer librement en harmonie avec le tempérament national, emprunter à la Renaissance ses grandes lignes, et à la nature ses éléments décoratifs.

\section{d/ L'Anatomie pittoresque.}

Le cours d'anatomie pittoresque est exclusivement destiné aux élèves qui devront utiliser la figure humaine dans leurs compositions décoratives. Ils étudient le squelette, et, d'après un écorché, les muscles dont le jeu peut amener une modification dans l'aspect de la figure.

L'élève, qui a suivi assidùment les cours préparatoires, possède une éducation artistique et une habileté manuelle sérieuses; il a une idée des styles et des ressources décoratives, possède une notion claire des scien- 
ces exactes qui forment la base des métiers, et il peut commencer avec succès son éducation professionnelle.

\section{LES COURS PROFESSIONNELS.}

\section{Admission.}

Pour ètre admis comme élève régulier aux cours professionnels et aux ateliers, il faut, en règle générale :

Io Ėtre âgé de I7 ans ;

$2^{\circ}$ Posséder les sciences fondamentales et la culture artistique que donnent les cours préparatoires;

3o Payer une contribution scolaire de 30 florins par an; les élèves indigents et doués peuvent être admis gratuitement.

\section{Tendance de L'Enseignement.}

Tout l'enseignement évolue vers quelques spécialités déterminées des arts industriels. L'école se débarrasse ainsi des élèves, qui viendraient encombrer les cours dans le seul but de développer leur talent artistique. Elle a une direction précise, et rejette comme un lest dangereux, tous ceux qui tendraient à dénaturer son enseignement ou à le faire dévier de la ligne qu'elle s'est tracée. 
L'Ecole lutte d'ailleurs vigoureusement contre la tendance fatale des élèves vers les arts purs. A Vienne, à Dresde et à Munich comme dans nos écoles de dessin, les jeunes gens ne sont pas loin de penser, au début, que le métier, fút-il artistique, n'est que médiocrité à côté de l'art si charmant de peindre et de modeler pour la gloire et le renom. Mais le modèle en nature des différentes classes, ramène brutalement l'enseignement et les idées dans la voie de l'industrie.

Les fabricants et les membres de l'Association des Arts industriels tout en utilisant, les services de l'Ecole, lui donnent un puissant appui dans la lutte contre ce préjugé.

Lorsqu'ils désirent créer un article nouveau, ils se rendent à l'école pour mettre au concours le modèle de l'objet. Ils paient les frais du concours et allouent une prime à l'auteur du projet, qui réunit le plus de qualités. Ces concours font connaitre aux élèves les besoins de l'industrie, et dirigent leur activité dans le sens pratique des métiers.

L'Ecole organise aussi des concours mensuels et un concours annuel pour les élèves des différentes classes. Parmi les sujets nous trouvons : Ornements pour étoffes, pour châles etc., projets de tapis, d'encadrement 
de portes dans tel style, de pièces d'argenterie, de dentelles, de papiers peints, de lambris pour telle salle, etc.

D'étape en étape, les élèves sont ainsi appelés à mettre en œuvre leurs connaissances et leur habileté acquises en créant des projets, pour lesquels on précise les dimensions, la nature des matériaux et toutes les indications nécessaires à l'exécution à l'atelier.

Afin de permettre aux élèves indigents de tirer quelque parti de leurs travaux, la direction leur permet d'exécuter des commandes privées, qui tombent dans le cadre des études. Les relations intimes qui s'établissent de cette manière entre l'atelier et l'école, exercent une influence réciproque très salutaire. Les travaux conçus à l'Ecole d'après la tendance du Musée, servent de modèle à l'atelier et forment le goùt des ouvriers; l'exécution de commandes privées à l'Ecole, stimule l'ardeur et l'esprit inventif des élèves.

Division de L'ENSEIGNEMENT PROFESSIONNEL.

L'enseignement professionnel procède des trois branches de l'art plastique : de l'architecture, de la sculpture et de la peinture; il est strictement limité aux applications à l'industrie. 
I. La classe d'architecture a pour objectif l'étude des métiers qui travaillent le bois, le métal, la pierre, le verre, etc.

II. La classe de sculpture forme les sculpteurs, les stuccateurs, les orfèvres et les céramistes.

III. La classe de peinture conduit à la gravure, à la peinture décorative, aux arts textiles : la broderie, les étoffes, les dentelles etc.

Pour toutes les branches de l'art industriel, - lorsque l'installation est possible à l'école, - le maniement de l'outil marche de front avec les études théoriques, la composition avec l'exécution.

Dans ce but, on a organisé des ateliers

Io de ciselure et de repoussage;

$2^{\circ}$ de sculpture sur bois;

30 d'émaillerie et de céramique;

$4^{\circ}$ de dessin de dentelles;

$5^{\circ}$ de gravure sur bois;

6o de gravure sur métal.

\section{i. Classe d'architecture.}

Un cours d'architecture proprement dit n'existe pas à l'Ecole supérieure des Arts industriels de Vienne. On comprend sous 
cette appellation tous les métiers, dont les objets rappellant de près ou de loin une forme architecturale.

Parallèlement à l'étude directe de leur métier, les élèves suivent les leçons d'histoire de l'art et d'histoire des techniques, ils assistent aux expériences. sur les matériaux et dessinent d'après le modèle vivant.

Le but de la classe d'architecture, comme de toutes les classes professionnelles, est d'initier l'élève à la composition : les trois années d'enseignement préparatoire ont cultivé le goùt, les aptitudes, la mémoire des formes, par l'étude patiente de l'ornement emprunté au métier; l'intelligence s'est ouverte par les cours oraux, et l'imagination créatrice s'est formée par les exercices de composition, par les concours mensuels et annuels. Aussi, le cours de composition avance-t-il très loin les élèves dans leurs métiers respectifs.

Classe des Ébénistes.

Les ébénistes et les menuisiers forment une division importante de la classe d'architecture.

L'enseignement de l'industrie artistique du bois donnera une idée de la méthode suivie dans les autres cours. 


\section{$-207-$}

Les élèves ont devant eux un meuble, qu'ils étudient dans ses parties au double point de vue de l'ornementation et de la structure architectonique. Ces parties sont dessinées en grandeur nature ou en réduction, avec les coupes et les indications indispensables; une vue pittoresque complète ce dessin. L'étude de la partie mène insensiblement au tout, suivant une marche synthétique très logique.

On comprend que cette première étape n'est franchie qu'après une longue et patiente étude.

Quand l'élève se rend bien compte de la structure du meuble, il s'applique à le transformer en vue des usages modernes et le revèt d'une décoration en rapport avec cette usage et dans un style donné. Parmi les meubles et pièces de menuiserie ou d'ébénisterie servant de modèles, nous avons remarqué deux superbes bahuts Henri II, à deux vantaux : l'un merveilleux par son architecture élégante, l'autre par quatre bas-reliefs - les quatre saisons - et par un médaillon central, sculpture admirable par la délicatesse du modelé et par la grâce de la forme. Les élèves étudiaient le modèle, chacun à son point de vue et le prenaient comme point de départ de 


\section{$-208-$}

la composition d'un meuble moderne, dans le style Henri II.

Il est inutile d'insister sur la valeur éducative d'une telle méthode.

Pour développer leur talent et leurs aptitudes sous toutes les faces, les élèves étudient une série de meubles variés de forme, d'usage et de style.

Cette seconde étape est généralement franchie en une année. A mesure que les études avancent, les élèves continuent à composer dans un style déterminé; mais à côté de ces études de transformation ou d'adaptation, ils font des compositions dans lesquelles ils s'affranchissent de plus en plus des anciens; ils se laissent aller à leur imagination et composent en s'inspirant d'eux-mêmes, en appliquant la figure humaine, la flore, la faune, librement interprétées; ils créent ces charmants meubles à ornementation originale, élégante et discrète, qui caractérise l'ébénisterie viennoise.

Aux cours pour ferronniers, marbriers, céramistes, verriers, dessinateurs de tissus, le modèle d'après nature emprunté du Musée est aussi le point de départ; tout l'enseignement chemine vers la composition libre, ou subordonnée à certaines conditions 
d'usage, de style et de matériaux.

\section{LA PEINTURE.}

Ce cours apprend aux élèves les différents procédés de peinture : la peinture décorative, la peinture sur verre, sur porcelaine, la gravure et le dessin spécial de dentelles.

Les études se font strictement d'après nature; d'abord d'après des objets isolés, tels que coquillages, fleurs, fruits, rinceaux, oiseaux et animaux, etc.; puis d'après ces mêmes objets arrangés en sujets décoratifs avec des étoffes, des vases, des plats, etc., empruntés au Musée.

Un horticulteur fournit des fleurs ornementales pendant toute l'anriée.

La peinture se réduit d'abord à la simple copie; ce cours exerce les élèves au choix et au mélange des tons et développe le sens de la couleur. Les sujets, méticuleusement choisis et variés, parcourent toute la gamme des tonalités et sont groupés de manière à former des oppositions harmonieuses.

A mesure que les études avancent, le professeur attire l'attention des élèves sur les principes de la décoration : l'unité, l'harmonie dans la forme et dans les couleurs, la distribution pondérée du sujet, etc. Il leur apprend 
à saisir les traits caractéristiques des objets, et à déposer un accent personnel clans leur travail; ainsi ce cours s'élève à l'interprétation. Quand le professeur juge le moment arrivé, il permet aux élèves de s'exercer à la peinture du modèle vivant dans ces grands plans et suivant les procédés de leurs métiers respectifs.

Les sujets de compositions à domicile et les concours mensuels permettent aux élèves de développer leur imagination dans le sens professionnel. Ces compositions et ces concours préparent directement aux études des ateliers spéciaux de peinture décorative, de gravure, d'émaillerie et de céramique.

\section{Le modelage.}

Les exercices de modelage conservent un caractère général et sont choisis, sans tenir compte de la future profession des élèves.

Le modelage enseigne la composition décorative en vue de la sculpture sur bois, de la décoration du bâtiment, de l'orfèvrerie, de la céramique, et prépare à l'atelier de sculpture. Les élèves étudient d'abord les modèles classiques de leurs professions; ils en transforment l'ornementation et y substituent un autre rinceau, une autre fleur, un autre 
animal, interprétés d'après les différents styles; ils finissent par créer l'objet et sa décoration.

L'étude du modèle vivant, obligatoire pour tous les élèves de cette classe, est le point de départ d'une série d'applications : substitution d'une figure étudiée à une figure classique dans un ensemble ornemental, composition décorative pour un objet dans lequel la figure humaine forme l'élément principal.

Les trois classes fondamentales : l'architecture, la peinture et la sculpture, ont surtout un but éducatif ; elles donnent aux élèves le moyen de recueillir les matériaux, d'acquérir les aptitudes et la culture artistique nécessaires à l'étude du métier d'art; leur enseignement progresse graduellement et méthodiquement vers les ateliers spéciaux. 
III. LES ATELIERS.

\section{L'ATELIER DU PROFESSEUR.}

Les professeurs ont un atelier particulier, attenant à celui des élèves. Sans être des industriels, ils reçoivent des commandes qui cadrent plus ou moins avec les études, les exécutent à l'école et complètent ainsi leurs appointements.

Les élèves les plus avancés peuvent être admis à collaborer à ces travaux, et cela dans le seul intérêt de leurs études, sans que, réglementairement, ils aient droit à aucune rémunération.

L'atelier du professeur n'existe nulle part en Belgique joint aux écoles d'art industriel; et cependant, rien n'est plus propre à favoriser les études.

Le professeur n'a pas à craindre de tomber dans la routine; les commandes privées le tiennent au courant du progrès des idées et de l'évolution des formes; elles talonnent sans cesse son effort vers le mieux, le forcent à approfondir son art, à marcher à la tête du travail artistique, à frayer la voie à la fabrication. Aussi les travaux exécutés pour 
l'industrie, lui assurent vis-à-vis des élèves un prestige précieux. Il donne un enseignement permanent par l'exemple.

Le professeur n'est pas méticuleusement tenu à la disposition des élèves de telle à telle heure, parce que le tempérament artistique le plus solide doit se fausser à la longue par un régime aussi déprimant; il se retrempe dans ses travaux privés.

Dans cette intimité professionnelle l'apprentissage des élèves se fait dans les meilleures conditions; tous les travaux du professeur étant destinés au public, l'enseignement, pénétré de l'esprit moderne, est constamment vivifié par le contact avec les idées du dehors.

\section{L'ATELIER DES ÉLÈVES.}

Dès le début du mouvement en faveur de l'enseignement professionnel, les Associations d'art industriel et la Direction des écoles et des musées examinèrent, si l'industrie pourrait employer tous les jeunes gens, auxquels les nombreuses écoles nouvelles donneraient des aptitudes théoriques au dessin et au modelage. Les faits leurs prouvèrent déjà alors, que l'industrie n'utilise que fort peu de dessinateurs et de modeleurs, que, pour se relever, elle a surtout besoin d'ouvriers- 
artistes, capables de concevoir et d'exécuter les objets de leur métier et d'exercer sur leurs compagnons une influence éducative.

Pour sauver, d'autre part, les derniers vestiges de la tradition du travail artistique, l'organisation d'un apprentissage s'imposait plus impérieusement, à mesure que la mécanisation et la division du travail de plus en plus envahissantes rendaient la formation des artisans presque impossible à l'atelier. Les discussions dans les congrès germanoautrichiens et au sein des associations d'art industriel avaient fait naitre la conviction, qu'un retour aux belles époques de l'art national pouvait seul ranimer l'industrie artistique, qui se ravalait à copier servilement les produits étrangers. Or, le seul moyen d'acquérir sur l'industrie une influence suffisante pour la faire sortir de l'ornière, était de lui procurer des artisans d'élite, qui pouvaient prêcher d'exemple en créant et en exécutant des objets dont la forme se rattachait à la Renaissance, mais mise en harmonie avec les besoins modernes.

C'est sous l'empire de ces préoccupations et pour obvier à tous les inconvénients qu'il fut décicé, que les cours professionnels se 
développeraient en gradation logique jusqu'aux ateliers.

\section{L'ATELIER DE CISELURE, DE REPOUSSAGE : ORFĖVRERIE.}

Pour être admis à cet atelier, les élèves doivent, en dehors des conditions générales d'admission, fournir la preuve qu'ils possèdent une aptitude très prononcée au dessin et au modelage ornementaux et figuraux. Ils doivent avoir suivi avec succès le cours d'anatomie pittoresque, d'histoire de l'ornement, et justifier des connaissances élémentaires des projections et de la perspective.

Ceux qui ont des notions de ciselure sont admis de préférence.

Les élèves assistent aux cours pratiques et aux leçons de chimie industrielle, d'histoire de l'art et des styles, et à l'étude des matériaux; ils dessinent d'après le modèle vivant en vue des applications décoratives.

L'enseignement de l'atelier comprend l'étude pratique et théorique de la ciselure, du repoussage et des branches parentes.

A. Le Repoussage.

MÉTHODE.

Les écoles de Dresde et de Vienne ensei- 
gnent sensiblement d'après une série de seize modèles analogues, basés sur le même principe. Ces modèles ont été acquis par le Gouvernement saxon et par le Gouvernement autrichien et ne peuvent être reproduits sans leur consentement.

\section{L'ornement plan.}

Quatre modèles en métal forment une première série, d'après laquelle l'élève travaille pour s'exercer au maniement des outils. Ce sont des ornements géométriques plans, des carrés, des hexagones, des cercles concentriques, une volute, qui présentent les premières difficultés du travail au ciselet.

Lorsque l'élève a copié la série en grandeur nature, en réduction ou en agrandissement, il applique les notions acquises, en abordant une deuxième série d'ornements plans: contours d'une feuille, d'une fleur, d'un rinceau, d'un ornement complet. Il s'exerce entretemps à la copie d'ornements, de gravures ou de dessins de sa propre composition, afin de développer son habileté en tous sens.

On ne permet pas aux élèves la copie d'après nature; les modèles sont tous des interprétations : un coup de burin mal 
appliqué, détruit le caractère de l'ornement ; l'élève est ainsi obligé de s'adonner au travail avec une attention soutenue, et de s'appliquer à la copie exacte du modèle.

\section{L'ornement en relief.}

Une feuille, interprétée encore, est reproduite dans ses différentes phases d'exécution sur quatre plaques de cuivre $:$ I $^{\circ}$ le contour; $2^{\circ}$ la feuille repoussée dans ses grandes masses; 30 la feuille refoulée au point; $4^{\circ}$ achevée.

L'élève modèle d'abord, en cire, la feuille à reproduire, et réalise en métal la série de quatre modèles, qui présentent aussi, une à une, les difficultés du repoussage et de la ciselure.

Il applique ces notions dans l'étude d'ornements analogues et dans l'exécution de petits sujets décoratifs : rinceaux, guirlandes et d'autres objets de forme gracieuse. L'apprentissage s'élargit par l'étude d'objets du métier empruntés au musée, et par la composition de plats, de pièces d'orfèvrerie, etc.

\section{La figure.}

Le repoussage de la figure est enseigné d'après une série de quatre modèles, qui 
présentent la figure humaine dans les différentes phases d'exécution : Io tête repoussée dans ses grandes masses; $2^{\circ}$ limitée dans ses contours et refoulée au point; $3^{\circ}$ achevée dans ses grands plans; $4^{\circ}$ achevée complètement.

L'étude patiente de ces modèles conduit graduellement à l'exécution de travaux complets tels que, services de table, calices, bonbonnières, bijoux, etc. etc., que l'élève modèle d'abord en cire, exécute en métal par fragments, soude et polit.

\section{B. La Ciselure.}

Pour que l'élève acquière des idées générales et possède toutes les ressources de sa profession, le professeur évite de le cantonner dans une spécialité; il étudie toutes les branches de son art, et aussi la ciselure, très ardue et très longue à apprendre, mais assez rémunératrice.

Il s'exerce au ciselage d'une série d'objets en bronze ou en cuivre fondu, d'après des modèles créés par lui, des clinches de portes, des accessoires de meubles, des objets à décoration figurale, tels que fourreaux et poignées d'épée, pendules, jardinières, vases, 
candélabres, cassettes, objets de piété, statuettes, etc.

Fidèle aux principes de l'école, l'atelier fait marcher de front l'éducation artistique et l'éducation technique. Les superbes collections d'orfèvrerie du musée, les gravures de la bibliothèque servent de point de départ aux études; cependant, tout en se rattachant visiblement à la Renaissance, elles laissent un champ libre à l'interprétation de la nature. Les nombreuses commandes privées permettent aux élèves de se préparer à la vie pratique, et leur donnent l'occasion d'exécuter des travaux d'après des données : dimensions, style et prix.

L'atelier de M. Schwartz de Vienne, comme du reste celui de M. Richter à Dresde, est hautement apprécié à l'étranger; il peut ètre considéré comme la perfection clans son genre. Le syndicat des orfèvres parisiens n'a pas dédaigné d'y envoyer des délégués chargés d'en étudier l'organisation, afin de l'appliquer à l'école qu'il vient de fonder.

M. Schwartz a fourni à cette industrie charmante des ouvriers-artistes, qui ont régénéré l'orfèvrerie et affirmé au dehors la supériorité de l'article viennois. 
2. L'ATELIER DE SCULPTURE SUR BOIS.

L'art de la sculpture sur bois et sur ivoire si brillant à l'époque de la Renaissance flamande n'est plus, dans la fabrication du meuble actuel, que l'ombre, la parodie de ce qu'il était alors. Le meuble de Malines, le seul caractéristique en notre pays, présente une ornementation monotone, faite d'après une formule fixe : un rinceau et quelques bustes plus ou moins moyenâgeux, invariablement reproduits sur les meubles de tous prix et de toutes dimensions. C'est l'ancien falsifié! Aucune recherche de nouveau, de la copie éternellement recommencée !

Aucun enseignement spécial n'existe d'ailleurs pour former des sculpteurs sur bois, capables de créer et d'exprimer leurs sentiments et leurs idées. Il y a bien le modelage des " académies ", mais malheureusement, dès que le jeune homme est à même de modeler une tète, il se croit appelé à de plus hautes destinées; comme sculpteur ornemaniste, il pourrait se faire une brillante position; seulement, son rève est de devenir sculpteur tout court; le sculpteur, lui, s'affuble du nom de statuaire!

La sculpture sur bois est un art distingué, 
qui assure une position stable et d'avenir; il sera toujours impossible de remplacer le travail manuel par la mécanique. Il est vrai qu'il exige cinq années d'apprentissage, au moins, et qu'il est difficile.

Chaque pays reprend sa Renaissance pour se créer une architecture et un ameublement nationaux; le manque de bons sculpteurs sur bois ralentit l'épanouissement de cette excellente tendance.

C'est dans le but de combler cette lacune, que les écoles d'art industriel de Tienne, de Dresde et de Munich se sont annexé des ateliers spéciaux de sculpture sur bois et sur ivoire.

L'atelier de M. Klotz, professeur à Vienne, nous donne une idée assez nette de ce que devait ètre l'apprentissage de ce métier artistique jusqu'à la fin du xviII ${ }^{e}$ siècle, c'està-dire sous le régime des corporations.

De nos jours l'élève sculpteur n'a,il est vrai, qu'une partie de meuble à exécuter, notamment l'ornementation; c'est une concession à la division extrême du travail; cependant, grâce à un enseignement varié, ses études de l'architecture et des styles lui permettent de concevoir simultanément l'ornement et la structure architectonique du meuble : il 
deviendra un ouvrier complet.

\section{MÉTHODE.}

Les élèves apprennent le maniement de l'outil par la copie d'une série de modèles gradués, frgurant un ornement dans ses clifférentes phases d'exécution.

Io Feuille interprétée, ébauchée dans ses grandes masses; - même feuille avec indication plus précise des nuances; - enfin achevée complètement;

$2^{\circ}$ Fleurs, fruits, rinceaux, draperies.

Ces premiers exercices sont complétés par des copies d'après des meubles de choix des belles époques, et par des études d'après des ornements, conçus et modelés en terre par l'élève même.

Le modelage d'après le modèle vivant, étudié parallèlement, introduit à l'interprétation décorative de la figure humaine.

L'étude de la figure est d'autant plus indispensable, que la décoration actuelle du meuble ne se maintient plus aussi strictement qu'autrefois dans les limites de l'ornement. La sculpture sur bois a une tendance à élever son niveau d'art.

La figure est étudiée d'après une série de 
modèles qui la montrent dans ses phases successives d'achèrement:

Io Figure dans ses cubes et dans ses grandes proportions;

$2^{\circ}$ même figure avec indication plus détaillée des parties, et enfin

3o achevée complètement.

Sous forme de travaux à domicile et de concours mensuels, les élèves esquissent des compositions, telles que cadres, médaillons, panneaux, encadrements de portes, ornements pour meubles, lambris et caissons de plafond et les exécutent à l'atelier sous la direction du professeur. Les fabricants font fréquemment des commandes de modèles pour leurs industries, et offrent aux élèves l'occasion d'exercer leur esprit inventif et de se préparer à la pratique du métier.

L'atelier a repris les traditions des corporations, non seulement par l'esprit de confraternité et par l'éducation variée et intégrale des sculpteurs sur bois, mais plus encore par le procédé de sculpture.

Le professeur a renoncé à la mise au point et apprend aux élèves à modeler librement le bois, tout comme les artistes de la Renaissance; ils enlèvent l'ornement et la figure au bout de l'outil. Ils gâchent longtemps et 
gaspillent beaucoup de bois, au début; ils parviennent cependant à une telle assurance dans le maniement du ciseau, qu'ils finissent par donner au bois, directement et avec aisance, toutes les formes que leur inspirent leurs sentiments.

La sculpture sur ivoire n'est qu'une application spéciale du métier précédent, et s'enseigne d'après les mêmes principes : l'élève préparé à la sculpture sur bois, parvient à modeler directement, avec la même précision, les objets de piété, les statuettes, les objets de fantaisie et de toilette en ivoire, en se servant de la lime, de la râpe et du grattoir.

L'étude approfondie des œuvres du passé dans lesquelles les artisans mettaient tant de goùt et d'intelligence, cultive à un haut degré le sens artistique des élèves. L'étude de la nature introduit des éléments nouveaux dans la décoration et permet de créer une ornementation caractéristique bien moderne. 


\section{SUJETS DE CONCOURS.}

Nous ne saurions, pour terminer, mieux définir l'esprit des écoles de métiers, qu'en transcrivant littéralement la traduction des sujets du concours pour aoùt I 893 à Munich.

I. - Industrie du meuble, menuiserie. - Projet de salle à manger - lambris, portes, fenêtres, mobilier. - Le dessin (plan, élévation et coupes) peut être réduit à $\mathrm{I} / 4^{\circ}$ et fait avec une teinte d'ombre. Le buffet seul doit être dessiné à ${ }^{I} /$ ro et lavé soigneusement aux couleurs. Style au choix.

II. - Modelage et sculpture. - Une fontaine pratique pour cabinet de travail. - Le bassin doit être relié au récipient. - Matière : bronze. - Style au choix. - Hauteur, o.8o m. Le projet doit être fourni en plâtre.

III. - Industrie décorative. - a) Un particulier désire orner sa maison (en Renaissance italienne) d'une frise en majolique, dans le goût florentin. Dimensions : longueur 6.3o m., largeur I.05 m. La frise est à I2 m. du sol. Dessin $1 /$ ıo coloré - 2 carreaux doivent être exécutés complètement. Observation : $\mathrm{Ne}$ pas trop découper le dessin par les joints, 
et maintenir la peinture dans la tonalité de la majolique italienne.

b) Broderie pour tapisser un boudoir. Style : rocaille.

Le fond est une étoffe de soie bleu-pâle; les broderies : or et soie de couleur; les cadres sont en bois sculpté. La couleur de la frise : soie gris-bleu sans décoration. Projet I/ro. Exécution : 2 parois grandeur nature.

IV. - Arts graphiques. - Affiche pour fabrique de machines. Le projet doit être exécuté en chromolithographie; Io à I2 couleurs et or.

Dessin : grandeur nature. Dimensions r.10/0.75 m.

V. - La ciselure. Une corne à boire posée sur pied, pour société de chasseurs. Dessin : grandeur nature. Le pied en bronze, la corne avec monture en argent.

VI. Professeur de dessin. - a) Projet de diplôme d'honneur à offrir à un architecte, qui a construit une église. Dimensions : $0.80 \%$. 60 m. Exécution colorée.

b) Etui en cuir avec fermoir, initiales et revêtement de métal : Renaissance. 


\section{XII. - CONCLUSION}

Notre enseignement primaire et moyen du second degré, qui est destiné au monde des ouvriers et de la petite bourgeoisie travailleuse, détourne les élèves des professions manuelles; nos rares écoles d'art et d'industrie n'inspirent pas aux jeunes gens l'amour du métier, l'enseignement nécessairement théorique, en l'absence d'ateliers, ne saurait ètre animé d'un esprit suffisamment industriel pour combattre la tendance irrésistible vers le grand art.

Nous avons toujours constaté avec peine, que les jeunes gens de I4-I6 ans, quittant les écoles primaires et moyennes, nourrissent un fier dédain pour les métiers, et arouent avec honte la profession de leur parents : leur rêve est de devenir employés. Lorsque les écoles inculquent pareils principes, il n'est pas étonnant que les métiers manuels soient abandonnés. Deviennent seulement artisans, ceux qui 
par manque d'intelligence ou de conduite sont abaissés, en guise de châtiment, à cette dégradation morale qu'entraîne le métier; les autres, les intelligents, forment cette armée de quémandeurs, qui se mettent en mouvement chaque fois que les administrations font appel aux candidats agents de police, gardesconvoi, commis, etc. etc. On voit alors le spectacle lamentable de milliers de jeunes gens instruits, porteurs des plus beaux diplômes, se soumettre avec l'acharnement du désespoir au concours, toujours sans résultat pour la plupart d'entre eux.

Tels sont les fruits de notre enseignement public! Le savoir abstrait est glorifié dans nos écoles populaires et moyennes, parce qu'il suffit aux emplois dans l'administration. Ces pauvres enfants de I2-I4 ans vous dessineront la carte de l'Afrique avec ses moindres sinuosités, et vous énumèreront les caps, les golfes, les montagnes; demandez leur le nom des outils qu'emploie le menuisier ou tout autre artisan, et l'idée qu'ils se font des ingénieuses et simples combinaisons de la menuiserie! Rien. Cependant l'étude scientifique des métiers ne serait-elle pas aussi éducative et aussi utile que n'importe quelle branche de l'école populaire ou moyenne? 
Aux yeux de beaucoup de gens, l'instruction des écoles moyennes surtout, n'aurait plus de raison d'être si, comme en Allemagne, les fonctions de l'Etat et des communes étaient données à des militaires. Ce serait un bonheur, parce que toutes les énergies et toutes les intelligences iraient aux professions manuelles.

Après une ère de grande prospérité, le retour du commerce, de l'industrie et du métier à leur mouvement normal, a fait affluer trop de jeunes gens vers les professions libérales et surtout vers " les bureaux », pour que l'école doive favoriser le courant. Elle doit le combattre vigoureusement en introduisant dans son programme, les éléments des branches qui, tout en cultivant les facultés intellectuelles et morales, apprennent aux élèves des notions intéressantes et utiles, et éveillent leur attention pour les industries et les métiers.

Nous avons vu enseigner à Leipsig, le commerce, l'exportation, l'importation, les voies de communication, un cours sérieux de dessin et de travaux manuels, qui empruntent partiellement leurs modèles à l'industrie et aux métiers locaux.

En quittant l'école, les élèves ont une idée 
des industries en général, et ils estiment très haut le métier manuel.

La formation de professeurs de dessin est la question primordiale; un choix de modèles doit, en second lieu, déterminer la tendance pratique de l'enseignement. Les modèles doivent être en partie ornementaux, et en partie dérivés de la géométrie, afin que leur étude jette les bases exactes et artistiques de tout métier.

Tendance vicieuse de nos ÉCOLEs DE DEssin.

Nos écoles de dessin et d'industrie et des arts décoratifs n'exercent aucune influence dominante sur l'industrie artistique dans l'état actuel de leur organisation. Elles ne s'occupent nullement de l'apprentissage des métiers, attendu qu'elles n'enseignent pas le maniement de l'outil; elles ne favorisent donc pas l'instruction de la moyenne des artisans.

Une foule de jeunes gens y acquièrent des notions théoriques de dessin et de modelage dans un sens plus ou moins professionnel, mais ces connaissances ne sont directement utiles, que par leur application aux industries. Ces écoles forment des dessinateurs et des modeleurs, incapables d'exécuter leurs projets ; ils seront des travailleurs 
intellectuels, des employés, absolument distincts des travailleurs manuels.

C'est par l'adjonction d'ateliers, que les écoles de métiers acquièrent leur véritable caractère d'utilité pratique.

Les cours oraux donnent l'éducation artistique et scientifique, l'atelier fait l'ouvrier : l'école professionnelle complète seule peut former le travailleur intellectucl et manuel à la fois.

Comme le développement des aptitudes dépend en grande partie du milieu dans lequel on vit, l'éducation des artisans doit ètre basée sur l'étude des travaux du passé, le musée d'art industriel, comme la bibliothèque, sont inséparables de l'école; celle-ci ne saurait avoir une direction ni une tendance précises, ni exercer toute sa puissance éducative, sans posséder comme matériel d'enseignement, une collection de travaux modèles, et une bibliothèque pourvue de reproductions et de livres relatifs aux arts industriels.

L'action bienfaisante de l'école ne doit pas ètre limitée aux élèves et aux artisans-artistes, elle doit contribuer à la culture esthétique du public : organiser des conférences, des expositions, ouvrir un bureau de renseignements, une salle de lecture et de dessin 
facilement accessibles au public.

Un organisme aussi complet, dirigé avec enthousiasme, provoquerait une régénérescence des métiers d'art. Pareilles institutions attireraient vers les carrières professionnelles les jeunes gens intelligents, tous les talents épars et fourvoyés; elles relèveraient le niveau de notre travail national, et nous mettraient en situation de lutter avec avantage contre la concurrence étrangère.

\section{But A POURSUIVRE.}

L'école des arts industriels, complétée par les ateliers, ne vise pas uniquement au perfectionnement de la machine humaine, elle réalise un idéal plus élevé.

Elle donne aux futurs ouvriers l'occasion de développer d'une manière générale tous leurs talents et toute leur intelligence, avant qu'ils ne soient obligés par la force des choses à spécialiser à l'atelier.

L'ouvrier actuel est découragé par mille causes, mais surtout par la spécialisation excessive du travail.

Enserré dans une occupation étroite et uniforme, il a perdu toute curiosité intellectuelle et par conséquent toute faculté inventive. Or, par l'organisation d'un apprentissage 
rationnel à l'école, il acquerra d'avance une culture artistique et scientifique suffisante, pour réagir contre les effets déprimants de la division extrême du travail.

L'avénement de la masse du peuple à la vie politique attirera plus encore l'attention des autorités publiques sur les écoles de métiers, ces leviers si puissants du relèvement social des travailleurs. Le temps est proche où l'organisation des écoles d'apprentissage s'imposera impérieusement dans le pays, au détriment des nombreuses "académies " de province. A l'enseignement stérile du grand art entretenu à grands frais jusque dans les villes les plus infimes, succédera l'enseignement fécond du travail artistique.

Deux ou trois académies des beaux-arts suffiraient amplement pour développer les natures vraiment douées, et les besoins artistiques de notre petit pays n'en demandent pas davantage.

Les travailleurs artistes ont surtout droit à la sollicitude des pouvoirs publics; ils sont les véritables éléments d'ordre et les créateurs de la richesse publique : d'un bloc informe de métal ou de bois ils font naître des œuvres d'autant plus précieuses, que leur habileté et leur goût sont plus cultivés. 
Il serait dangereux de laisser enraciner cette idée, qu'ils doivent attendre de quelque bouleversement social le relèvement de leur condition. Les écoles de métiers leur démontreront, que chaque ouvrier de bonne volonté porte en soi son bonheur, que par la culture de son goùt et par le développement de son talent, il rendra son travail plus rémunérateur et relèvera sa condition morale et sociale. 


\section{ÉCOLE DE MÉTIERS ARTISTIQUES}

\section{DE DUSSELDORF}





\section{XIII. - DUSSELDORF}

\section{La Ville.}

La ville de Dusseldorf est située au centre de la région la plus industrielle des bords du Rhin; elle forme une tache riante au milieu de ce fouillis sombre d'usines et de manufactures.

A en juger par son enseignement artistique, elle est à la hauteur du rôle auquel elle est appelée par sa situation géographique : Dusseldorf possède, en effet, une des premières écoles de l'Allemagne, et son influence salutaire se fait sentir dans toute la région.

Cette ville présente une physionomie bien originale; une gare monumentale en renaissance allemande d'un beau cachet domine la ville; les larges artères qui conduisent au centre, offrent un aspect pittoresque. Chaque architecte semble avoir cherché quelque détail caractéristique; toutes les construc- 
tions sont conçues d'après un plan différent : il y en a de tous les styles; tous les éléments décoratifs et tous les matériaux ont été utilisés pour créer une œuvre originale et nouvelle. Le bon goùt règne partout; si une erreur vient par hasard jeter une note discordante dans cet ensemble harmonieux, elle est aussitôt rachetée par quelque détail ravissant; ces balcons en fer artistement ouvragé, ces portes et châssis en bois de chêne sculpté, ces pignons aux formes gracieuses, ces pentures et heurtoirs en cuivre ciselé, ces bustes en bronze, en marbre ou en majolique qui émergent des trumeaux, ces frises peintes qui courent sous la corniche : tout révèle un goùt très fin, une recherche de variété du plus heureux effet, et nous montre, qu'une foule de travailleurs d'élite : peintres-décorateurs, sculpteurs, ferronniers, ciseleurs, ébénistes, céramistes, ont pu exercer leurs talents et y ont trouvé un large profit.

\section{L'ÉCOLE.}

Admission des élèves. - Frais d'écolage.

Pour être admis à l'école de Dusseldorf il faut : 
I" Etre àgé de $\mathrm{I}_{4}$ ans ;

$2^{\circ}$ Posséder une bonne instruction primaire à prouver par des certificats de fréquentation;

$3^{\circ}$ Avoir fait la choix d'un métier;

$4^{\circ}$ Payer une taxe.

Si l'on observe que le programme des écoles primaires allemandes est très étendu, et correspond sensiblement au programme de nos écoles, étudié sous le régime de l'enseignement obligatoire, l'on avouera que les élèves n'entrent pas sans peine à l'école de métiers, et que le niveau des cours y doit être assez élevé.

Dès leur entrée, les jeunes gens sont obligés de faire le choix d'une profession, ce qui permet aux professeurs de leur donner dès le début, outre les notions générales du dessin et de la composition, quelques exercices spéciaux tendant aux métiers d'art qu'enseigne l'école.

Ce qui parait surtout étrange, c'est que le principe de la gratuité aux écoles d'ouvriers n'est généralement pas admis en Allemagne. A Dusseldorf la taxe scolaire s'élève, pour l'école préparatoire et pour l'école de métiers, à $60 \mathrm{mk}$. par an, et pour l'école de perfectionnement à $20 \mathrm{mk}$. Les indigents qui en sont dignes, obtiennent facilement la remise totale 
ou partielle de la contribution. Il y a quelques associations d'industriels et d'ouvriers et beaucoup de patrons qui paient les frais d'écolage de leur protégés ou apprentis.

Quand je fis remarquer que les écoles belges analogues donnent l'enseignement gratuit, pour ne pas écarter les pauvres qui désirent s'instruire, on me répondit avec quelque raison, que la contribution scolaire, si minime qu'elle soit, éloigne les mauvais éléments, stimule le zèle et l'assiduité des élèves et intéresse les parents aux travaux de leurs enfants et à la prospérité de l'école.

\section{Division des cours. - But.}

L'école chôme par suite des vacances. Malgré ce fâcheux contretemps, il m'est possible de donner une idée approximative de l'organisation et du fonctionnement de l'établissement, grâce à la bienveillance de M. Hermann, professeur et bibliothécaire, qui me donne avec une amabilité parfaite, tous les renseignements désirables sur les méthodes, procédés et principes fondamentaux de l'enseignement.

Le bàtiment est vaste ; au rez-de-chaussée, la bibliothèque, le musée permanent de produits d'art industriel et quelques classes 
de l'école préparatoire; aux étages les classes de métiers et les ateliers.

L'enseignement comprend :

I. Une école du jour, préparatoire (Norjoule) qui enseigne aux élèves les connaissances générales du dessin, des styles et des sciences indispensables à ceux qui clésirent fréquenter l'Ecole professionnelle.

II. L'école professionizalle du jonr (ivthidule). Elle a pour but l'éducation complète de l'ouvrier et du contre-maitre.

III. L'école professionnelle pour adultes (jortbiloungidule) qui clonne aux ouvriers et aux apprentis, comme complément à la pratique journalière de leur profession, les notions d'art et de sciences indispensables à l'exercice intelligent de leur métier.

Dans l'ÉCOLE PRÉPARATOIRE, on enseigne:

A) Le dessin à main libre, d'après des ornements plans, des modèles géométriques et des fragments architecturaux;

в) Le dessin géométrique : les projections, la perspective, la perspective des ombres;

c) Les styles : étude des éléments décoratifs à travers les différentes époques, et appliqués aux différents métiers enseignés à l'école.

L'ÉCOLE DE MÉTIERS se réduit aux divisions suivantes : 
A) L'ébénisterie : dessin de meubles d'après des modèles en nature, d'après des gravures et des croquis cotés;

B) La peinture décorative. Copie d'ornements en relief, étude des éléments décoratifs et de leur caractère dans les différentes époques. Projets d'ornementation dans les différents styles.

c) La figire - dessin - peinture. Cet enseignement est donné en vue de la décoration. Il comprend le dessin d'après nature, et la peinture de fragments du corps humain. Dessin de mémoire. Composition de sujets décoratifs (becorativer Stiffeben).

D) Modelage. Ornements et figures en terre et en cire en vue de la sculpture sur bois et du repoussage.

E) Sculpture sur bois. Ornements - figure. Copies d'après nature, d'après des dessins et des gravures. Projets décoratifs.

F) Atelier de gravure, de cischure ct de repoussage. Modelage en cire d'après des modèles, des gravures et des dessins. Objets usuels, objets de luxe. Composition.

Chaque élève doit assister selon sa profession, aux cours de dessin et de peinture de fleurs, d'animaux, aux cours de composition, de décoration et d'anatomie pittoresque; il 
ne peut en ètre dispensé que s'il fournit la preuve, qu'il a suivi ces cours avec fruit dans d'autres écoles.

L'ATELIER DE CISELURE,

DE REPOUSSAGE ET DE GRAVURE.

Parmi les cours de l'école de Dusseldorf, l'atelier de ciselure, de repoussage et de gravure mérite une mention spéciale, en raison de son importance pour notre industrie artistique.

Ce cours occupe deux salles contiguës : $I^{\circ}$ la classe d'enseignement, et $2^{\circ}$ l'atelier proprement dit; il est dirigé par un orfèvre pratiquant.

Salle d'enseignement. - $\mathrm{Au}$ milieu, une table encombrée de travaux d'élèves, de dessins et de gravures. Les murs couverts de modèles en cuivre repoussé et ciselé, méthodiquement classés :

a) Ornements plans : fleurs, feuilles, rinceaux, silhouettes d'animaux, figure humaine, etc.

b) Ornements en relief : fleurs, animaux, figure, sujets décoratifs, etc.

c) Objets usuels : plats, manches de couteau ciselés, vases ornés, etc. Objets de luxe : services et surtouts de table, cassettes etc. 
L'atelier. - Une table autour de la salle; outils et gâteaux de résine, çà et là ; dans une petite salle close, vitrée, un laboratoire avec feu de forge, un soufflet mù par une pédale.

En somme, outillage et installation simples et peu coùteuses.

Les élèves qui ont passé par l'école préparatoire, entrent à l'atelier sans aucune préparation professionnelle; ils possèdent des notions générales des styles et du dessin ornemental.

Ils s'exercent d'abord au modelage en cire, d'après des moulages et des objets en nature appartenant au musée attaché à l'école, d'après des gravures et des esquisses ; ils modèlent aussi de mémoire et d'après des dessins de leur propre composition.

\section{Le Repoussage.}

Plus que toutes les autres industries du métal, le repoussage est un art sans limites, qui doit ètre étudié en relation intime avec la technique. Qu'il s'agisse de travaux destinés à la décoration du bâtiment ou appartenant à l'orfèvrerie, une étude théorique du modelage ne suffit pas pour incarner dans l'ouvrier le sentiment de la conception et de la ligne propres au métal. 


\section{$-245-$}

Le travail pratique doit compléter son éducation professionnelle, et lui donner le goût et l'habileté pour exécuter fidèlement la pensée de l'architecte ou du dessinateurorfèvre, pour retoucher un mouvement qui ne s'accorde pas avec la nature des matériaux employés, pour créer au besoin un motif ornemental.

L'atelier de repoussage de l'école de Dusseldorf applique les méthodes en vogue à Vienne et à Dresde, décrites page 2 I 5 .

Les élèves modèlent la feuille de métal avec un goût charmant, et s'efforcent, suivant l'exemple des travaux du moyen-âge, à laisser au métal l'apparence qui lui convient, sans prétendre simuler la pierre ou le bois sculptés, à l'encontre de toute saine logique.

Des concours mensuels stimulent l'ardeur des élèves ; les meilleurs travaux sont primés et exécutés en métal. Bon nombre d'entre eux sont intéressants, quelques-uns remarquables. Il y a là des ornements fouillés, avec verve et originalité : l'effet d'outil bien personnel que présentent certains travaux, témoigne d'une excellente éducation professionnelle.

A côté des objets usuels, tels que cuillers, plats, vases ornés, on admire d'une part, des épingles de cravate en or et en argent ciselés, 
des lettres entrelacées, des fourreaux d'épée, des poignées, des manches de psyché, des cadres pour glaces et pour photographies très artistement ouvragés; d'autre part, des couronnements d'édifices, des groupes décoratifs, des statuettes, des enseignes en métal repoussé, pleins de caractère.

Les élèves doués, qui quittent l'atelier après trois années d'un apprentissage journalier, sont admis avantageusement chez les orfèvres et chez les ferronniers d'art, et parviennent sans peine à se créer une position lucrative.

ROLE DES CORPORATIONS ET DES ASSOCIATIONS DANS LA CRÉATION DES ÉCOLES D'APPRENTISSAGE.

Un des caractères les plus marquants de la vie industrielle en Allemagne, c'est l'esprit de corporation, conservé vivace parmi les gens de métier. Jamais le régime corporatif n'a été radicalement supprimé; il s'est transformé, modernisé.

Pendant que notre population ouvrière, encore désorientée, hésite d'adhérer aux groupes professionnels, les ouvriers allemands sont associés en de puissantes corporations (smunugen), (jui ne risent pas seulement au 


\section{- 247 -}

bien-être matériel de leurs membres, mais surtout à leur éducation morale et intellectuelle.

La force de l'industrie allemande réside dans le concours des associations au développement de l'enseignement professionnel et industriel. La plupart des anciennes corporations ont organisé des écoles ou des cours professionnels.

L'art. 97 de la “ loi industrielle » impose aux nouvelles corporations l'obligation de régler la situation des apprentis, de veiller à leur éducation technique, industrielle et morale (I).

L'art. $97^{\mathrm{a}} \S$ I et 2 de la mème loi leur donne qualité pour établir et pour diriger des écoles d'apprentissage (2).

(I) Art. $97 \$ 3$ : Dbligatorifche 24ufgabe Der tteuen Sit= uturgen ift :

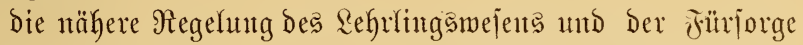

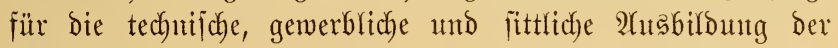
Rehrlinge.

(2) Art. $97^{\mathrm{a}}$ : Jafultative 2fujgabe.

Snsbejondere jtegt ifnen $31 t$ :

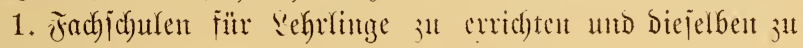
Yeitent;

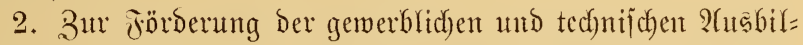

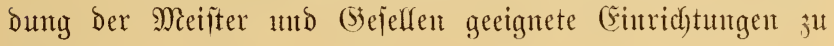
treffen. 
Confiant dans l'initiative privée, le Gouvernement allemand a soin de décentraliser l'enseignement d'art industriel; il abandonne volontiers à des villes ou à des associations, l'organisation des institutions, qui ont pour but cet cnseignement. Il soutient l'œuvre de ses subsides et se contente de veiller, par ses inspecteurs, à l'emploi utile des subventions et à l'exécution des règlements.

L'école de Dusseldorf était privée au début, et doit son existence aux corporations locales et à un groupe d'industriels, constitués en société : (Eentral Semerbe \$erein, "Union centrale d'industrie ".

Ces hommes de cœur ont entrepris la tàche dc relcrer l'industicic régionale. Dans ce but ils répandent l'éducation professionnelle parmi les ouvriers, affinent et épurent le goût esthétique de leurs compatriotes, en leur mettant sous les yeux des objets ayant un cachet artistique.

On peut l'arouer, le mal qu'ils combattent est universel. Peu de gens ont assez de goût pour porter un jugement sur la forme, la couleur ou le caractère artistique d'un produit industriel; ils sont rares ceux qui sont péniblement affectés par le laid. L'Union centrale d'inclustrie de Dusseldorf a porté remède à 
cet état de choses, en créant à còté de l'Ecole des ouvriers, une Bibliothèque et un Musée de produits d'art industriel, destinés aux fabricants, aux ouvriers et aux particuliers. Le musée est alimenté par les industriels eux-mèmes, qui sont heureux de pouvoir y déposer, à titre de réclame, les meilleurs produits de leur fabrication.

LA BIBLIOTHEQUUE. - LE MUSÉE.

Le musée et la bibliothèque forment un tout complet et inséparable,

La bibliothèque, très riche et admirablement organisée, possède, outre les ouvrages classiques et les revues, une collection de gravures. relatives à toutes les professions artistiques.

Rien de plus intéressant que le spectacle des ouvriers, industriels, apprentis, còte à còte, étudiant, copiant les formes anciennes, ou les créations récentes de leur industrie et de leur métier. Ils trouvent en ce lieu du papier, des crayons et des bibliothécaires dévoués, prêts à leur donner toutes les explications. Ceux qui le désirent, peuvent expédier leurs échantillons par la poste; les professeurs les renvoient corrigés ou complétés. La bibliothèque est un bureau de renseignements et de correction. 
Le musée 'est destiné à élever le goùt du public; il offre au producteur et au consommateur des objets de style pur des différentes époques et des différentes professions. Il fournit d'excellents modèles à l'école. Tous les produits d'art industriel y sont représentés, groupés d'après la matière dont ils sont fabriqués. Ce classement logique permet de montrer les procédés techniques et l'ornementation qui conviennent à chaque matière, et les transformations multiples que l'art et l'industrie font subir à cette matière, pour les besoins du luxe et pour les besoins usuels de la vie.

\section{Exposition ambuLANTE.}

Pour faire participer les autres villes industrielles de la région aux avantages de cette institution, l'Union centrale a établi des succursales, espèces d'expositions ambulantes, qui sont un auxiliaire précieux pour les écoles d'art et pour les industries locales; elle use de son influence auprès des écoles, pour peser à la fois sur l'enseignement et sur la fabrication. De cet échange constant d'idées et de modèles est né, dans toute la région du Rhin, un mourement artistique considérable, qui exerce un effet bienfaisant 
sur les industriels et les particuliers, et qui a relevé le niveau intellectuel et matériel des travailleurs.

Un fait typique entre beaucoup d'autres. Il y a quelque vingt ans, la commune de Neroth était le centre de la région la plus misérable de la Province rhénane. Les habitants tâchaient de subvenir aux besoins de leur triste existence en fabriquant des souricières; mais celles-ci étaient si lourdes et si grossières, que les paysans incultes euxmêmes n'en voulaient acheter. La Eentral (5emerbe Berein y dépècha un professeur-apòtre, qui réunit dans une salle les intéressants industriels du village, leur distribua quelques souricières de forme élégante, et leur apprit à les imiter. Ils se mirent à la besogne. Les souricières nouvelles s'écoulèrent comme par enchantement.

Maintenant Neroth prospère et se glorifie de son monopole.

Voilà pourquoi, au musée, parmi les cuillers, plats et tire-bouchons ciselés, parmi les balustrades et les enseignes en fer forgé, on est tout étonné de voir une souricière. 
MODÈLES. - MÉTHODES. - TENDANCES.

Le choix des modèles a une importance considérable aux écoles de métiers d'art, ils impriment la direction et la tendance à l'enseignement. L'examen attentif des modèles et des travaux des élèves nous a permis de conclure, que l'enseignement de l'école de Dusseldorf est individuel.

L'élève éclairé par les conseils de son professeur, choisit ses modèles, d'abord parmi les collections de plâtres et d'objets démontables, puis parmi les objets du Musée.

Les sculpteurs sur bois tirent un parti avantageux des frises, lambris, portes et châssis sculptés qui abondent. Les ferronniers pourraient-ils dessiner les objets forgés du Musée, étudier les gravures de la Bibliothèque, sans les comparer à leurs travaux de tous les jours? Cette liberté relative de l'élève développe sa personnalité, qui ne tarde à se révéler; chacun interprète l'ornement selon son tempérament et ses goûts : l'on s'explique ainsi comment, malgré l'influence fascinante de l'étranger, la décoration et l'architecture allemandes ont pu recouvrer leur caractère 
propre, expression sincère du caractère national.

L'école de métiers artistiques de Dusseldorf prépare ses élèves à la composition. Le dessin de mémoire est en honneur dans toutes les classes, et les concours mensuels permettent aux élèves d'appliquer les motifs décoratifs qui ont frappé leur imagination, et les procédés techniques, qu'on leur a enseignés.

Le plus grand souci des professeurs est de donner aux études artistiques le caractère le plus strict d'art appliqué à l'industrie. Aussi, tous les modèles rattachent l'enseignement à des faits, dont l'ouvrier fait journellement l'expérience; la figure humaine n'est étudiéc que comme élément décoratif. La peinture, la sculpture, la ciselure, le dessin, sont considérés comme des moyens d'embellir l'industrie, et non comme des métiers flatteurs, destinés à attirer les jeunes gens, pleins d'illusions, dans les sentiers charmants du grand art. Pour ne pas faire de médiocres artistes, on maintient les élèves rigoureusement dans la vie industrielle, par l'esprit de l'enseignement, par les leçons pratiques et par le travail à l'atelier. Ceux qui se sentent irrésistiblement attirés aux arts purs, quittent 


\section{$-254-$}

ce lieu profane pour l'Académie des Beauxarts, couronnement de l'enseignement artistique de Dusseldorf.

Les élèves guidés par les modèles pratiques clu musée, formés par les méthodes basés sur le travail, n'ont pas tous la touche délicate; leurs dessins sont sévères; mais qu'ils se rassurent, ils deviendront des ouvriers d'élite; leurs étucles graphiques et techniques leur permettront de tracer et d'exécuter avec art les projets qu'on leur soumet; ils pourront expliquer, grâce aux cours scientifiques, les causes et les effets de leurs travaux, discuter la préparation et le prix de revient des matières qu'ils emploient, déterminer exactement la valeur des objets façonnés, et par conséquent établir le taux d'un salaire équitable.

"Métier vaut rentes » toujours et partout.

Tant de malheureux artistes vivotent, sans parvenir à la célébrité!

$\mathrm{Si}$, au lieu de vouer à l'art toute leur activité et toute leur intelligence, ils en avaient réservé une partie à l'industrie, celle-ci leur aurait assuré une existence moins précaire. 


\section{XIV. - CONCLUSION}

L'école de dessin et d'industrie doit-elle être professionnelle? Doit-on faire entrer l'enseignement de l'atelier à l'école? Nous répondrons: oui. La question est définitivement résolue en Allemagne. Dans toutes les écoles professionnelles et industrielles secondaires, l'apprentissage des métiers relevant de l'art a été introduit avec succès et établi sur des bases solides, après de longues années d'étude et de tâtonnement. Chaque école enseigne à fond une ou plusieurs spécialités, en mème temps que les notions générales cles autres métiers manuels et des sciences qui s'y rattachent. Ces spécialités sont les professions dominantes de la ville et des environs.

L'Ecole de T)usseldorf a ses ateliers de 
ciselure et de dćcoration, Remscheid et Iserlohn enseignent les travaux du métal; Créfeld, le tissage; Aix-la-chapelle, les sciences fondamentales des industries, Dresde, la décoration de la céramique, etc.

L'élève qui a acquis, dans les classes préparatoires, les notions générales du dessin, des styles et des sciences, doit faire le choix d'un métier, et s'engage suivant sa vocation ou après une épreuve préparatoire, dans une des trois voies qu'ourrent les trois branches des arts plastiques : l'architecture, la peinture et la sculpture; l'enseignement et les modèles convergent vers les ateliers d'apprentissage.

L'architecture $\left\{\begin{array}{l}I^{\circ} \text { Atelier pour mécaniciens, } \\ \text { serruriers, constructeurs. } \\ \text { 2o Architecture, coupe des } \\ \text { pierres, ébénisterie, char- } \\ \text { ronnerie et carrosserie. }\end{array}\right.$

3o Modelage pourstuccateurs, sculpteurs sur bois et sur pierre.

La sculpture $4^{\circ}$ Ciselure, gravure et repoussage.

50 Ferronnerie, travail artistique du plomb et du zinc. - Repoussage. 
La peinture

6. Atelier de composition décorative.

$7^{\circ}$ Imitation de bois et marbres.

$8^{\circ}$ Peinture sur verre, sur porcelaine.

Le travail aux ateliers est éducatif; les jeunes gens s'y livrent avec ardeur et patience, parce qu'il clonne immédiatement des résultats visibles; chaque coup de lime, de ciseau, de rabot est un acheminement vers l'achèvement du travail. Cette activité et cette patience, soutenues habilement par un choix gradué de modèles, finissent par devenir des qualités morales habituelles chez l'apprenti.

L'enseignement des ateliers est démocratique; il s'adresse exclusivement aux travailleurs manuels. L'enseignement qui se borne à l'étude purement graphique et théorique des métiers est incomplet et manque son but; il crée surtout des employés et des dessinateurs, mais peu d'ouvriers.

Un apprenti, quelque peu instruit, entre à l'école professionnelle; son esprit se forme par l'étude des sciences positives, son goùt esthétique s'épure par l'imitation de modèles artistiques, sa main acquiert une habileté technique dans les ateliers; il en sort ouvrier, 
grandi moralement, respecté pour son savoir par ses compagnons, et capable de gagner un bon salaire.

L'ECOLE DE DESSIN ET D'INDUSTRIE

DE Schaerbeek.

Si une transformation de l'Ecole de dessin et d'industrie de Schaerbeek était jugée nécessaire, il semble qu'elle devrait prendre un caractère franchement professionnel. Le local de la rue Teniers se prêterait assez bien à l'organisation d'ateliers. Le terrain de l'ancien cimetière, déblayé, fournirait un emplacement suffisant pour l'édification éventuelle des constructions; les sous-sols pourraient être aménagés pour y recevoir les moteurs électriques ou autres, qui actionneraient les tours, les machines à scier, à polir, à limer, à forer, à raboter, etc.

Quel spectacle intéressant que cette ruche ouvrière en activité, et quelle salutaire influence elle exercerait sur les esprits.

Elle préparerait les ouvriers à la petite industrie indépendante et paisible, dont le centre est le foyer domestique; elle contribuerait à restaurer ce mode de fabrication et réagirait ainsi contre la grande industrie, qui réduit l'ouvrier à l'état d'automate par la 
mécanisation et par l'extrème division du travail.

L'organisation des ateliers d'apprentissage détruira peut-être le reste de prévention qui règne encore, dans certains milieux, contre le travail même ennobli par l'art. Beaucoup de gens considèrent comme la dernière déchéance de faire apprendre un métier à leurs enfants. Tous ceux qui sont doués aspirent à un emploi public, ou au moins, " au bureau ». Les " cancres " seuls se font ouvriers; notre enseignement trop théorique prépare les enfants à ne pas avoir d'initiative ni de caractère, attendu que la première qualité d'un bon employé est la résignation passive. En Allemagne, l'enseignement provoque l'éclosion de l'initiative et trempe le caractère; il développe le sens pratique des enfants et les destine au commerce, à l'industrie ou aux métiers.

Les écoles de métiers d'art jettent annuellement dans les usines et dans les ateliers toute une population de jeunes gens instruits, actifs et audacieux.

L'Ecole de dessin et d'industrie de Schaerbeek, complétée par l'organisation des ateliers, et dirigée dans la voie tracée par nos voisins d'Outre-Rhin, serait appelée à un 


\section{$-260-$}

grand avenir. Plus que par un enseignement purement graphique et oral, elle répandrait le gout des belles choses parmi le public; les ouvriers y viendraient acquérir cette supériorité professionnelle qui décuple la valeur du travail; son enseignement ouvrirait leur esprit, raffinerait leur sentiment du beau et leur montrerait qu'ils doivent chercher avant tout le relèvement de leur condition dans le développement de leurs talents professionnels. 


\section{L'ÉCOLE DE MÉTIERS \\ DE BERLIN}

$(\tilde{y} a \mathfrak{d}$ werferid) 



\section{XV. - CONSIDÉRATIONS GÉNÉRALES}

Le mouvement puissant en faveur des écoles professionnelles, industrielles et d'art industriel n'est pas, en Allemagne, le résultat d'une entreprise gouvernementale; il est né de l'aspiration de plus en plus pressante de la population ouvrière vers un degré plus élevé de bien-être matériel et intellectuel.

Les ressources naturelles restreintes et la densité extrème de la population rendent la lutte pour l'existence plus âpre que dans les autres pays. Lorsque les expositions universelles eurent montré aux Allemands les progrès du travail et la supériorité des produits étrangers, la cause du malaise se révéla, et l'extension de l'enseignement professionnel apparut dès lors commel'unique moyen de relever le niveau économique de la nation. Le Gouvernement obéit à la poussée partie de tous les points du pays, Bismarck 
lui-mème prit la direction du Département de l'Industrie et du Commerce, et s'appliqua à stimuler l'activité commerciale et industrielle de ses compatriotes. De cet époque datent la transformation des écoles de dessin en écoles professionnelles, la création de nouvelles écoles dans toutes les régions de l'empire, et une série de mesures législatives, dont nous indiquerons brièvement la portée.

A. La Comaisgion de l'Enseignement professionnel de Prusse.

Par la loi du 2 I janvier I 879 a été instituée une Commission permanente de 25 membres, choisis parmi les représentants les plus autorisés de l'industrie, et parmi les directeurs et professeurs des Ecoles de métiers; président de droit : le ministre de l'Industrie et du Commerce.

La Commission est consultative; elle se réunit à des époques variables pour examiner le régime, les programmes, les tendances des écoles professionnelles, industrielles et d'art industriel; elle étudie les questions administratives et péclagogiques qui lui sont soumises par les autorités supérieures, et élabore les avant-projets de lois et de règlements.

C'est au sein de cette Commission que se concilient les tendances presque contraires 
de l'enseignement artistique et de l'enseignement technique : les industriels et les artistes-industriels exposent les besoins de l'industrie, ses lacunes, ses défauts; les esthètes font valoir les droits de l'art en toutes choses; les professeurs donnent un corps à ces principes et les adaptent aux conditions d'enseignement; les représentants de l'autorité administrative recherchent les formules les plus pratiques pour faire accepter par les pouvoirs législatifs et communaux les désiderata de la Commission.

De son côté, le Gouvernement réalise les propositions dans la mesure des ressources budjétaires, et en harmonie avec les intérêts généraux de l'industrie et du commerce.

Des délibérations de cette Commission sont sorties des mesures pratiques, qui ont contribué puissamment à l'extension et à la prospérité de l'enseignement des métiers.

B. RÉgLementation de L'Apprentissage DANS LES ATELIERS

Les efforts les plus persévérants pour la diffusion de l'enseignement professionnel seraient stériles, si l'apprentissage à l'atelier ne concourait pas avec l'école pour former de bons travailleurs.

Nous avons dans nos différentes études, 
attiré l'attention sur l'apprentissage lamentable dans la plupart des ateliers; le temps des jeunes gens y est gaspillé sans scrupule; là où ils travaillent réellement, ils servent d'instruments pour la production à bon compte; dans peu d'ateliers les exercices et les travaux des apprentis sont coordonnés en vue de favoriser l'étude du métier.

Lorsqu'il peut gagner plus dans un autre atelier, il arrive trop souvent que l'apprenti, oublieux de tous ses devoirs, quitte brusquement, sans préavis, le patron qui s'est même consciencieusement occupé de son éducation.

De cette situation mal définie est née une méfiance réciproque désastreuse pour l'apprentissage.

La " loi industrielle » allemande à dissipé cette méfiance en réglant avec prudence et fermeté les droits et les devoirs des apprentis et des patrons.

Aucune forme n'est prescrite pour le contrat d'apprentissage ; mais, qu'il soit tacite, oral ou écrit, le patron est tenu d'enseigner à l'apprenti les travaux de son industrie, dans l'ordre et avec le développement que comporte le but de l'apprentissage.

Lui-même, ou le représentant expressément désigné par lui, doit diriger l'apprentis- 
sage ; sous prétexte de travaux à exécuter, il ne peut refuser à l'apprenti ni le temps ni l'occasion de fréquenter les cours professionnels et d'assister aux services religieux les dimanches et les jours fériés.

Il doit lui inculquer des habitudes de zèle et de moralité, et le détourner des excès. (Art. I 26). (I)

La sanction est formulée par l'art. I 48 \$ 9 .

Peut être puni d'une amende de I $50 \mathrm{mk}$. et en cas d'insolvabilité de quatre semaines de prison, celui qui contrevient aux prescriptions légales concernant les apprentis qui lui sont confiés. (2)

(I) Art. I26: Der Segrtgerr ijt verpflidftet den Lefrring in dent bei jeinem Betriebe vorfommenton 2trbeiten des Beswerbes

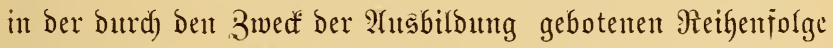

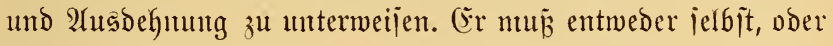
burch) einen geeigneten, ausorüafflid) dazu bejtimunten Wertreter,

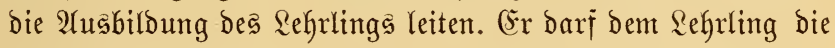
zu jeiner Thusbildunt und zum Bejuche des Gottesbienjtes an Sonn= und Fejttagen erförberliche Beit und (Selegenfeit durdh

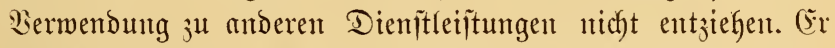
gat Dent Segrling zur 2frbeitjamteit und $3 \mathfrak{u}$ guten Sitten anju=

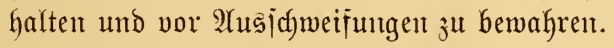

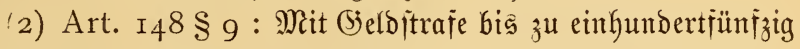

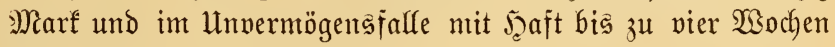
wiro bejtraft :

Wer bie geję̧lichen Wiflichten gegen bie ifgm anvertrauten Eerflinge verleţt. 
La question de l'apprentissage est très délicate. Tout en sauvegardant rigoureusement les intérèts sacrés de l'enfant, il faut concilier la liberté des transactions, le progrès et les conditions de la fabrication, et la situation industrielle du pays sur le marché universel.

Néanmoins, l'exemple de l'Allemagne prouve, qu'on peut réglementer l'apprentissage, sans entraver l'expansion de l'industrie.

Dans l'intérêt du travail, autant que dans l'intérêt de la moralité publique, il est temps de soustraire les jeunes gens aux hasards de l'engagement, d'imposer un contrat d'apprentissage qui porte l'enseignement intégral et logique du métier.

Si une jurisprudence existait pour punir les patrons qui abusent de l'inexpérience, de l'ignorance des parents et de la faiblesse des enfants, des abus criants disparaîtraient; l'apprentissage à l'atelier deviendrait sérieux et contribuerait, avec les études aux écolesateliers, à former une génération de travailleurs d'élite.

Tels ont été les effets des mesures législatives en Allemagne. L'instruction solide répandue parmi les ouvriers, leur fait entrevoir les ressources qu'offre une profession manuelle 


\section{$-269-$}

scientifique et artistique; aussi affluent-ils en masse vers les écoles de métiers.

La Commission de l'enseignement professionnel de Prusse et les Commissions semblables des autres états allemands, d'accord avec les pouvoirs provinciaux et communaux, ont imprimé une tendance pratique à l'enseignement des métiers : le but est de former des ouvriers, plutôt que des dessinateurs de profession.

Les résultats d'un régime aussi rationnel ne se sont pas fait attendre : les ateliers soignent l'éducation professionnelle des apprentis, leurs efforts s'ajoutent à ceux de l'école, pour former des ouvriers supérieurs; et les industries ont pris un essor formidable, inconnu jusqu'à ce jour en Allemagne. 


\title{
XVI. - BERLIN
}

\author{
La Ville.
}

La ville de Berlin est dotée d'un enseignement de métiers artistiques digne d'une capitale; son influence salutaire se fait sentir vivement dans toutes les branches de son industrie.

Il semble qu'elle ait retrouvé, particulièrement au point de vue de la décoration et de l'industrie du livre, la voie de l'art national : la construction et l'ornementation des maisons, surtout aux abords du Tiergarten, les produits variés de l'industrie du fer forgé, la décoration sculpturale et picturale des façades, ornées de terres cuites et de frises peintes, l'illustration et la reliure du livre, la papeterie, tout révèle sincèrement un esprit caractéristique propre avec ses défauts et surtout avec ses qualités. 
Tels sont les fruits de l'enseignement des métiers dans les deux cents écoles ouvrières, fréquentées par vingt-deux. mille élèves, et plus spécialement de l'Ecole de métiers, située Lindenstrasse, 97-98, et de l'Ecole supérieure des arts industriels.

\section{L'ÉCOLE DE MÉTIERS.}

Le bâtiment de l'Ecole de métiers n'offre rien de bien remarquable au point de vue architectural. Une large porte monumentale conduit à une cour intérieure couverte, occupée par le marché aux fleurs. Les trois étages sont répartis entre le logement du directeur et du concierge d'une part, et d'autre part en dix-neuf salles immenses pouvant contenir chacune au moins cent élèves. Toutes les classes sont très hautes, admirablement éclairées de gauche à droite par de larges baies qui s'ouvrent sur la cour intérieure et qui distribuent à profusion la lumière. Cet emplacement, occupé depuis quelques années à peine, est déjà trop exigu pour les deux mille deux cent-cinquante élèves qui assistent aux cours; un second établissement est à l'étude et sera incessamment créé pour recevoir le trop-plein d'élèves. 


\section{- 272 -}

Éclairage

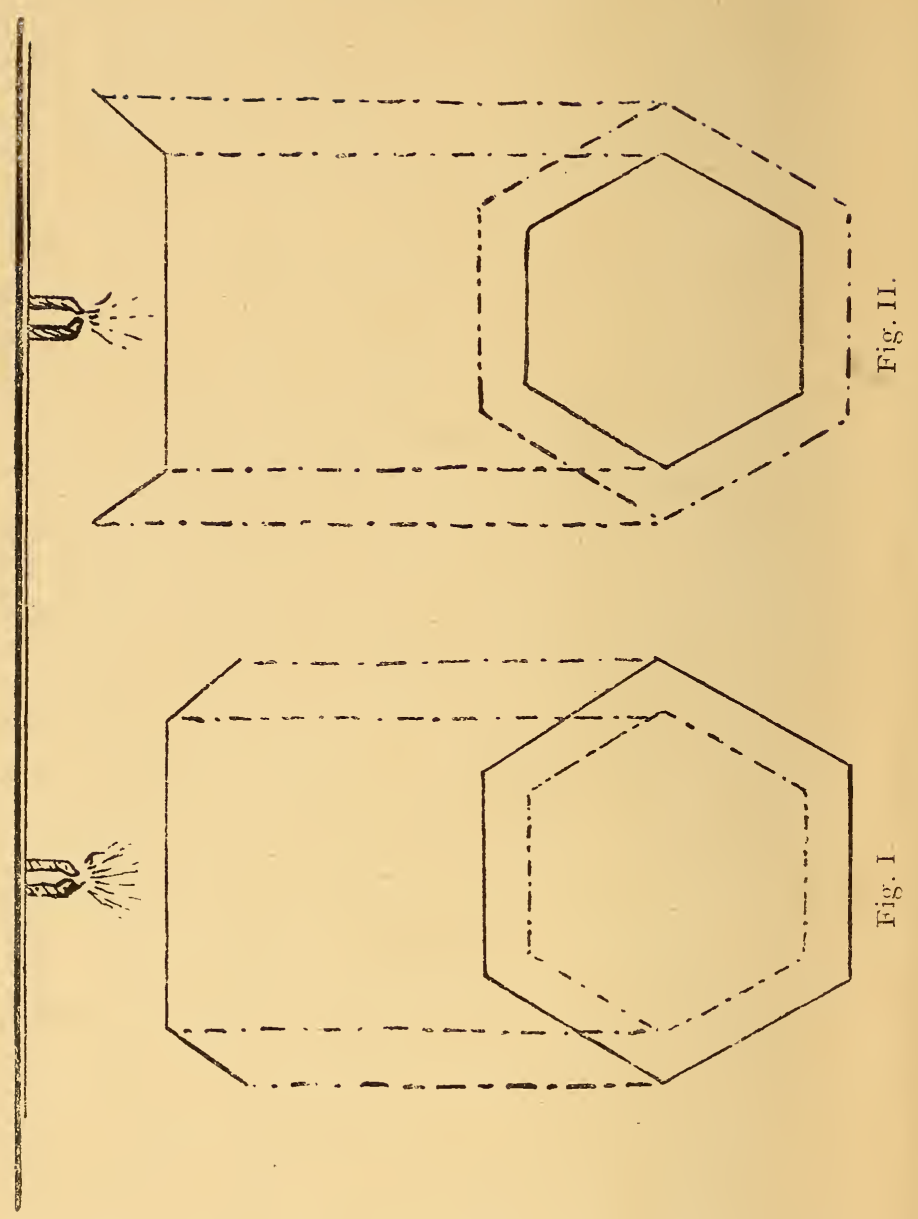




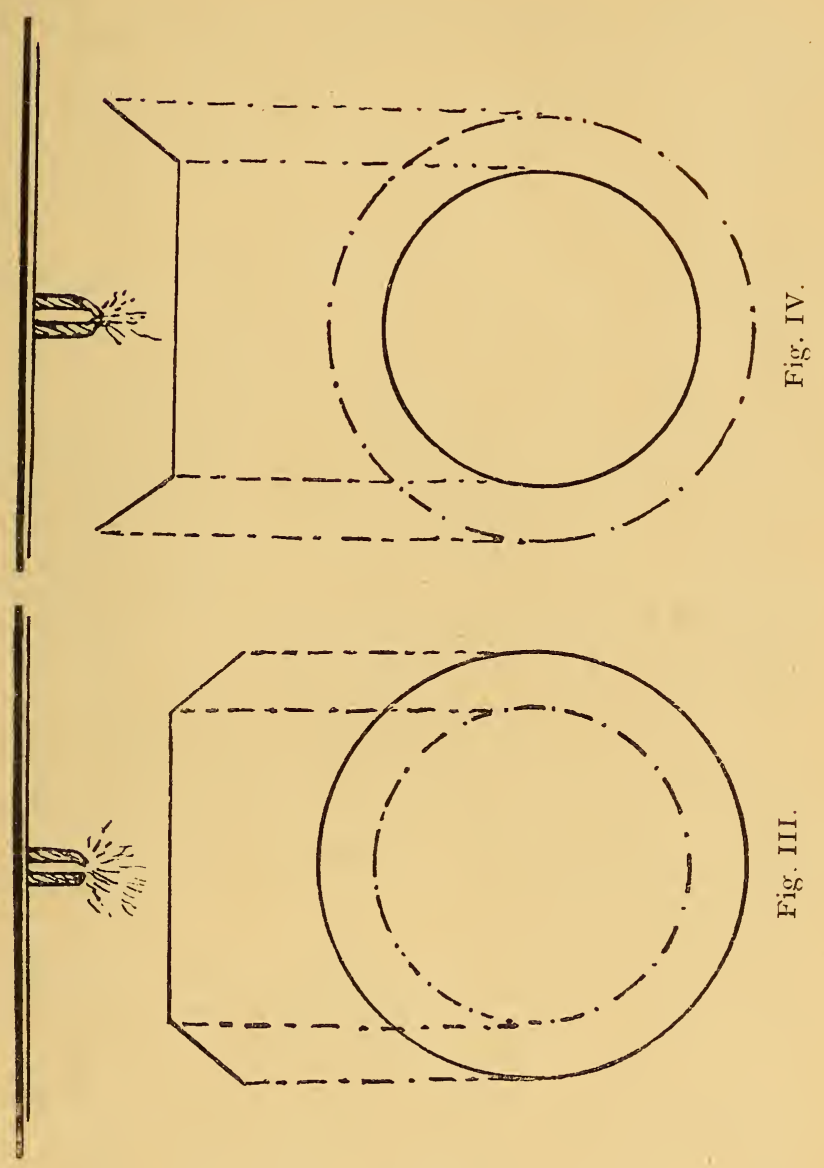


Les classes sont éclairées le soir à l'électricité. Trois foyers puissants, suspendus au plafond, inondent les salles d'une lumière abondante. A la suite de longues expériences, les lampes à incandescence (Edison) ont été définitivement écartées et remplacées par les lampes à arc, qui donnent une teinte plus chaude. Les lampes sont voilées au moyen d'un écran de toile blanche légère qui tamise la lumière, la rend diffuse et agréable à la vue et harmonise les tonalités des modèles et des travaux des élèves. La forme des écrans détail très important - varie, un type unique n'ayant pas encore été adopté. (Voir croquis ci-dessus, fig. I, II, III et IV.)

Les lampes à incandescence ont été conservées pour la classe de modelage : les ombres et les lumières, vivement tranchées, accentuent le caractère des modèles et favorisent le travail de l'élève.

BUT DE L'ÉCOLE. - DIRECTION. - CORPS PROFESSORAL.

L'École de métiers a pour but de donner aux ouvriers, artisans et apprentis, âgés de I4 ans au moins et pourvus d'une instruction primaire, - de préférence dans leurs heures de loisir, - les notions de sciences et d'art 


\section{$-275-$}

qui complètent l'apprentissage à l'atelier.

L'Ecole de Berlin a exercé une influence considérable sur le développement de l'enseignement professionnel dans toute l'Allemagne.

L'initiative' de sa création est partie des Corporations et des Associations professionnelles berlinoises. Par leurs requètes successives elles attirèrent l'attention du ministre de l'Industrie et du Commerce sur la nécessité d'organiser, dans la capitale, un enseignement de métiers plus complet.

Les délégués de la ville, d'accord avec le Gouvernement, conclurent à la création d'une École avec ateliers, à l'instar de l'Allgemeine Gewerbeschule de Hambourg.

L'État versa une somme de Io.00o mk. pour l'achat d'instruments et de modèles, et alloua un subside de $20.000 \mathrm{mk}$; la ville équilibra le budjet par une subvention annuelle de $64.800 \mathrm{mk}$. et prêta les locaux.

Le plan était réalisé. L'organisation et la direction de l'École furent confiées à $\mathrm{M}$. Jessen, homme d'une haute capacité et d'une activité infatiguable, autant que modeste et serviable.

Appelé en I88I dans la capitale allemande par la municipalité, il créa l'enseignement 
de métiers artistiques suivant des méthodes toutes nouvelles, déjà expérimentées par lui avec succès aux écoles ourrières de Hambourg.

L'expérience de quinze années du système Jessen à Berlin a démontré la supériorité de son enseignement.

L'État a organisé dans son ćcole des cours temporaires pour professeurs et instituteurs, et a pris les méthodes et les procédés du célèbre professeur comme base de la réorganisation de l'enseignement du dessin à tous les degrés dans l'Empire allemand.

M. Jessen est admirablement secondé dans sa tàche par un corps professoral d'élite, pénétré de ses principes, soucieux, comme lui, de conserver et de développer dans les élèves le sens pratique de la profession, d'éloigner d'eux tout ce qui pourrait faire naitre une tendance non justifiée vers les arts purs. Ces professeurs, artisans établis pour la plupart, connaissent les besoins de leurs élèves; ils savent comment on dessine à l'atelier, une table, une chaise, un mur, un encadrement, un grillage, et comment on les orne; ils sont convaincus que l'ornement n'est utile aux vrais ouvriers, que pour autant qu'il est directement applicable au métier, que, par conséquent, la tech- 
nique du métier est la base de l'enseigement professionnel artistique; ils inspirent à leurs élèves l'amour du travail manuel et sont incapables de les détourner de leur métier pour les pousser dans la voie du grand art, au profit de leur vanité personnelle.

\section{HEURES DES COURS. - RÉTRIBUTION SCOLAIRE.}

L'enseignement se donne en hiver et en été, le soir, de 5 à 7 heures et de 7 à 9 heures. Les dimanches de 8 heures à midi.

Dans la plupart des localités, les patrons licencient leurs apprentis à partir de 5 heures du soir, afin de leur donner l'occasion de fréquenter les cours professionnels.

Il y a en outre, le jour, des cours de modelage, de peinture et de dessin professionnel pour ébénistes.

A leur inscription, les élèves doivent indiquer les cours qu'ils désirent suivre, et paient d'avance une rétribution scolaire, fixée comme suit :

Pour huit heures de cours ou moins par semaine, $6 \mathrm{mks}$.

Pour neuf à douze heures de cours par semaine,

$9 \mathrm{mks}$. 
Pour treize heures et plus de cours par semaine, I 2 mks.

Cours du jour, 5 marks par mois.

Les indigents peuvent obtenir facilement la dispense des frais d'écolage; les associations ouvrières paient la rétribution de leurs membres et protégés, et beaucoup de patrons celle de leurs apprentis.

\section{MUSÉE ET BIBLIOTHÈQUE.}

La Bibliothèque et le Musée, établis dans les ailes du somptueux bâtiment de l'École supérieure des arts industriels, sont des institutions de l'État au service des écoles et des industries.

La Bibliothèque, très riche et admirablement organisée, possède, outre les ouvrages classiques et les revues, une collection complète de gravures et de dessins relatifs à toutes les professions manuelles.

Le Musée des arts appliqués offre une image fidèle des productions artistiques et industrielles de toute l'Allemagne; il est destiné à l'éducation simultanée des ouvriers et du public, des consommateurs et des producteurs, des maitres et des élèves artisans. Son influence se fait sentir dans tout le pays; les objets vont et viennent de l'école aux ateliers, 


\section{$-279-$}

sont exportés en province et mis à la disposition des villes, des écoles, des centres de production, pour y rehausser l'éclat des expositions locales, pour indiquer la voie à la fabrication artistique, pour peser sur l'enseignement des métiers.

Malgré la richesse et la diversité des objets du Musée, un classement logique permet à l'artisan le plus inexpérimenté de s'y retrouver sans peine.

\section{CLASSIFICATION.}

Tous les produits exposés sont groupés, autant que faire se peut, d'après la matière dont ils sont fabriqués: bois, pierre, métal, céramique, tissus, papier, etc., etc. La matière est le point de départ de cette classification; elle subdivise les objets en une série de groupes, résultant des transformations variées que l'industrie fait subir à la matière, pour les exigences du luxe et pour les besoins usuels de la vie.

Supposons le groupe bois. Il est exposé dans sa forme brute, scié en tous sens et présentant les ressources qu'il offre à l'industrie. Celle-ci le façonne, le polit et fait apparaitre sa coloration naturelle, - deuxième phase.

Mis en œuvre, le bois devient charpente, 
ébénisterie, menuiserie; il est sculpté, incrusté, plaqué, etc., et donne naissance à une foule d'industries, qui toutes empruntent à l'art leur richesse et leur éclat.

De cette succession logique de formes et de coloration adaptées aux besoins de chaque matière, l'artisan intelligent déduira, par un raisonnement simple et une observation constante des faits, les règles qui régissent l'ornementation.

C'est dans ce but que tous les élèves de l'École de métiers se rendent deux fois par semaine au Musée des arts industriels, sous la direction de leurs professeurs, pour y étudier, au point de vue technique et ornemental, les objets de leur profession.

\section{BRANCHES PRÉPARATOIRES ET FONDAMENTALES.}

\section{i. - Dessin a main Levée.}

Le programme porte : dessin à main levée d'après des modèles simples : ustensiles. outils, ornements, plantes vivantes, animaux empaillés, masques - en contontr (croquis) ou en exécution plus achevée, selon la profession de l'élève.

L'enseignement de l'École de métiers est 
la continuation et l'épanouissement de l'enseignement du dessin à l'école primaire. Les élèves du degré supérieur de ces écoles dessinent d'après des solides géométriques, et une série de modèles ornementaux simples (quatre heures par semaine); ils reproduisent en croquis des objets industriels. Ils acquièrent l'habitude du relief et se préparent, par conséquent, admirablement au dessin professionnel.

\section{Modèles (Dessin a main levée).}

Les modèles impriment la direction à l'enseignement du dessin et en déterminent la tendance. Ceux qui sont employés à l'École de Berlin, conduisent en ligne droite aux métiers artistiques.

Les élèves dessinent d'après une série graduée de solides en bois de Io centimètres de hauteur environ, dérivés des solides géométriques. (Modèles Stuhlmann.)

Cette série de modèles présente, une à une, les difficultés techniques du dessin, initie les élèves aux tracés simples, dans lesquels ils doivent tenir compte des lois de la perspective et des projections. Ces modèles évoluent insensiblement vers le dessin professionnel, but final de tout l'enseignement préparatoire. 
Comme complément à ce dessin exact, les élèves copient, en croquis d'abord, puis en exécution plus achevée, d'après leur profession, une série d'objets variés, en nature, tels que : plumes de paon, fruits, pommes de sapin, rinceaux de houblon, branches de chêne, pipes, tonnelets, étoffes peintes, facsimile de bijoux, coquillages, raisins, violons, pots, pieds de cerf, de brebis, gerbes d'avoine et de blé; une série d'objets en fer forgé : des fleurs, feuilles, serrures, pentures, etc., et forment au moyen de ces objets usuels des groupes ornementaux simples et agréables. Les plus avancés s'exercent au dessin d'animaux empaillés, d'ornements, de masques, etc., des différents styles.

Pendant le courant du printemps et de l'été, les élèves empruntent des pots-à-fleurs au marché établi dans la cour intérieure, les reproduisent en grandeur nature ou en réduction, au trait, en exécution complète ou en couleur, chacun suivant les besoins de sa profession.

\section{MÉTHOdE.}

L'enseignement du dessin à main levée est individuel; les cours collectifs sont interdits. Chaque élève a devant lui un modèle diffé- 
rent de ceux de ses voisins; il l'examine, le mesure avant de le dessiner.

Les professeurs inspectent continuellement le travail de l'élève, attirent son attention sur le caractère, la direction des lignes, la structure, etc. Ils suivent pas à pas la marche de l'élève, qui reçoit ainsi une instruction personnelle intime, variée et rapide, calculée d'après son degré d'avancement, son aptitude, son tempérament et sa profession.

La marche suivie dans l'enseignement du dessin bouleverse quelque peu nos idées, concernant la méthode. Les élèves tracent d'abord, à vue, tel point, telle ligne, telle face $\mathrm{du}$ solide, puis vérifient, au moyen d'une construction simple de perpendiculaires, horizontales ou obliques, si le point, la ligne, la surface sont bien établis. Il y a lieu de croire que cette marche oblige l'élève à plus d'attention et plus d'effort que notre méthode à construction préalable, dans laquelle, une fois les points géométriquement déterminés, la ligne, la surface s'obtiennent fatalement.

Aussitôt que l'élève est à même de dessiner, on lui met entre les mains des objets de sa profession.

Les modeleurs, orfèvres, ébénistes, ma- 
çons, tailleurs de pierres, sculpteurs, dessinent au trait.

Les graveurs, lithographes, dessinent, à la plume, des objets simples, puis des groupes ornementaux, qu'ils arrangent sous forme d'entêtes de diplòmes, d'affiches, etc., en contour d'abord, puis ombré.

Les peintres-décorateurs et les tapissiers rendent les effets d'ombre.

En tout cas, l'école a pour règle fixe de ne pas permettre aux élèves d'ombrer leur dessin, avant qu'ils ne dominent absolument la forme.

Le dessin de mémoire, sert de transition à la composition; il est très en honneur dans l'École de métiers de Berlin.

Après avoir copié le modèle dans un cahier spécial, l'élève fait le dessin du même objet de mémoire, sur une feuille destinée à l'exposition annuelle. Cet exercice développe les facultés intellectuelles les plus précieuses de l'élève; une série de formes esthétiques s'incrustent dans son esprit, et la main apprend à exécuter fidèlement les ordres de la pensée.

Le dessin de mémoire conduit à la composition; l'élève met en ourre les motifs décoratifs qui ont frappé son imagination et 


\section{$-285-$}

son intelligence; il les transforme, les complète et les applique à l'ornementation des objets de son métier.

\section{Mobilier.}

Le mobilier est adapté aux besoins de l'enseignement individuel. Les pupitres sont très larges : une table légèrement inclinée et une tablette horizontale. Ils peuvent aussi bien servir au dessin à main levée, qu'au dessin à l'aide d'instruments ou à l'écriture. (Voir croquis, fig. V.)

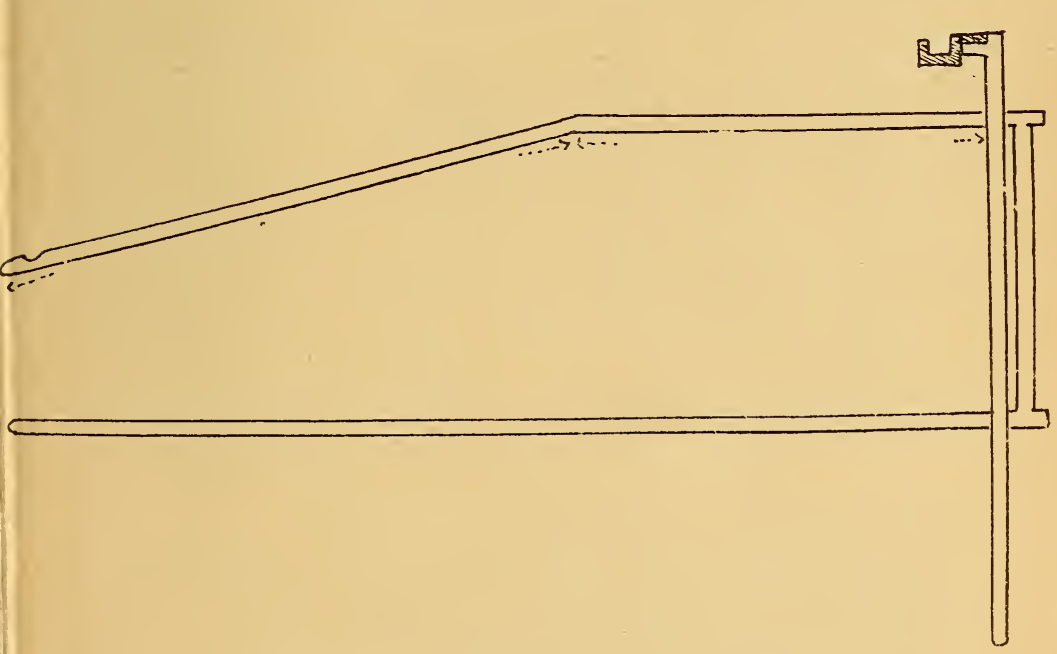

Fig. V. 
Les modèles peuvent être placés sur la tablette horizontale ou suspendus à un crochet, fixé à une réglette verticale, qui glisse à coulisses dans la tablette. La hauteur peut être réglée.

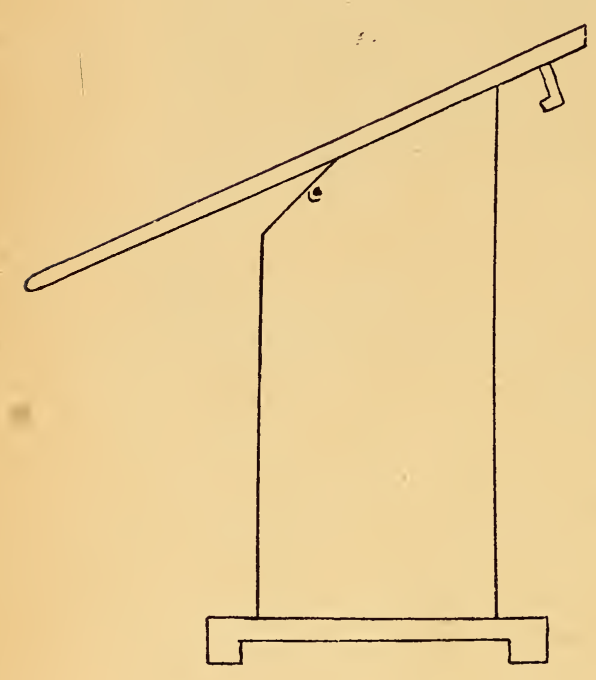

Fig. VI.

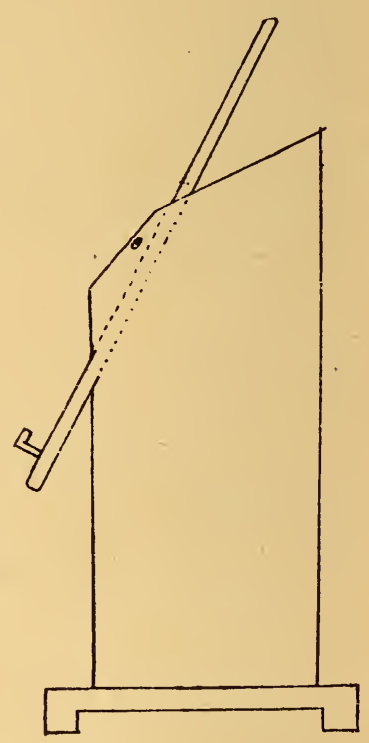

Fig. VII.

Un pupitre-chevalet, très ingénieusement construit et répondant parfaitement à ses usages multiples, est figuré dans les croquis VI et VII. C'est un pupitre ordinaire, dont 
la table, pourvue de tous les accessoires, est mobile autour d'une charnière; lorsque la table est couchée (fig. VI), le pupitre sert au dessin à l'aide d'instruments et à l'écriture ; la table levée (fig. VII), il sert au dessin à main libre. Ce pupitre est complété par un support qui porte les modèles.

ii. - Le dessin a L'aide d'instruments. - Les projections.

Le dessin à l'aide d'instruments et les projections forment, avec le dessin de croquis, la base de l'enseignement préparatoire des métiers.

Le dessin géométrique a pour but de reproduire, avec leurs dimensions réelles ou suivant une échelle de proportions, les figures ou ornements plans, dérivés de la géométrie ; il apprend aux élèves le tracé des courbes les plus usitées dans l'ornementation, le raccordement des lignes, etc., et les ressources considérables que certaines races ont tirées de l'ornement géométrique.

Des figures géométriques fondamentales dérivent des panneaux décoratifs, des ornements courants : lambrequins, méandres, rosaces, etc., du plus bel effet, que les élèves combinent, sous la direction du professeur, 
selon leur goùt personnel et les besoins de leurs métiers.

L'étude de quelques bons spécimens de décorations géométriques arabes, byzantines, celtiques, romanes et gothiques, viennent compléter l'étude du dessin à l'aide d'instruments.

Chaque élève consigne dans un cahier spécial les dessins expliqués par le professeur, et cela suivant certaines dimensions ou proportions données; dès le début, les élèves s'habituent à dessiner d'après un croquis coté et à utiliser l'échelle des proportions; ils se préparent ainsi au dessin professionnel et plus immédiatement aux projections.

\section{Les Projections.}

Programme.

Projections orthogonales: plan, élévation et projection latérale; projections obliques ; développement de solides, dessin de coupes planes en grandeur nature.

Caractere de l'Enseignement.

Cet enseignement procède de l'intuition et est dégagé de toute la théorie préliminaire sur le point, la ligne, la surface. Il met l'élève à même de représenter un objet quelconque 
sous ses divers aspects, avec ses dimensions réelles et toutes les indications qu'il faudrait à un ébéniste, à un maçon, à un ferblantier, etc. pour l'exécuter. Tel est bien le but utilitaire du dessin que l'école doit poursuivre dans les applications aux métiers. Les architectes et ingénieurs, les ébénistes et menuisiers, les zingueurs et plombiers, basent leurs dessins et leurs plans sur les projections; il est, dès lors, indispensable que ceux qui sont chargés de l'exécution de ces dessins, soient à même de les lire convenablement et de les faire, au besoin, selon les désirs du client. Sans la connaissance des projections, le métier devient une routine inintelligente, qui abrutit l'artisan, puisqu'il travaille machinalement sans se rendre compte de la raison d'être de ses travaux.

\section{LES PROJECTIONS OBLIQUES.}

Les projections obliques, aussi appelées. perspective parallèle ou cavalière, constituent le véritable dessin de l'artisan; il permet d'embrasser d'un coup d'œil la forme générale ainsi que les principaux détails d'un objet, et complète ainsi avantageusement le dessin des projections. Il est pour l'artisan d'un usage facile et rapide, tandis que la perspective 


\section{$-290-$}

proprement dite est plus spécialement du domaine de l'artiste, et doit, pour cette raison et à cause des constructions plus compliquées qu'elle nécessite, ne pas trouver une place à l'école de métiers.

Le cours de projections obliques est en honneur à l'École de métiers de Berlin; il est obligatoire pour tous les élèves dont les professions ne sont pas purement ornementales.

\section{MODÈLES.}

La collection des modèles Witt et Stuhlmann (voir catalogue Zergiebel) qui servẻnt à l'étude des projections, est composée d'une série d'objets vaguement ornementaux, dérivés des formes géométriques, tels que colonnettes, balustres, culs de lampe, assemblages, moulures, têtes de boulon, écrous, poulies, pieds de vases, etc., etc.

Ces objets sont en bois, comme pour le dessin à main levée, et coupés aux endroits les plus favorables à l'exécution du dessin. Ils résument de la manière la plus concise et la plus complète les constructions ordinaires du métier et forment un minimum de modèles à dessiner. Ces exercices sont entremêlés d'études d'objets variés appartenant à la profession de chacun des élèves. 


\section{Géométrié. - Calcul.}

Les cours de projections et de dessin à l'aide d'instruments supposent la connaissance pratique de la géométrie et du calcul. Ces branches sont enseignées d'après le programme suivant :

Calcul, deux houres par semaine. - Calcul de l'intérêt, des surfaces et des volumes, des solides ordinaires. Les proportions.

Géométrie. - Géométrie plane : les surfaces. La similitude des polygones réguliers. Le cercle. Les solides, surface latérale et volume.

Les cours sont absolument concrets; l'élève peut faire les tracés sur des objets matériels, et trouver ainsi les résultats et les propriétés à établir, avant que le professeur en fasse la démonstration ou le calcul au tableau.

Le meilleur moyen d'allier le travail manuel au travail intellectuel, est de rendre l'enseignement des sciences palpable en mettant sous les yeux les surfaces, les corps dont on étudie les propriétés.

Toutes les branches fondamentales et préparatoires se pénètrent ct s'enchaìnent; elles convergent avec une assurance et une unité admirables vers le but final : le dessin professionnel. 
Elles contiennent en germe toutes les applications de l'art du dessin aux métiers. Le choix judicieux des modèles, la méthode individuelle adaptée aux besoins de chaque profession, la variété des exercices, donnent aux élèves une culture générale et spéciale : générale, parce qu'elle contient les principes généraux de l'art et de la science du dessin; spéciale, parce qu'elle conduit aux applications diverses du dessin.

C'est sur cette base positive et solide que repose l'éducation professionnelle de l'élève.

\section{LE DESSIN PROFESSIONNEL.}

I. Classe des Ébénistes et des menuisiers.

Le cours de dessin d'ébénisterie et de menuiserie est dirigé par un ébéniste établi. Les élèves y apprennent ce qu'ils doivent absolument savoir pour ne pas être voués à une médiocrité irrémédiable, et ce qu'ils apprendraient lentement et mal à l'atelier, savoir :

Io Lire le dessin d'un meuble, d'une construction de menuiserie;

$2^{\circ}$ Travailler d'après un dessin d'atelier;

3o Faire un dessin selon un modèle, - le transformer; 


\section{$-293-$}

$4^{\circ}$ comme but le plus éloigné, composer un dessin d'atelier.

L'enseignement du dessin d'ébénisterie et de menuiserie procède du dessin géométrique et des projections, combinés avec le dessin de l'ornement. Les élèves apprennent la technique du métier tout en s'initiant à l'ornementation, par l'étude sur nature d'objets de leur profession, empruntés au musée d'arts industriels.

\section{Modèles.}

C'est après un examen approfondi et une longue épreuve que les modèles sont définitivement acquis pour l'École de métiers de Berlin.

La collection Schwartzenhauer qui y est en usage, met l'élève immédiatement en présence du métier. Les constructions ordinaires de l'ébénisterie et de la menuiserie sont condensées en une série d'objets que les élèves connaissent et qu'ils manient tous les jours à l'atelier; le professeur les analyse sous leurs yeux, au double point de vue de la structure technique et de l'ornementation; ces explications jettent une vive lumière sur les constructions et concourent à l'éducation professionnelle. 


\section{Méthode.}

\section{Etudes de copie.}

Les élèves ébénistes s'exercent au dessin exact en grandeur nature, des fragments de meubles qui constituent la membrure, la construction : les montants et les traverses, le soubassement, la corniche, d'abord très simples, puis agrémentés de quelques moulures; ensuite, ils abordent l'étude des panneaux et des différents systèmes d'assemblages. Les menuisiers s'appliquent à reproduire des fragments de boiseries empruntés à la construction de bàtiment: chàssis et panneaux de portes, chambranles, seuils et croisées de fenêtres, lambris et plafonds.

Ébénistes et menuisiers font le lever exact sur ces fragments en nature, les reproduisent par les projections obliques sous toutes leurs faces utiles, et complètent ces indications, en y ajoutant les coupes indispensables, pour obtenir le véritable dessin d'atelier.

Si l'élève a montré de l'intelligence dans ce travail, il passe au dessin du meuble entier, clont il a étudié les éléments. Le professeur en explique les assemblages, la structure, le caractère ornemental, les profils; il appelle l'attention de l'élève sur les difficultés tech- 


\section{$-295-$}

niques et ornementales qu'il présente pour l'exécution.

Ces explications comprises, l'élève prend le croquis coté du meuble et esquisse vaguement l'ornementation; il réalise, au moyen de ce croquis, le dessin du meuble entier sans le secours d'aucun modèle, d'abord en grandeur nature, puis à l'échelle de ${ }^{\mathrm{I}} / \mathrm{ro},{ }^{\mathrm{I}} / 20$, ${ }^{1} / 30$, toujours avec les coupes et les vues de perspective parallèle nécessaires à l'exécution.

Par l'étude patiente de plusieurs objets de son métier, l'élève saisit à fond la structure de tout meuble et s'initie à l'ornementation. Les formes artistiques : profils, balustres, consoles, etc., se fixent dans sa mémoire et y forment une précieuse provision pour ses compositions futures.

\section{Composition.}

L'élève exécute une esquisse de l'objet à composer d'après certaines données : dimensions, usage, style. Ce travail étant corrigé et approuvé, il trace les détails et compose à l'aide de tous ces éléments, un dessin coté d'ensemble, avec les coupes et les indications nécessaires.

Comme les élèves poursuivent chacun un but différent, il ne saurait être question d'un 
cours simultané; d'ailleurs, le mobilier de cette classe est encore adapté aux besoins de l'enseignement individuel.

Les élèves se rendent deux fois par semaine au Musée d'arts industriels pour prendre des croquis d'objets de leur profession; ces croquis et notes sont consignés dans un cahier ad hoc, qui renferme à la fin des études, un trésor de formes appliquables aux objets de leur métier.

Le dessin au Musée est toujours double: l'esquisse pour le client et le non initié, la copie exacte, scientifique pour l'homme de métier chargé de l'exécution.

Ces exercices complètent d'une manière heureuse l'éducation professionnelle de l'artisan ; à mesure qu'il avance dans ses études, son goût s'affine, son travail s'épure, et il prend un plaisir infini dans la contemplation des chefs-d'œuvre de son métier.

Au point de vue pittoresque, la classe des travailleurs du bois offre un spectacle émotionnant; une centaine d'artisans, ébénistes et menuisiers, en habit de travail, courbés sur leurs dessins, manient, mesurent les modèles, cherchent fiévreusement le " secret du métier " que leurs patrons se gardent bien de leur montrer à l'atelier. 
Ainsi toutes les difficultés du dessin professionnel sont vaincues une à une. L'élève qui a patiemment étudié sous toutes ses faces et compris la série des modèles, a résolu toutes les questions ordinaires de son métier; il sera capable de lire les dessins d'atelier, de les transformer et de les composer, suivant les indications du client ou selon sa propre inspiration.

\section{ir. Classe des ferronniers,} SERRURIERS, FERBLANTIERS ET ZINGUEURS.

L'industrie du zinc et du plomb a repris depuis quelques années une extension considérable. Pas une construction de quelque importance qui ne soit ornée de travaux artistiques de zinc ou de plomb : vases, pinacles, faîtages, pendentifs, tuyaux, gargouilles, cheneaux et lucarnes de tous styles.

Cette industrie relativement récente, appelle des intelligences et des bras. En raison même de son importance toujours grandissante, l'École de métiers de Berlin a créé un cours pour zingueurs et plombiers, et ces professions sont résolùment entrées dans le domaine de l'application de l'art à l'industrie.

Pour les ferronniers, zingueurs, etc., l'École de métiers à Berlin suit la mème méthode que pour les menuisiers et ébénistes. 
Les élèves qui entrent dans cette classe de dessin professionnel, doivent être versés dans le dessin à l'aide d'instruments et à main levée et posséder une certaine aptitude au dessin de croquis.

\section{Modéles.}

Série d'objets en zinc et en fer blanc: lucarnes, ornements de faîte, girouettes, ustensiles. Série de serrures, pentures et heurtoirs artistiques démontables, grillages, enseignes en fer forgé ou moulées en plâtre.

Méthode.

Les premiers exercices portent sur la construction du développement des solides en vue du découpage et sur le dessin au trait, d'objets relatifs au différentes branches du travail du métal.

Comme pour l'ébénisterie, la méthode est déterminée par une série graduée d'objets que l'élève étudie au double point de vue de la technique et de l'ornementation. Cet enseignement tend vers la création de dessins d'objets d'après des modèles de choix, et enfin de pure invention.

Les élèves serruriers et ferronniers poussent plus loin le dessin des développements; ils l'appliquent aux rosettes, fleurs, volutes, 
cartouches, et complètent ces dessins des vues d'ensemble nécessaires à l'exécution.

Parallèlement à ce cours de dessin, les ferronniers suivent les leçons de modelage, dont il sera parlé plus loin.

Le caractère utile des modèles ramène toujours l'élève dans la voie professionnelle.

iil. La peinture dÉcorative.

La classe de décoration a le caractère d'un atelier; elle a pour but immédiat d'initier les élèves à l'exécution de travaux de peinture d'après de bons modèles; pour but plus éloigné, de conduire les élèves jusqu'à la composition décorative.

\section{MÉTHOde.}

Les élèves de cette classe dessinent au charbon et à la craie, sur du papier blanc ou de couleur, une série graduée de moulages : moulures et ornements empruntés aux différentes époques artistiques, surtout à la Renaissance.

Faire acquérir un contour pur, le sens de la forme et du jeu des ombres et de la lumière, tel est le souci constant des professeurs.

Suivent des exercices préparatoires à la 


\section{$-300-$}

peinture, la préparation des couleurs, le maniement du pinceau. La préparation des couleurs se fait généralement le dimanche matin à la lumière du jour, pour pouvoir les employer à la lumière électrique.

Les élèves du cours de peinture sont divisés en trois groupes :

Premier groupe. - Le premier groupe est composé d'élèves ayant des notions éparses de dessin; ils reproduisent des modèles plans et des ornements en relief avec l'indication exacte des plans d'ombre.

Deuxième groupe. - Une fois ces notions variées du dessin coordonnées et une certaine habileté acquise, l'élève s'exerce au mélange harmonieux de couleurs, d'après des modèles d'étoffes ou de papiers peints.

Les ornements en relief sont d'abord dessinés exactement avec grand soin, pour que l'élève possède la forme avant d'attaquer les grandes difficultés inhérentes à la peinture.

Cet exercice mène à la peinture en gris, avec deux tons clairs et trois tons d'ombre tout au plus, aussi déterminés que possible. L'élève détaille de plus en plus les plans d'ombre et de couleur, de manière à s'approcher graduellement de l'effet du relief.

Troisième groupe. - Le troisième groupe 
s'exerce à la composition décorative d'encadrements, de médaillons, de rosettes, de frises, de panneaux,en s'inspirant des motifs étudiés, ou en mettant en œuvre telles fleurs, tels fruits, tels rinceaux déjà peints isolément d'après nature.

Tout l'enseignement converge vers l'exécution de travaux décoratifs : plafonds, panneaux d'appartements; les éléments sont: les sujets étudiés, les esquisses du professeur et des motifs de création pure.

\section{MARCHE SUIvie.}

Io Peinture du fond;

$2^{\circ}$ Le dessin est poncé avec les contours et les principaux plans d'ombre et de couleur;

30 Les ombres les plus fortes sont d'abord peintes, pour arriver à la pleine lumière en passant par toutes les tonalités intermédiaires.

iv. Classe des tapissiers.

Les élèves tapissiers reçoivent un enseignement préparatoire identique à celui des peintres décorateurs.

Arrivés à un certain degré d'aptitude, ils s'appliquent plus spécialement au dessin d'étoffes, puis de draperies qu'ils arrangent sur un châssis spécial, sous la direction du professeur. (Voir croquis VIII.) 


\section{$-302-$}

Ils ne sont pas admis à peindre avant de savoir parfaitement dessiner au trait et avec les indications exactes des ombres, les draperies, passementeries, broderies, etc. de toute

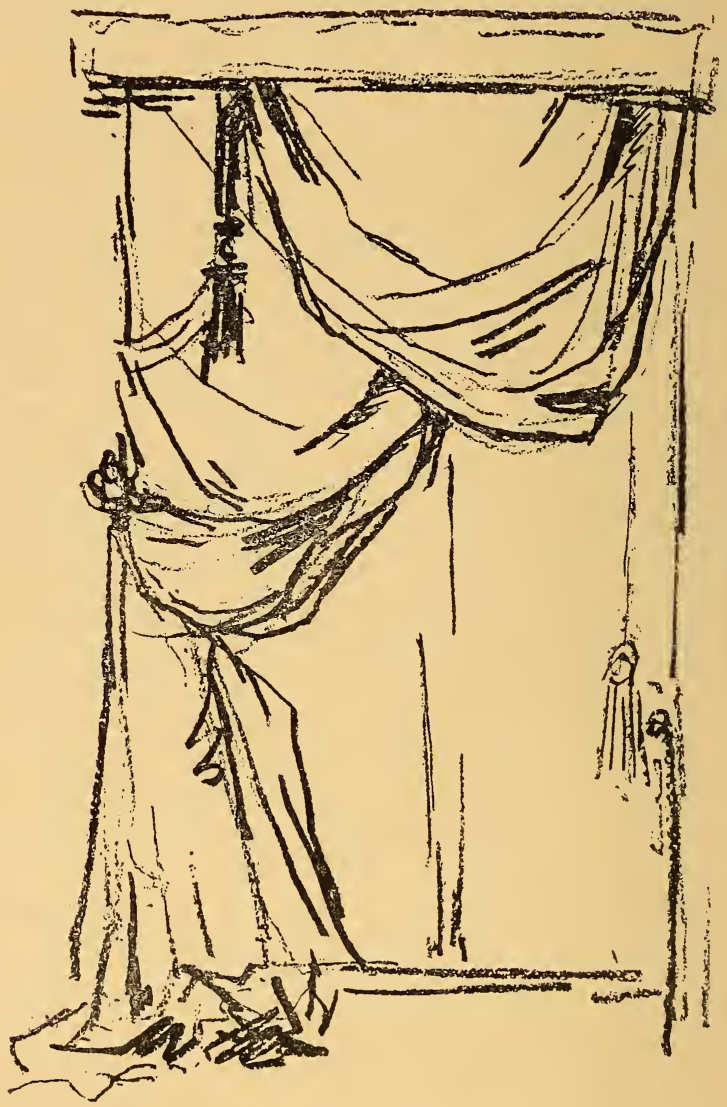

Fig. VIII. 
nature. Du dessin à la peinture de simples garnitures de portes et de fenêtres, il n'y a qu'un pas,que les élèves franchissent d'autant plus facilement qu'ils suivent un cours élémentaire de peinture à l'aquarelle.

L'enseignement s'amplifie par la peinture de meubles, de passementeries, de garnitures plus compliquées et par de nombreux exercices propres à donner aux élèves tapissiers le sens de l'harmonie des couleurs, notamment: l'arrangement de garnitures de portes et de fenêtres, de la tapisserie, en prefiant pour base la tonalité et le style du mobilier; inversement, composer pour les meubles une garniture qui s'harmonise avec la décoration de l'appartement, composer une garniture dans un style déterminé, ou d'après des études faites au Musée des arts industriels.

Le travail de l'atelier est relié aux études de l'École de métiers: les élèves font des esquisses de meubles, auxquels ils travaillent chez eux, et les complètent en classe suivant les indications du professeur.

Est-il besoin d'insister sur l'influence salutaire de pareil enseignement professionnel?

\section{v. Classe des lithographes.}

Dessiner sur papier, à la plume, sur pierre, 
à la craie lithographique, d'après des modèles en nature : fleurs, fruits, feuilles, etc.

Projets de lettres et d'écritures décoratives, d'étiquettes, de diplômes, d'affiches, etc. Transposer un dessin colorié en un dessin à l'encre noire, au crayon.

Tel est le programme.

L'industrie du livre et de la papeterie a pris un développement considérable dans ces dernières années; elle se concentre surtout dans les capitales, et y occupe un très grand nombre d'artisans-artistes : lithographes, graveurs, relieurs.

La lithographie avec la gravure est certes une des applications les plus agréables de l'art à l'industrie; en raison de l'installation très sommaire qu'elle nécessite et des grands résultats qu'elle produit, elle mérite une place à l'école de métiers artistiques.

L'École de métiers de Berlin enseigne la lithographie d'une manière complète. L'éducation préparatoire des lithographes est la même que pour la peinture décorative, dont elle n'est qu'une application spéciale.

Quand l'élève a acquis les notions générales du dessin artistique ornemental, il s'exerce à la copie des modèles qui tendent à la lithographie : entêtes de page, écritures 
décoratives : gothique, de la Renaissance, etc.; graduellement il s'applique à la composition de vignettes, de motifs ornementaux, de frontons, de culs de lampe, etc.

Ce métier d'art exige surtout une grande aptitude manuelle, une facilité exacte au dessin à la plume. C'est seulement quand le professeur juge cette aptitude bien acquise, qu'il initie les élères aux différents procédés de la lithographie : à la plume, à la craie lithographique sur pierre.

Les travaux des lithographes sont très variés. Pour permettre à l'artisan de suffire à la besogne multiple qu'on pourrait exiger de lui à l'atelier, le professeur évite de le renfermer, dès le commencement, dans une spécialité de sa profession; il doit s'exercer à la copie de sujets généralement en usage : cartes de visite, diplômes, comptes, effets de commerce, affiches, entêtes de lettre, vues d'hôtels, de fabriques, de magasins, de machines, etc.

L'École de métiers développe largement toutes les aptitudes des lithographes; le cours d'histoire de l'ornement et les études à la Bibliothèque et au Musée d'arts industriels, complètent leur éducation esthétique. 


\section{LA GRAVURE.}

Parmi tous les métiers enseignés à l'École professionnelle de Berlin, la gravure est sans contredit la plus haute expression cle l'art appliqué à l'industrie. Elle a quelque chose de plus noble et de plus élevé que les autres professions manuelles : simple cifet de la prépondérance de l'art sur la technique.

Bien de jeunes gens doués pourraient se créer une situation brillante dans la gravure, si prospère dans les grands centres. Il y a trop peu de bons graveurs pour satisfaire aux besoins de l'industrie du livre. Tous ceux qui font imprimer des livres illustrés savent combien il est difficile, en notre pays, d'obtenir une illustration convenable. Les apprentis-graveurs étudient à l'atelier la tradition routinière de leur métier; il n'est pas étonnant, dès lors, que le graveur ne saurait comprendre suffisamment le dessin ou le tableau qu'il doit traduire, pour y faire vibrer l'émotion poétique que l'artiste y a déposée.

La base de l'enseignement de la gravure est le dessin à la plumc. Elle présuppose des connaissances pratiques de la perspective et des projections, et une grande aptitude au dessin ombré, branches que l'élève a patiemment étudiées clans les cours préparatoires. 
But. Méthode.

Dessin à la plume, d'abord d'après des gravures sur bois, sur cuivre, et d'après des photographies; puis d'après les moulages d'ornements, de fragments d'architecture et d'après les objets en nature, énumérés à propos du dessin à main levée. Exercices pour s'initier au maniement du burin : graver des lignes dans les différents sens, des courbes, des silhouettes, des contours. Effets d'ombre. - Transposer un sujet peint en gravure. Réductions.

Les élèves dessinent à la plume, en exécution achevée, des feuilles, des fleurs ornementales et des rinceaux; ils s'exercent à la copie coloriée de vignettes, de lettres décoratives dans les différents styles et passent à la composition de petits groupes, arrangés sous la direction des professeurs.

L'enseignement du dessin à la plume, en rue de la gravure, se donne suivant les principes méthodiques en vogue dans tous les cours. En raison du caractère essentiellement artistique de cette profession, le dessin ornemental est étudié avec le plus grand soin et est complété par la peinture à l'aquarelle.

Le cours d'histoire de l'ornement montre à l'élève comment les maitres graveurs ont 
interprété la nature et les auteurs. L'élève graveur reçoit une éducation esthétique complète: l'étude des œuvres aux musées, de l'ornement à l'école, raffinent son goût et le mettent à même de comprendre l'œuvre à graver.

D'ailleurs, depuis que des procédés mécaniques, tels que l'héliogravure, la zincographie, etc., ont remplacé la gravure à la main dans bien des produits de librairie, il ne reste plus un avenir qu'aux graveurs-artistes.

Les procédés mécaniques seront toujours employés comme moyen de reproduction, lorsqu'il s'agit de perpétuer le souvenir d'une œuvre ou lorsqu'on vise à rendre l'aspect exact dans un but didactique. Le graveur qui fait un usage artistique de son talent, qui révèle un tempérament dans son travail, contribuera à assurer l'existence de la gravure. Les deux procédés de reproduction peuvent coexister et se développer chacun dans leur domaine propre.

L'apprentissage du graveur doit être complet et son éducation artistique assez achevée pour qu'il puisse rendre l'effet d'ensemble, la vie, l'émotion que l'auteur a exprimés dans l'original. 


\section{vii. Modelage.}

Le modelage n'est pas considéré, à l'École de métiers de Berlin, comme un but, mais comme le moyen de donner aux ouvriers et artisans une plus grande aptitude dans les professions qui relèvent de la sculpture, notamment, dans les industries artistiques de la pierre, du métal, de la céramique. Il forme la base de l'enseignement de la sculpture sur bois et sur pierre.

Programme. Caractère du cours.

Modelage d'après des ornements empruntés spécialement à la Renaissance, en nature, en photographie, en gravure et en croquis. Modelage d'après nature : coquillages, insectes, feuilles, fleurs, fruits, oiseaux. Mèmes objets ou groupes, de ménoire. Composition ornementale. Transformer un bas-relief en haut-relief et réciproquement. Réductions, agrandissements.

Ce cours est commun à tous les ouvriers dont le métier touche à la transformation artistique de la matière. Lorsque les élèves ont vaincu les premières difficultés du modelage, ils choisissent, d'accord avec le professeur, chacun leurs ornements dans le sens de leurs professions respectives: les orfèvres, 
ciseleurs, repousseurs, refouleurs s'exercent de préférence à la copie et à l'interprétation de petits sujets finis, tels que : insectes, coquillages, boutons de fleurs, fleurs, oiseaux, plats, services ciselés ou moulés, vases ornés, coupepapier, pommeaux de canne, etc; les ferronniers étudient des torsades, des rinceaux ornementaux, des grilles, des fleurs, au point de vue de leur profession; les sculpteurs sur bois et sur pierre copient des motifs décoratifs, des chapiteaux, des frises appartenant à l'industrie de la pierre, des détails de meubles, etc. Tous entremèlent ces exercices d'études sur nature, qu'ils utilisent dans leurs compositions.

Cet enseignement, un par la méthode et varié par ses applications, jette la base artistique des professions ci-dessus énumérées; les cours spéciaux avancent l'élève dans la composition ornementale et établissent la base scientifique de ces professions.

\section{MÉTHODE.}

L'élève a le modèle à sa portée; il l'étudie sous toutes ses faces; le professeur lui explique le caractère de l'ornement, son histoire, son effet dans l'ensemble, sa structure, et montre la rue photographiée du monument 
ou du meuble auquel il a été emprunté.

Éclairé par ces explications, l'élève s'éfforce de saisir les grandes lignes du modèle, de manière à en rendre le caractère : il en fait une ébauche.

Quand l'élève a fait l'étude d'une série de modèles qui résument les caractères d'une période artistique et qu'il a acquis une certaine facilité à l'ébauche, il pousse le modelage jusqu'à l'achèvement complet.

Le souci constant des professeurs est d'attirer l'attention des élèves sur la manière dont la nature est interprétée dans les différentes périodes et de leur faire voir, comment chaque ornement porte la marque du génie de son époque. Ces exercices sont accompagnés d'études sur nature.

Un ornement étant donné, substituer au motif principal une guirlande, un feuillage, précédemment étudiés sur nature. Ainsi, le modelage chemine surrement vers la composition ornementale, dans laquelle l'élève crée et le diagramme et le motif, selon son goùt personnel et les besoins particuliers de l'objet de son métier qu'il s'agit d'orner. 


\section{XVII. - CONCLUSION}

\section{L'ÉDUCATION MORALE A L'ÉCOLE OUVRIÈRE.}

L'École resterait au dessous de sa mission, si elle se bornait à donner à l'apprenti les connaissances nécessaires au travail intelligent, son rôle est plus élevé : elle doit cultiver la personnalité morale du futur ouvrier.

Autant que les autres travailleurs, l'ouvrier manuel doit posséder d'éminentes qualités pour réussir dans sa carrière : le courage,pour supporter les fatigues et la douleur de l'effort physique, la persévérance et la patience, pour poursuivre la réalisation d'une œuvre difficile et vaste, l'exactitude pour aboutir à l'exécution ponctuelle des travaux, la tempérance et l'économie, pour faire servir son travail au relèvement de sa position sociale.

Les études de dessin contribuent, certes, à la culture esthétique des élèves, mais le travail à l'atelier seul peut développer les 
qualités indispensables au travailleur; les entretiens sur l'économie industrielle permettent des incursions dans le domaine de la morale; le tableau des ravages de l'alcoolisme, les explications concernant l'organisation des Caisses d'épargne et de retraite, sur le rôle du capital dans la production, peuvent suggérer des velléités fugitives de sobriété et d'économie; les sociétés de tempérance et d'épargne, établies dans les écoles ouvrières, pourront seules produire des effets durables, parce qu'elles font naitre de véritables habitudes morales par la pratique de l'abstention et de l'économie.

A l'école ouvrière l'épargne et la tempérance ont une base, les élèves sont de jeunes apprentis et ouvriers; ils gagnent de l'argent et peuvent donc épargner; elle a aussi un but immédiat : procurer aux ouvriers l'argent nécessaire pour acheter des outils, pour s'établir comme patrons, pour fonder une famille.

Les intéressés eux-mèmes administreraient la caisse sous la surveillance du directeur, du professeur d'économie industrielle ou de la Commission administrative; la tenue des livres, la vérification régulière, la conversion du produit de l'épargne en fonds publics, et 


\section{$-3 I_{4}-$}

toutes les opérations donneraient aux élèves une variété de notions intéressantes et utiles, et une idée exacte d'une comptabilité financière.

Ceux qui sont effrayés des difficultés et des responsabilités de pareilles institutions, objecteront : la Caisse d'épargne et de retraite sous la garar.tie de l'État, offre à chacun le moyen de déposer ses économies, mème de se créer une rente; pourquoi engager la responsabilité du personnel de l'école?

Évidemment, mais l'école doit joindre l'action à la parole, stimuler l'épargne en multipliant les occasions de mettre le superflu en lieu sûr. Le plus grand avantage des Caisses scolaires est, de permettre aux jeunes gens de déposer, par petites sommes, et surtout de débuter avec quelques centimes, ce qui n'est raisonnablement pas possible dans les caisses de l'État.

La tempérance et l'épargne prennent racine à l'école primaire; c'est aux ecoles ouvrières qu'elles doivent porter leurs fruits.

Nous signalons l'idée, sans insister pour le moment sur la portée morale et sociale des sociétés de tempérance et d'épargne aux écoles industrielles, professionnelles et d'art industriel. 
MISSION DE L'ÉCOLE DE MÉTIERS

DE BERLIN.

L'école de métiers artistiques de Berlin réalise l'idéal d'un enseignement qui consacre l'alliance intime de la science et de l'art, pour donner à l'artisan une éducation professionnelle totale : la science lui apprend à lire un dessin d'atelier, à travailler d'après ce dessin et à le composer au besoin ; les notions artistiques le mettent à mème de comprendre l'ornementation qui convient aux objets à créer, lui apprennent à orner un dessin, en tenant compte de la destination de l'objet et cle la matière dont il cloit ètre construit.

L'école de métiers s'est assigné un ròle modeste mais considérable : elle a pour préoccupation de faire pénétrer dans la masse des artisans et ouvriers une lueur scientifique et artistique; la science, qui ourre l'intelligence, fortifie le raisonnement et leur permet de résoudre les mille questions qui se dressent devant eux dans l'exercice de leur profession; le dessin ornemental artistique et l'étude des modèles en nature au Musée d'arts industriels, qui épure leur goùt, leur inspire l'amour du travail, la conscience de leur valeur et les convainc que, comme 
ouvriers, le plus bel avenir social peut leur ètre réservé.

A l'encontre de nos écoles de dessin et “ academies », l'École de Berlin donne aux ouvriers une culture intellectuelle et esthétique solide et ne se contente pas de les couvrir d'un vernis qui les trompe eux-mêmes sur leur propre force.

Les travaux des élèves, que nous avons pu voir à Berlin, n'ont pas tous une légèreté élégante, un contour impeccable ni un coloris sans reproche; on y sent souvent le travail pénible et la main lourde et calleuse de l'artisan; c'est là un signe qu'on ne vise pas au tape-à-l'œil, qu'on ne néglige pas le fond, pour poursuivre uniquement cette chose chimérique pour un simple artisan : la grâce des formes, l'éclat et la délicatesse du coloris, la pondération de l'ensemble; l'esprit du véritable travailleur ne saurait jamais saisir ces nuances délicates; en s'appliquant à cultiver exclusivement ses facultés esthétiques on le détournerait de sa profession.

Elle laisse à l'Académie des beaux-arts le soin de développer les natures artistiques de haute envergure et y envoie ceux de ses élèves, qui montrent des dispositions évidentes à l'art supérieur. 
L'École de métiers artistiques reste dans son rôle. Tout pour le métier! voilà sa devise.

Une collection d'objets artistiques de toute nature est le complément indispensable de toute école de métiers. Elle fournit des modèles de choix, auquels les artisans s'intéressent au plus haut degré, parce qu'ils leur révèlent des secrets techniques et ornementaux; ils sont un guide sûr pour leur travail à l'atelier.

La collection d'objets d'art industriel donne au public un enseignement par les yeux : au client pour ses commandes, à l'artisan pour ses travaux et au peuple, si avide de belles choses, pour la culture de son goût; tous apprennent à trouver, dans la contemplation des objets artistiques de tout usage, une jouissance noble et infinie.

Pour que pareille collection remplisse sa mission, il faut qu'elle soit un Musée du travail, non une collection compliquée et prétentieuse, destinée aux archéologues et aux esprits cultivés, mais aux humbles et incultes consommateurs si rarement appelés à contempler des choses de fabrication irréprochable.

Quelle influence salutaire pareille institu- 
tion ne ferait-elle pas rayonner autour d'elle! Quel travail fécond ne produirait pas l'artisan, imprégné de l'esprit positif et artistique cle l'école et cultivé par l'étude des objets de son métier au Musée d'arts industriels!

\section{NOS ÉCOLES DE DESSIN.}

On se plaint de l'ignorance de nos artisans. A l'étranger ils ne peuvent trouver de l'ouvrage, parce que leur métier est routinier; les artisans étrangers viennent leur disputer le pain quotidien sur place mème! Qu'a-t-on fait pour remédier à cette triste situation? Où sont les écoles qui enseignent les métiers d'une manière rationnelle?

Et nos écoles de dessin, nos académies clestinées, d'après le programme, à former des artisans, des contre-maitres?

Un leurre! Sous cette fausse étiquette on attire l'artisan dans un véritable guet-apens; il y copie des moulages, inconsciemment, pour apprendre à orner le métier... qu'il ignore! Il use son dessin et parvient mème, à force de labeur, à reproduire les défauts du modèle! A-t-il, par hasard, tracé un contour pur, rendu péniblement le jeu des ombres et de la lumière, il est proclamé coloriste, 
artiste! Oui, il marchera glorieusement sur la trace de ses ancêtres? Le malheureux, grisé par tant de louanges, fasciné par des succès futurs, la gloire, l'immortalité entrevus, s'applique de toutes ses forces, suit le cours de peinture à l'Académie des Beaux-arts, laisse pousser sa chevelure à l'instar des grands maîtres; sa figure devient émaciée et symbolique et, du haut des sphères sereines du grand art, il regarde dédaigneusement le vil métier auquel il s'était d'abord destiné... et va bientôt rejoindre l'armée des meurt-defaim déclassés, maudissant l'école et les professeurs qui l'ont poussé dans cette voie.

Ce tableau n'est pas exagéré. L'ouvrier, le véritable élève, qui s'égare, par erreur, dans cette école, a la touche maladroite et lente, - il n'a aucune disposition, dit-on, on n'en tirera jamais rien! Non, il n'affirmera, certes, pas la gloire artistiquc de ses professeurs et de son école, mais, s'il a le courage de résister à la funeste tendance, il se créera une position lucrative et honorera le travail.

Quittons résolument l'ornière des acaclémies de province, ces antichambres et pourvoyeuses des Académies des Beaux-arts, et entrons résolument dans la voie que nous tracent nos roisins d'Outre-Rhin. Comme 
eux, soyons de notre époque et inspironsnous des véritables intérêts de la population ouvrière. Consacrons ces écoles aux artisans et faisons-y régner cette atmosphère particulière, qui nous saisit en entrant dans un atelier de travail. Le monde ouvrier appréciera nos efforts et affluera en masse dans nos établissements, pour y puiser cette supériorité professionnelle, qui décuple la valeur du travail. Nous serons assez récompensés, si nous avons adouci quelques souffrances et contribué au relèvement moral, intellectuel et social des travailleurs. 



\section{DU MÊME AUTEUR.}

Pour paraître prochainement :

\section{PRÉCIS DE GÉOMÉTRIE DESCRIPTIVE}

appliquée aux travaux du bois,

de la pierre et du fer,

A L'USAGE DES ÉCOLES INDUSTRIELLES

ET PROFESSIONNELLES. 




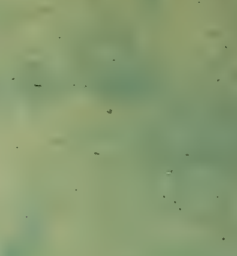

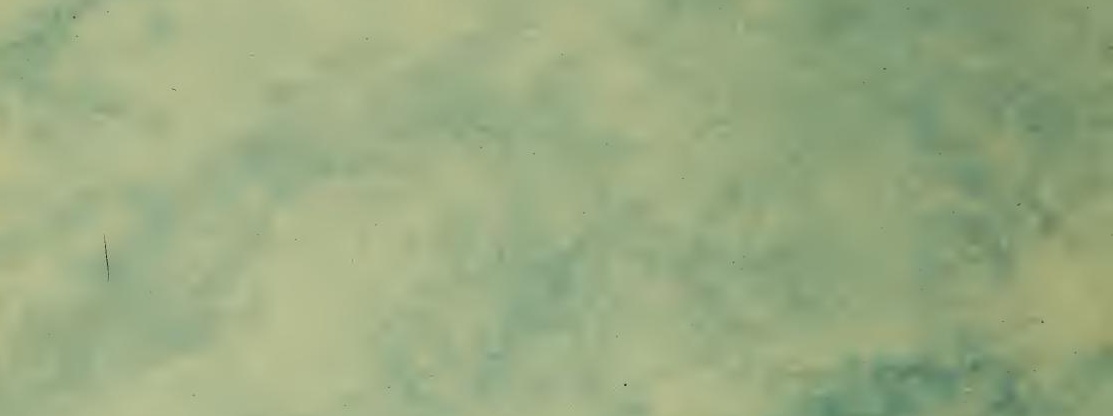

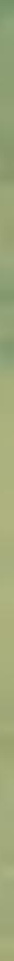




